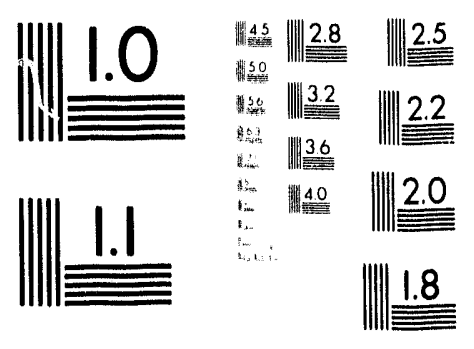

|||||||.25 

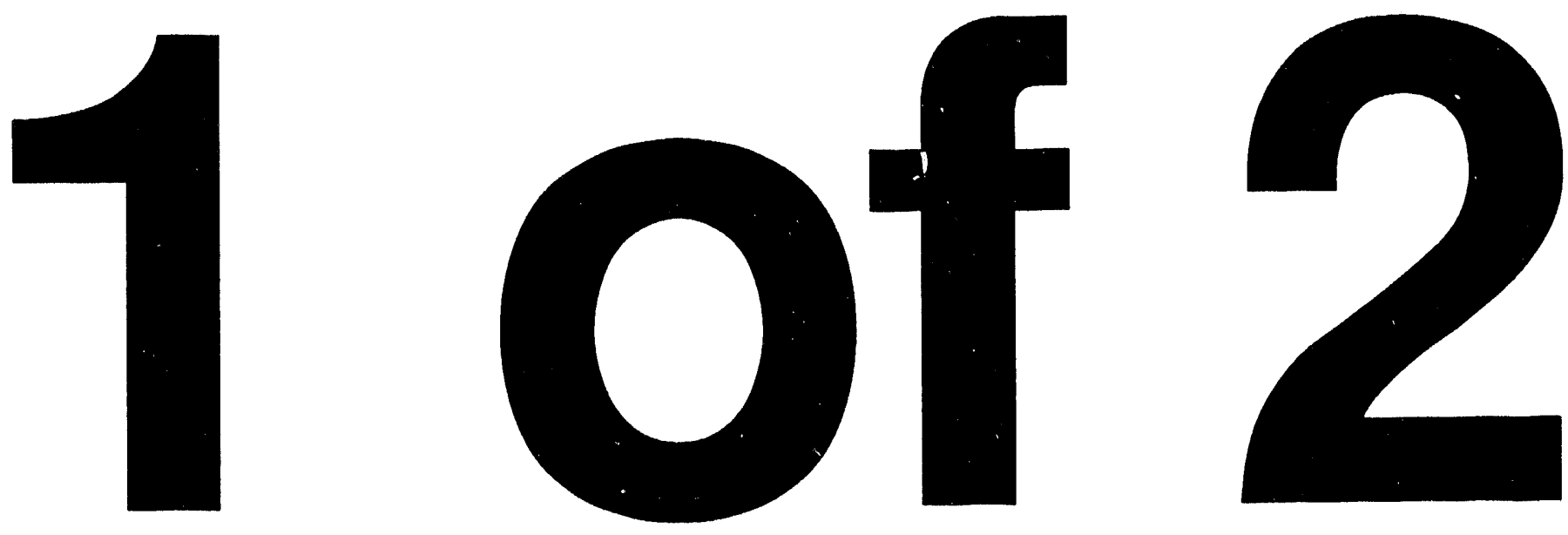
NUREG/CR-6(1)98

BMI-2175

RF, R5

\section{Loading Rate Effects on Strength and Fracture Toughness of Pipe Steels Used in Task 1 of the IPIRG Program}

Manuscript Completed: September 1993

Datte Published: October 1993

Prepared by

C. W. Marschall, M. P. L andow, (3. M. Wilkowski

Battelle

505 King Avenue

Columbus, ()H 432()1-2693

\section{Prepared for}

Division of Engineering

Office of Nuclear Regulatory Research

U.S. Nuclear Regulatory Commission

Washington, DC 20555-0001

NRC FIN D2060 
This report is a work prepared for the United States by Battelle. In no event shall either the United States or Battelle have any responsibility or liability for any consequences of any use, misuse, inability to use, or reliance upon the information contained herein, nor does either warrant or otherwise represent in any way the accuracy, adequacy, efficacy, or applicability of the contents hereof. 


\section{ABSTRACT}

Material characterization tests were conducted on laboratory specimens machined from pipes to determine the effect of dynamic loading (i.e., rates comprable to those for high amplitude seismic events) on tensile properties and fracture resistance at $288 \mathrm{C}(550 \mathrm{~F})$. Specimens were fabricated from seven different pipes, including carbon steels and stainless steels (both base metal and weld metal), which were to be subjected to full-scale pipe tests in IPIRG Task 1.0.

For the stainless steels tested at $288 \mathrm{C}(550 \mathrm{~F})$, no pronounced harmful effects of dynamic loading were evident. Tensile strength was unchanged, while yield strength and fracture resistance were increased. The increase in fracture resistance was modest for the wrought base metals and substantial for the weld metal and the cast base metal.

The carbon stefls, on the other hand, because of their susceptibility to dynamic strain aging, displayed both temperature and strain rate effects that are not expected for most ductile metals. The carbon steel base metal and welds exhibited ultimate tensile strength values at $288 \mathrm{C}$ $(550 \mathrm{~F})$ that were greater than at room temperature. Furthermore, the ultimate tensile strength at $288 \mathrm{C}(550 \mathrm{~F})$ was lowered significantly by increased strain rate and, in the carbon steel base metals, increased strain rate also lowered the fracture resistance, substantially in the base metal of one pipe.

In comparing these results to the IPIRG pipe test results to date, it was found that the trends of these tests agree well with the Subtask 1.2 quasi-static and dynamic pipe fracture experiments. Loads measured in the Subtask 1.1 pipe experiments were, however, somewhat higher than would have been expected by the trends observed in the laboratory tests. 
ABSTRACT. . . . . . . . . . . . . . . . . . i i i

LIST OF FIGURES . . . . . . . . . . . . . . . . . vii

LIST OF TABLES. . . . . . . . . . . . . . . . . . . xii

ACKNOWLEDGEMENTS. . . . . . . . . . . . . . . . . $x V$

NOMENCLATURE. . . . . . . . . . . . . . . . . . . . . xvii

EXECUTIVE SUMMARY . . . . . . . . . . . . . . . . . . 1

1.0 INIRODUCTION AND BACKGROUND ..................... 1

1.1 Selection of Displacement Rates In Material

Characterization Tests............. 1-1

1.1 References. .................. 1-2

2.0 MATERIALS INVESTIGATED . . . . . . . . . . . . . .

2.1 References ................ 2-1

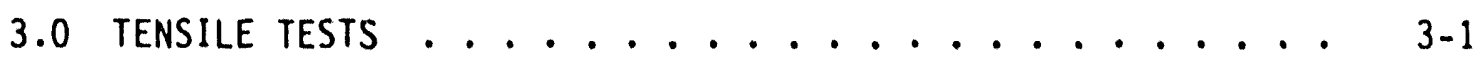

3.1 Experimental Procedures ............ 3-1

3.2 Tensile Test Results . . . . . . . . . 3-2

3.2.1 Carbon Steel Tensile Test Results. . . . . . . 3-2

3.2.2 Austenitic Stainless Steel Tensile Test Results. . 3-5

3.2.3 Cast Stainless Steel Tensile Test Results. . . . 3-7

3.3 References ............... 3-. . . . . .

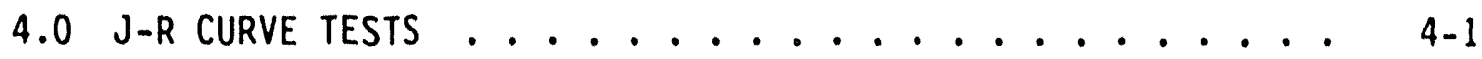

4.1 Experimental Procedures .............. 4-1

4.1.1 Fabrication and Testing of Compact Specimens .. . 4-1

4.1.2 Calculation of $\mathrm{J}$ at Crack Initiation and the
J-Resistance Curve................. 4-3

4.2 Experimental Results ............. 4-5

4.2.1 Carbon Steels J-R Curve Results. . . . . . 4-6

4.2.2 Austenitic Stainless Steels. ........ . 4-10 
4.2.3 Centrifugally Cast Stainless Steel ..... . 4-12

4.3 References ............... 4-. . . . . .

5.0 DISCUSSION OF RESULTS ...................... 5- .

6.0 SIGNIFICANCE OF RESULTS TO PIPE FRACTURE ANALYSES ..... 6-1

6.1 Significance of Laboratory Specimen Test Results on Pipe

Fracture Analyses................. 6-1

6.1 .1 Tensile Test Results ........... 6- 6-1

6.1 .2 J-R Curve Toughness Results. ....... 6-3

6.1.3 Significance of Results and Comparison to ASME

6.1 J-R Curves for In-Service Flaw Evaluations ... 6-3

6.1.4 Significance for Leak-Before-Break Analysis. . . 6-4

6.2 Comparison of Laboratory Specimen Results to IPIRG

Subtask 1.1 and 1.2 Pipe Fracture Experiment Results . 6-5

6.2.1 Results of Tests on Ferritic Pipe DP2-F30. . . 6-5

6.2 .2 Results of Tests on Austenitic Pipe DP2-A23. . $6-5$

6.2.3 Resolution of Discrepancies in Trends from

Laboratory Specimen and Pipe Experiments . . . 6-6

6.3 References .................. 6-6 
Page

Figure 1.1 Determination of equivalent time to crack initiation for stainless steel pipe with a surface crack (Subtask 1.3)............ 1-3

Figure 3.1 Flat specimen used for dynamic tensile tests . . . 3-15

Figure $3.2 \quad$ Schematic illustration of optical displacement sensors used in dynamic tensile tests. . . . . 3-16

Figure 3.3 Example of dynamic tensile test data; Pipe DP2-A40 (Aged A351 Type CF8M Cast Stainless Steel), tested at $300 \mathrm{C}(572 \mathrm{~F})$ at a strain rate of $8.1^{\mathrm{s}-1}$. . . 3-17

Figure 3.4 Effect of strain rate and test temperature on tensile properties of Pipe DP2-F30 (A106 Grade B carbon steel).................... 3-18

Figure 3.5 Engineering stress-strain curves at $288 \mathrm{C}(550 \mathrm{~F})$ for Pipe DP2-F30 (A106 Grade B carbon steel) tested at several different strain rates . . . 3-19

Figure 3.6 True stress-strain curves at $288 \mathrm{C}$ (550 F) for Pipe DP2-F30 (A106 Grade B carbon steel) tested at several different strain rates. . . . . . 3-20

Figure 3.7 Tensile properties at $288 \mathrm{C}(550 \mathrm{~F})$ versus strain rate for Pipe DP2-F30 (A106 Grade B carbon steel). . 3-21

Figure 3.8 Tensile properties versus temperature for Pipe DP2-F29 (A106 Grade B carbon steel)........ 3-22

Figure 3.9 Engineering stress-strain curves at $288 \mathrm{C}(550 \mathrm{~F})$ for Pipe 0P2-F29 (A106 Grade B carbon stee1) tested at several different strain rates.... 3-23

Figure 3.10 True stress-strain curves at $288 \mathrm{C}(550 \mathrm{~F})$ for Pipe DP2-F29 (A106 Grade B carbon steel) tested at several different strain rates....... 3-24

Figure 3.11 Tensile properties at $288 \mathrm{C}(550 \mathrm{~F})$ versus strain rate for Pipe DP2-F29 (A106 Grade B carbon steel pipe)................ 3-25

Figure 3.12 Engineering stress-strain curves at 288 C (550 F) for a submerged-arc weld (DP2-F29W) in an A106 Grade $B$ carbon steel pipe, tested at several different strain rates........ 3-26 
Figure 3.13 True stress-true strain curves at $288 \mathrm{C}(550 \mathrm{~F})$ for a submerged-arc weld (DP2-F29W) in an A106

Grade $B$ carbon steel, tested at several

different strain rates......... 3-27

Figure 3.14 Tensile properties at $288 \mathrm{C}(550 \mathrm{~F})$ versus strain rate for a submerged-arc weld (DP2-F29W) in A106

Grade B carbon steel pipe. . . . . . . . 3-28

Figure 3.15 Tensile properties versus temperature for Pipe DP2-A23 (A376 Type 304 stainless steel)..... 3-29

Figure 3.16 Engineering stress-strain curves at $288 \mathrm{C}(550 \mathrm{~F})$

for Pipe DP2-A23 (A376 Type 304 stainless stee1)

tested at several different strain rates . . . . 3-30

Figure 3.17 True stress-strain curves at $288 \mathrm{C}(550 \mathrm{~F})$ for

Pipe DP2-A23 (A376 Type 304 stainless steel)

tested at several different strain rates . . . . 3 3.31

Figure 3.18 Tensile properties at $288 \mathrm{C}(550 \mathrm{~F})$ versus strain rate for Pipe DP2-A23 (A376 Type 304 stainless

steel).......................... 32

Figure 3.19 Tensile properties versus temperature for Pipe

DP2-A8 (A358 Type 304 stainless steel)..... 3-33

Figure 3.20 Engineering stress-strain curves at $288 \mathrm{C}(550 \mathrm{~F})$

for Pipe DP2-A8 (A358 Type 304 stainless steel)

tested at several different strain rates... . 3-34

Figure 3.21 True stress-strain curves at $288 \mathrm{C}(550 \mathrm{~F})$ for

Pipe DP2-A8 (A358 Type 304 stainless steel)

tested at several different strain rates . . . . 3-35

Figure 3.22 Tensile properties at $288 \mathrm{C}(550 \mathrm{~F})$ versus

strain rate for Pipe DP2-A8 (A358 Type 304

stainless steel).............. 3-36

Figure 3.23 Engineering stress-strain curves at $288 \mathrm{C}(550 \mathrm{~F})$

for a submerged-arc weld (DP2-A8W) in Type 304

stainless steel, tested at several different

strain rates............ 3-37

Figure 3.24 True stress-strain curves at $288 \mathrm{C}(550 \mathrm{~F})$ for a submerged-arc weld (DP2-A8W) in a Type 304

stainless steel pipe, tested at several different

strain rates.................3-38

Figure 3.25 Tensile properties at $288 \mathrm{C}(550 \mathrm{~F})$ versus strain rate for submerged-arc weld (DP2-A8W) in Type

304 stainless steel pipe.......... 3-39 
Figure 3.26

Engineering stress-strain curves at $300 \mathrm{C}$ (572 F) for Pipe DP2-A40 (artificially aged A351 Type CF8M cast stainless steel), tested at several different strain rates.............. 3-40

Figure 3.27 True stress-strain curves at. $300 \mathrm{C}(572 \mathrm{~F})$ for Pipe DP2-A40 (artificially aged A351 Type CF8M cast stainless steel).............. 3-41

Figure 3.28 Tensile properties at $300 \mathrm{C}(572 \mathrm{~F})$ versus strain rate for Pipe DP2-A40 (artificially aged A351 CF8M cast stainless steel)........... 3-42

Figure 4.1 Schematic illustration of direct-current electric potential method employed at Battelle to monitor crack growth in $C(T)$ tests.......... 4-24

Figure 4.2 Transient recorder trace for dynamic test of A106 Grade B carbon steel specimen F30-109 at

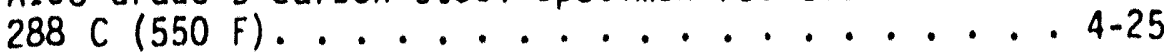

Figure 4.3 Example of unreduced data for dynamic test of austenitic stainless steel weld $C(T)$ specimen $A 8 W-107$ at $288 C(550 \mathrm{~F})$............... 4-26

Figure 4.4 Schematic illustration of the method used at Battelle in the Degraded Piping and IPIRG programs to estimate the crack initiation point and to construct the J-R curve........... 4-27

Figure 4.5 Schematic illustration of a J-resistance curve that employs a blunting line in estimating the point of crack initiation........... 4-28

Figure 4.6 J versus crack extension for Pipe DP2-F30 (A106 Grade $B$ carbon steel) compact specimens tested quasi-statically at $288 \mathrm{C}(550 \mathrm{~F})$ at MEA . . . 4-29

Figure 4.7 Load-displacement curve for dynamic test of A106 Grade B carbon steel specimen F30-109 at 288 C (550 F)........................ 40

Figure 4.8 Electric potential versus displacement curve for dynamic test of A106 Grade B carbon steel specimen F30-109 at $288 \mathrm{C}(550 \mathrm{~F})$................. 41

Figure 4.9 Load-displacement curves for quasi-static tests of compact specimens from Pipe DP2-F30 (A106 Grade $B$ carbon steel), illustrating crack instabilities with and without partial unloadings. . . . . . 4-32 
Figure 4.10 Load-displacement data for compact specimens from Pipe DP2-FjO (A106 Grade B carbon steel), tested at 288 C $(550 \mathrm{~F}) \ldots \ldots$. . . . . . . . . . . 33

Figure 4.11 J-resistance curves for compact specimens, up to the point of the first large crack instability, from Pipe DP2-F30 (A106 Grade B carbon steel)

tested at $288 \mathrm{C}(550 \mathrm{~F})$ in $\mathrm{L}-\mathrm{C}$ orientation .... 4-34

Figure 4.12 J-R curves at $288 \mathrm{C}(550 \mathrm{~F})$ used in ASME IWB-3650

ferritic-pipe flaw evaluation criteria . . . . 4-35

Figure 4.13 Load-displacement curves at $288 \mathrm{C}(550 \mathrm{~F})$ for $C(T)$ specimens from Pipe DP2-F29 (A106 Grade B carbon steel) ................... 4-36

Figure 4.14 J-resistance curves for rompact specimens from Pipe DP2-F29 (A106 Grade B carbon steel) tested at 288 C (550 F) . . . . . . . 4-37

Figure 4.15 Load-displacement curves at $288 \mathrm{C}(550 \mathrm{~F})$ for $C(T)$ specimens from a submerged-arc weld (DP2-F29W)

in an Al06 Grade B carbon steel pipe ...... 4-38

Figure 4.16 J-resistance curves for compact specimens from a submerged-arc weld (DP2-F29W) in A106 Grade B carbon steel pipes tested at 288 C (550 F) . . . 4-39

Figure 4.17 J versus crack extension for Pipe DP2-A23 (Type 304 stainless steel) specimens tested quasistatically at $288 C(550 \mathrm{~F})$ at MEA . . . . 4-40

Figure 4.18 Load-displacement-crack extension curves for compact specimens from Pipe DP2-A23 (Type 304 stainless steel), tested at 288 C( $550 \mathrm{~F}) . \ldots$. 4-41

Figure 4.19 J-resistance curves for compact specimens from Pipe DP2-A23 (Type 304 stainless steel) tested at 288 C (550 F) . . . . . . 4 4 . 42

Figure 4.20 Load-displacement curves at $288 \mathrm{C}(550 \mathrm{~F})$ for $C(T)$ specimens from Pipe DP2-A8 (A358 Type 304 stainless steel) .............. 4-43

Figure 4.21 J-resistance curves for compact specimens from Pipe DP2-A8 (A358 Type 304 stainless steel) tested at $288 C(550 \mathrm{~F}) \ldots \ldots$ 4 . . . . . . 44

Figure 4.22 Load-displacement curves at $288 \mathrm{C}(550 \mathrm{~F})$ for $C(T)$ specimens from a submerged-arc weld (DP2-ABW) in a Type 304 stainless steel pipe . . . 4-45 

$\begin{aligned} & \text { Figure } 4.23 \text { J-resistance curves at } 288 \mathrm{C}(550 \mathrm{~F}) \text { for compact } \\ & \text { specimens from a submerged-arc weld (DP2-ABW) in }\end{aligned}$

a Type 304 stainless steel pipe. . . . . . . 4-46

Figure 4.24 Load-displacement curves at $300 \mathrm{C}(572 \mathrm{~F})$ for $C(T)$ specimens from Pipe DP2-A40 (aged A351 Type CF8M cast stainless steel).............4-47

Figure $4.25 \mathrm{~J}$-resistance curves at $300 \mathrm{C}(572 \mathrm{~F})$ for compact specimens from Pipe DP2-A40 (aged A351 Type CFBM cast stainless steel)............. 4-48 
Table 2.1 Description of Task 1.0 pipe subjected to material characterization tests.......... $2-2$

Table 2.2 Chemical composition of Task 1.0 pipes ........ 2-3

Table 3.1 Tensile test results for specimens machined from Pipe DP2-F30, Type A106 Grade B carbon steel . . . . 3-9

Table 3.2 Tensile properties of Pipe DP2-F29 (ASTM Al06 Grade B carbon steel). .......... 3-10

Table 3.3 Tensile properties of submerged-arc weld (DP2-F29W) in Pipe DP2-F29 (ASTM A106 Grade B carbon steel) at $288 \mathrm{C}(550 \mathrm{~F}) . . . . . . . . . .3-11$

Table 3.4 Tensile test results for specimens machined from Pipe DP2-A23, Type 304 stainless steel . . . . . 3-12

Table 3.5 Tensile properties of Pipe DP2-A8 (ASTM A358, Type

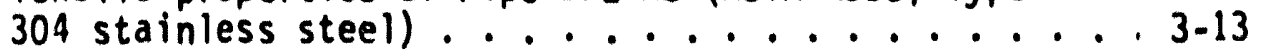

Table 3.6 Tensile properties of SA weld (DP2-ABW) in Pipe A8 (ASTM A358, Type 304 stainless steel) at

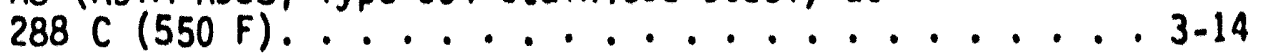

Table 3.7 Tensile properties of Pipe DP2-A40 (aged CF8M cast stainless steel) at $300 \mathrm{C}(572 \mathrm{~F}) . . . . . . . .3-14$

Table 4.1 Actual loading rates in tests of $C(T)$ specimens. . . 4-15

Table 4.2 Summary of $J_{j}$ and $d J / d a$ values for Pipe DP2-F30 obtained from compact specimens tested at $288 \mathrm{C}$ (550 F) at Materials Engineering Associates...... 4-16

Table 4.3 Summary of $J_{j}$ and $d J / d a$ values for Pipe DP2-F30 obtained from compact specimens tested at $288 \mathrm{C}$ (550 F) at Battelle.................. 4-17

Table 4.4 Summary of $J_{i}$ and $d J / d a$ values for Pipe DP2-F29. . . 4-18

Table 4.5 Summary of $J_{j}$ and $d J / d a$ values for submerged-arc weld (DP2-F29W) in Pipe DP2-F29.......... 4-19

Table 4.6 Summary of $J_{j}$ and $d J / d a$ values for Pipe DP2-A23 obtained from compact specimens tested at $288 \mathrm{C}$

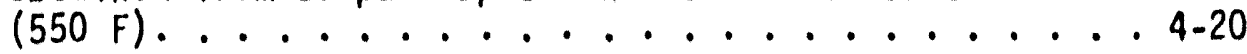


Table 4.7 Summary of $J_{j}$ and $d J / d a$ values for Pipe DP2-A8 . . . . 4-21

Table 4.8 Summary of $J j$ and $d J / d a$ values for submerged-arc weld (DP2-ABW) in a Type 304 austenitic stainless

steel pipe.................... 4-22

Table 4.9 Summary of $J_{j}$ and $d J / d a$ values for compact specimens

from Pipe DP2-A40 tested at $300 \mathrm{C}(572 \mathrm{~F})$. . . . . 4-23

Table 5.1 Summary of dynamic effects on tensile properties

and fracture resistance. ......... 5-3 


\section{ACKNOWLEDGMENTS}

The IPIRG program is an international group program being coordinated by the U.S. Nuclear Regulatory Commission's Materials Engineering Branch of the Office of I uclear Regulatory Research under Contract No. NRC-04-86106 to Battelle. Mr. M. Mayfield is the NRC program manager. Dr. R. Schmidt is the Battelle program manager.

The members of the IPIRG program and their representatives to the IPIRG Technical Advisory Group (TAG) are:

$\frac{\text { Canada }}{-A E C B}(a)$

- Ontario Hydro

$$
\begin{aligned}
& \text { France } \\
& \hline \text { - CEA }(a) \\
& \text { - EDF } \\
& \text { - Framatome }
\end{aligned}
$$

$\frac{\text { Italy }}{- \text { ENEA }}(a)$

$\frac{\text { Japan }}{-\operatorname{CRIEPI}}(a, c)$

Republic of China

- AIT $(\mathrm{a})$

- ROC-AEC

- INER

$\frac{\text { Sweden }}{- \text { SKI }}(\mathrm{a})$

Switzerland

- HSK(a)

- Kernkraftwerk Union
Dr. Ali Omar(b) and Dr. B. Jarman

Mr. M. Kozluk

Mr. Ph. Jamet (b)

Mr. C. Faidy

Mr. S. Bhandari

Dr. P. Milella(b)

Dr. K. Kashima(b)

Mr. Y. H. Cheng(b), Taiwan Power Co.

$\mathrm{Mr}$. R. Y. Wu

Or. K. Ting

Dr. B. Brickstad (b), AB Statens Anläggningsprovning

Mr. H. Njo(b)

Dr. D. Burns

(a) Contractual organization.

(b) TAG representative.

(c) Other Japanese members include, Mitsubishi, Toshiba, Hitachi, IHI, and 13 electric utilities. 
United Kingdom

- CEGB(a)

United States

- U. S. NRC-RES (a)

- U. S $(a)$ RRC-NRR
Dr. B. J. Darlaston (b)

Nuclear Labs

Mr. M. Mayfield (b)

$M r$. K. Wichman (b)
$M r$. J. Gilman $(b)$

We appreciate the support and interest of the IPIRG members in this program.

We express our thanks to $P$. Held and D. Rider for their careful work in performing the experiments and to $E$. D'Andrea and the staff of the Battelle Machine Shop for fabrication of specimens. Appreciation is expressed also to $E$. Fromm for quality assurance reviews, to D. Hayes for drawing of figures, to R. Schmidt and J. Ahmad for technical guidance and for review of the report, and to Ms. C. Pepper and Ms. B. Blanton for report typing and coordination.

(a) Contractual organization.

(b) TAG representative. 
NOMENCLATURE

1. SYMBOLS

A

a

$a_{0}$

b

${ }^{B} N$

dJ/da

$d J / d t$

E

$i, i-1$

J

$\mathrm{J}_{\mathrm{D}}$

$\mathrm{Jel}$

$\mathrm{J}_{i}$

$J_{M}$

$J_{p l}$

$\mathrm{J}_{\text {IC }}$

$\mathrm{J}_{0.2 / \mathrm{BL}}$

K

$\mathrm{P}$
Area under the load-displacement curve in compact specimen tests

Crack length measured from original load line in compact specimens

Original crack length

Uncracked ligament length $(w-a)$

Net thickness of side grooved compact specimen

Slope of $J$ versus $\Delta$ a curve; unless specified otherwise, it was calculated over a range of crack

lengths from 0.15 to $1.5 \mathrm{~mm}(0.006$ to 0.060 inch)

Average rate at which $J$ rose from zero to $J_{i}$ in compact specimen tests

Young's modulus of elasticity

Subscripts used to represent consecutive test record increments in calculating a J-resistance curve

$\mathrm{J}$-integral fracture parameter

Deformation J-integral

Elastic component of $\mathrm{J}$-integral

J-integral at crack initiation but not necessarily a valid $\mathrm{J}_{\text {IC }}$ by ASTM E813

Modified J-integral

Plastic component of $\mathrm{J}$-integral

Value of J-integral at crack initiation under plane strain conditions, as specified by ASTM E813

Value of J-integral at $0.2 \mathrm{~mm}$ of fset from a calculated blunting line, as specified in a 1987 draft Standard (EGF-P1-87D) prepared by the European Group on

Fracture

Applied stress intensity parameter

Load in a tensile or compact specimen test 
NOMENCLATURE (Continued)

\begin{tabular}{|c|c|}
\hline$S_{m}$ & ASME design stress \\
\hline$S_{u}$ & ASME Section III ultimate tensile strength \\
\hline$y$ & ASME Section III yield strength \\
\hline$U$ & Direct-current electric potential \\
\hline$U_{0}$ & Value assigned to $U$ at the onset of crack growth \\
\hline$V_{L L}$ & $\begin{array}{l}\text { Displacement measured at the original load line in a } \\
\text { compact specimen test }\end{array}$ \\
\hline$w$ & Width of compact specimen \\
\hline$y$ & $\begin{array}{l}\text { Half spacing of potential probes on compact specimens } \\
\text { when using d-c EP method to measure crack extension }\end{array}$ \\
\hline$\gamma$ & $\begin{array}{l}\text { Factor used in calculating } \mathrm{J} \text {-integral, equal to } 1+ \\
0.76 \mathrm{~b} / \mathrm{w}\end{array}$ \\
\hline$\Delta a$ & Crack extension $\left(a-a_{0}\right)$ \\
\hline$\epsilon$ & Strain \\
\hline$\dot{\epsilon}$ & Strain rate \\
\hline$\eta$ & $\begin{array}{l}\text { Factor used in calculating } \mathrm{J} \text {-integral, equal to } 2+ \\
0.522 \mathrm{~b} / \mathrm{w}\end{array}$ \\
\hline$\nu$ & Poisson's ratio \\
\hline$\sigma_{f}$ & $\begin{array}{l}\text { Flow strength, equal to the average of yield strength } \\
\text { and ultimate tensile strength }\end{array}$ \\
\hline
\end{tabular}


2. ACRONYMS AND INITIALISMS

ASME

ASTM

$C(T)$

d-c EP

DSA

Dyn

EGF

GTAW

IPIRG

$L-C$

LLD

MEA

NRC

QS

SAW

SMAW

SMTS

SMYS
American Society of Mechanical Engineers

American Society for Testing and Materials

Compact (tension) specimen, often called simply compact specimen

Direct-current electric potential

Dynamic strain aging

Dynamic

European Group on Fracture

Gas tungsten arc weld

International Piping Integrity Research Group

Orientation code that indicates crack plane is normal to longitudinal axis $(L)$ and crack direction is circumferential (C)

Load line displacement

Materials Engineering Associates

Nuclear Regulatory Commission

Quasi-static

Submerged-arc weld

Shielded-metal-arc weld

Specified minimum tensile strength in ASME Section III

Specified minimum yield strength in ASME Section III 


\section{EXECUTIVE SUMMARY}

This report covers the results of material characterization tests conducted within Task 1.0 of the International Piping Integrity Rescarch Group (IPIRG) program. The IPIRG program is an international group program coordinated by the U. S. NRC and conducted at Battelle. The principal objective of the IPIRG program is to evaluate the mechanical behavior of nuclear piping containing flaws and subjected to dynamic loading. Dynamic loading in this report refers to loading rates comparable to those for high amplitude seismic events.

These material characterization efforts had two objectives. The first objective was to supply data for design and analys is of the pipe fracture experiments. The second and perhaps more important objective was to develop a data base to assess whether dynamic material properties are required for leak-before-break (LBB) or in-service flaw evaluation analyses. This report compiles the data in support of the first objective and directly addresses the second objective. It should also be noted that some of the quasi-static material property and pipe fracture experimental data referred to in this report were previously developed in the U.S. Nuclear Regulatory Commission's Degraded Piping Program.

The materials subjected to material characterization tests were those selected for full-scale pipe testing in IPIRG Task 1.0. They included $152 \mathrm{~mm}$ (6-inch) diameter, Schedule 120 ASTM A106 Grade B carbon steel pipe and ASTM A376, Type 304 stainless steel pipe from IPIRG Subtasks 1.1 and 1.2. Materials from IPIRG Subtask 1.3 included $406 \mathrm{~mm}$ (16-inch) diameter, Schedule 100 ASTM A106 Grade B carbon steel pipe and ASTM A376. Type 304 stainless steel pipe, submerged-arc girth welds in each of those two pipes, and a $406 \mathrm{~mm}$ (16 inch) diameter, artificially agnd ASTM A351, Type CF8M cast stainless steel pipe donated by Framatome. The CF8M pipe was originally cast with $50.8 \mathrm{~mm}$ (2 inch) wall thickness, but was subsequently machined from the inside surface to produce a 25.4 mm ( 1 inch) wall thickness for the companion quasi-static pipe test in the Degraded Piping Program.

Material characterization tests included uniaxial tensile tests in the longitudinal orientation and compact tension $[C(T)]$ tests in the $L-C$ orientation. All tests were conducted at $288 \mathrm{C}(550 \mathrm{~F})$, except for one of the materials, an aged cast stainless steel, which was tested at $300 \mathrm{C}(572 \mathrm{~F})$. For some of the materials, quasi-static test data at other temperatures were available from the Degraded Piping Program. Specimens were tested under displacement control with monotonically increasing displacement at constant rate, unlike some of the IPIRG pipe experiments in which loading was cyclic. Strain rates in tensile tests and change in $\mathrm{J}$ with time, $d \mathrm{~J} / \mathrm{dt}$, in $C(T)$ specimen tests were designed to approximate those in the Task 1.0 pipe fracture experiments.

Within the strain rate and loading rate ranges considered, the results of material characterization tests revealed important differences in the 
behavior of carbon steels and stainless steels. The three carben steels were found to be susceptible to dynamic strain aym, i.e. aning that occurs simultaneously with plastio straining and which depends on hoth temperature and strain rate. Because of their susceptibility to dymamic: strain aging, the three carbon strels were found to be stronger at 288 (: $(550 \mathrm{~F})$ than at room temperature, whereas the stainless steel; displayed decreasing strength with increasing teinperatures, as is commonly expected for metallic materials. While the increased tensile strength at elevated temperatures for the carbon steels could be conididered advantageous, it was accompanied by several potentially negative: effects. First, elevated temperature tensile strength was diminished significantly as strain rate was increased, though strength vilues remained in excess of ASME code values. Second, dynamic rales of loading decreased the fracture resistance for $C(1)$ specimens of the two cartion steel base metals tasted at $288 \mathrm{C}(550 \mathrm{~F})$. In one of those two steels, dynamic loading lowered the value of $d$ at crack initiation $\left(J_{i}\right)$ by 35 percent and the value of $d, / d$ d by 45 percent. For reasons that are not yet understood, the carbon steel weld metal behaved differently from the base metal in the $C(T)$ tests, even though the two materials. behaved similarly in tensile tests. In the dynamic C(T) tests at $2888^{\circ}$ $(550 \mathrm{~F})$, the fracture resistance of the weld metal, both $J_{i}$ and $\mathrm{d} / \mathrm{d}$ d. were improved by approximately 50 percent over quasi-static test results.

In addition to the loss of strength and fracture resistance in dynamic tests, the two carbon steel base metals displayed another undesirable trait that is not well understood but which is believed to be associated with dynamic strain aging. Both steels exhibited bursts of unstable crack extension between periods of stable tearing. The ( (I) specimens from smaller pipe showed unstable cracking in both the quasi-static and the dynamic $C(T)$ tests, whereas the $C(T)$ specimens of the larger pipe showed crack jumps only in the quasi-static tests.

In contrast to the results for the carbon steels, the stainless steols exhibited no pronounced deleterious effects of dynamic testing. Tensile strength values in dynamic tests were within approximately +5 percent of those in quasi-static tests, yield strenyth values were raised, and fracture resistance was increased. The increase in fracture resistance was modest in the case of wrought base metals and sutstantial for the weld metal and the cast base metal.

The results of these material characterization tests suggess that it would be prudent to use dynamic strength and toughness properties to evaluate flawed carbon steel pipes. For stainless steel pipes, on the other hand, quasi-static strength and toughness dita probably are adequate for pipe flaw analysis. These trends from the laboratory specimen data are generally in agreament. will the ouasi-static and dynamic pipe tests in IPIRG Sultasks 1.1 dnd 1.2. There are, however. some discrepancies between the trends of the laboratory specimen results in this report and some of the pipe experiments. for example, the.

Subtask 1.1 carbon steel and stainless pipe experiments showed higher 
failure loads than were observed in the Subtask 1.2 pipe experiments. These discrepancies need additional study.

Additional work is also needed in several areas. In order to determine the extent to which dynamic strain aging affects the properties of carbon steels in general, a data base needs to be developed by IPIRG members on the dynamic toughness and strength of ferritic pipes and ferritic pipe welds used in their countries. Also, a further assessment is needed of how to approximate strain rate effects in simplified ferritic pipe fracture analyses, i.e., limit-load and J-estimation scheme analyses.

A second area needing further study is dynamic strain aging and its effects on carbon steels operating near $288 \mathrm{C}(550 \mathrm{~F})$. Battelle has proposed additional work to the U. S. NRC in this area which, if funded, will provide practical methods for assessing the degree of susceptibility to dynamic strain aging of carbon steel piping. Beyond that, possible methods for producing carbon steel pipe that is less susceptible to dynamic strain aging should be investigated.

Finally, this report suggests that the effect of cyclic loading on both tensile properties and fracture resistance needs further study. Pipe experiments conducted in Task 1.0 revealed pronounced effects of cyclic loading, particularly when reversed loading was employed. Laboratory specimen tests of cyclic loading effects would allow several variables to be investigated much more economically than would full-scale pipe tests. At a minimum, the pipe materials used in cyclic pipe tests should be used for cyclic $C(T)$ tests with load histories similar to those of the IPIRG pipe experiments. 


\subsection{INTRODUCTION AND BACKGROUND}

The rate at which a metal is strained can have a strong influence on its mechanical behavior. In ferritic steels, which undergo a transition in fracture behavior from ductile to brittle as temperature is lowered within a certain range, increasing the strain rate can adversely affect performance by raising the transition temperature. However, in metals and alloys that display ductile behavior, it is generally observed that tensile strength is increased and fracture elongation is decreased by increasing the strain rate. Often, the strength increase outweighs the ductility decrease, thereby resulting in greater toughness at higher strain rates.

In Task 1.0 of the IPIRT, program, pipe fracture experiments were conducted in which strain-rate effects were expected to play a role in pipe behavior. Specifically, cracked pipes were tested under conditions of simulated seismic/dynamic loading. Thus, it was important to both the designers and andysts of the pipe experiments that laboratoryspecimen material characterization data be available for the Task 1.0 steels at appropriate rates of displacement. Data required included tensile stress-strain curves at several strain rates and $J-R$ curves at a displacement rate that caused crack initiation in approximately the same amount of time as in the dynamic pipe tests.

This report describes the experiments conducted to obtain the required material characterization data and the results of those experiments.

\subsection{Selection of Displacement Rates In Material Characterization Tests}

Displacement rates in material characterization tests were selected to provide data useful to the designers and analysts of Task 1.0 pipe fracture experiments. The pipe fracture experiments employed cyclic loading at a frequency of nominally $3 \mathrm{~Hz}$, with the expectation of crack initiation after approximately 10 cycles. The material characterization tests, on the other hand, employed monotonically increasing displacement.

Three different nominal strain rates were employed in uniaxjal tensile tests of Task 1.0 materials: $10^{-4} \mathrm{~s}^{-1}$ (quasi-static), $1 \mathrm{~s}^{-1}$, and $10 \mathrm{~s}^{-1}$. The two higher rates were selected to approximate the strain rates existing near the crack tip in dynamic $C(T)$ and pipe tests in Task 1.0 .

In order to estimate an appropriate displacement rate for J-R curve tests, finite element analyses were conducted for several pipe tests that were to be conducted with cyclic loading in Task 1.0. A nonlinear spring was used to simulate the cracked pipe section response (see Section 3 in Reference 1.1). Using the cyclic forcing function that had been selected for those tests, the finite element analyses calculated moment-versus-time graphs for specific pipe tests. An example of such a moment-time graph is shown in Figure l.la for a test of a surface- 
cracked stainless steel pipe in Subtask $\mathrm{i} .3$. In Figure 1.1b, segments $A B, B C$, and so on, are summed to provide an estimate of the time to reach ciack initiation, which was based on knowledge of the moment required to produce crack initiation in a quasi-static test of the same pipe material. The summation of these time segments effectively gives an equivalent monotonic loading time to crack initiation, which ignores the cyclic aspects. In the example shown in figure 1.1 , the time to crack initiation was estimated to be $0.19 \mathrm{~s}$. Using similar analys is methods for other pipe tests in Task 1.0, crack initiation times as Inry as $0.52 \mathrm{~s}$ were estimated. In order that the dynamic $C(T)$ tests be representative of the shortest estimated crack-iritiation times in dynamic pipe tests, displacement rates for dynamic C(I) tests were chosen to produce crack initiation in approximately 0.25 .

\subsection{References}

1.1 Wilson, M., Marschall, C., Olson, R., Schmidt, R., and Wilkowsk1, G.. "Stability of Cracked Pipe Under Inertial Stresses", Subtask 1.1 Final Report to IPIRG Members by Battelle, October, 1989. 

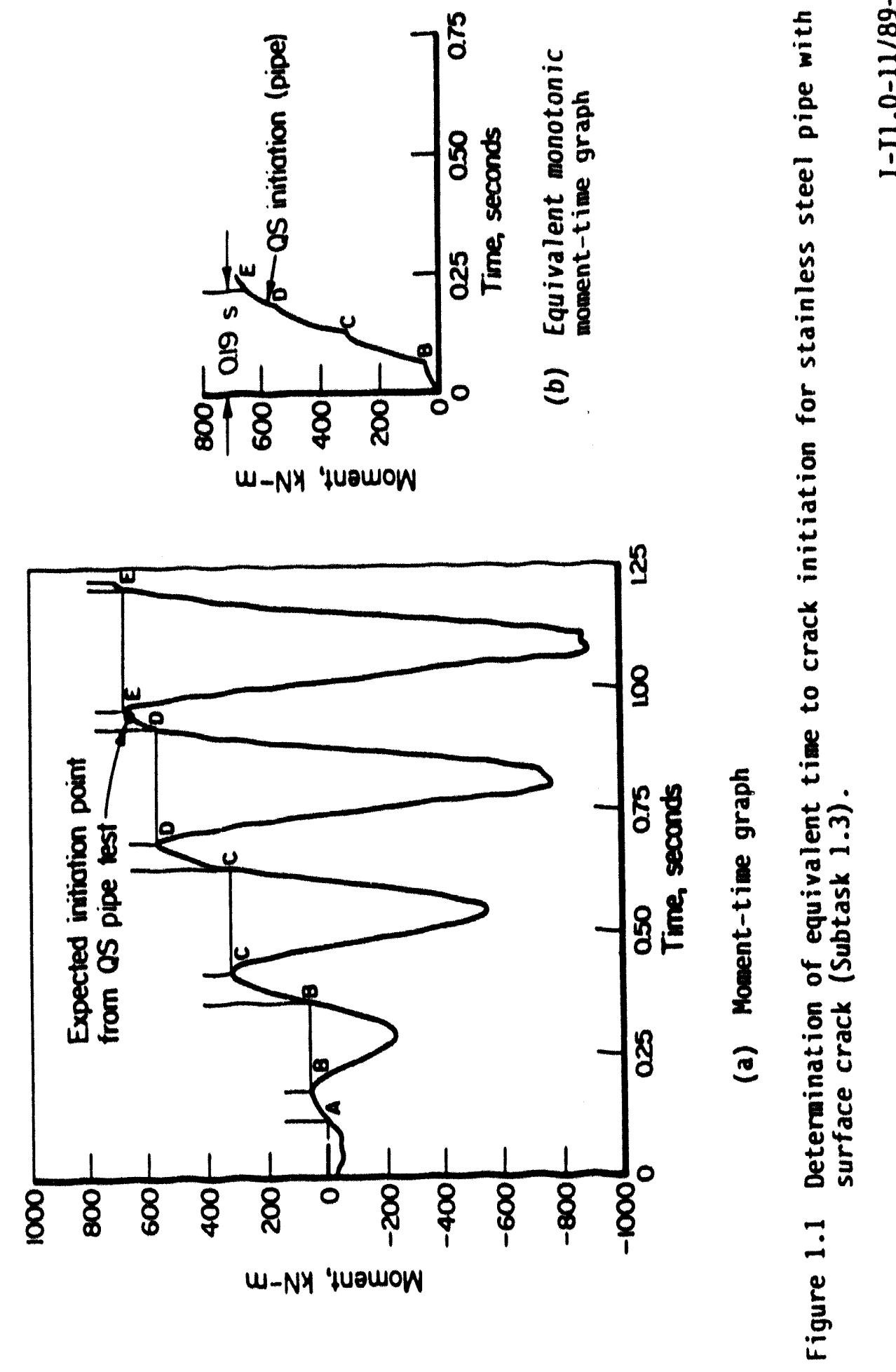

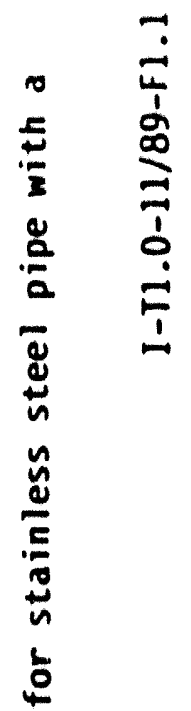




\subsection{MATERIALS INVESTIGATED}

Material characterization tests were conducted on seven materials, including five base metal pipes and two girth-welded pipes. A description of the seven materials is given in Table 2.1. Chemical compositions of the pipes and welds are shown in table 2.2.

Pipes $129, A 23$, and $A 8$ were procured from cancelled nuclear power plants in the United States as part of the NRC's Degraded Piping Program. Pipe F30 was purchased from a U.S. pipe manufacturer within the NRC's Degraded Piping Program. Pipe $A 40$ was artificially aged by Framatome and donated to the NRC's Degraded Piping Program (see References 2.1 and 2.2). The Framatome identification was Heat Y4331 for the A40 pipe.

Quasi-static pipe fracture experiments were conducted on all these pipes and welds within the NRC's Degraded Piping Program (Ref. 2.1). Pipes F30 and A23 were 6-inch-diameter pipes used in IPIRG Subtask 1.1 and 1.2 pipe experiments. Pipes $F 29, A 8, A 40, F 29 W$, and $F 8 W$ are being used in IPIRG Subtask 1.3 pipe system fracture experiments.

\subsection{References}

2.1 Wilkowski, G. M. and others, "Degraded Piping Program - Phase II", Seventh Program Report, October 1987 - January 1989, by Battelle Columbus Division, NUREG/CR-4082, Vol. 7, March, 1989.

2.2 Meyzaud, V., Ould, P., Balladon, P., Bethmont, M., and Soulat, P., "Tearing Resistance of Aged Cast Austenitic Stainless Steels", presented at NUCSAFE 88, Avignon, France, October, 1988. 


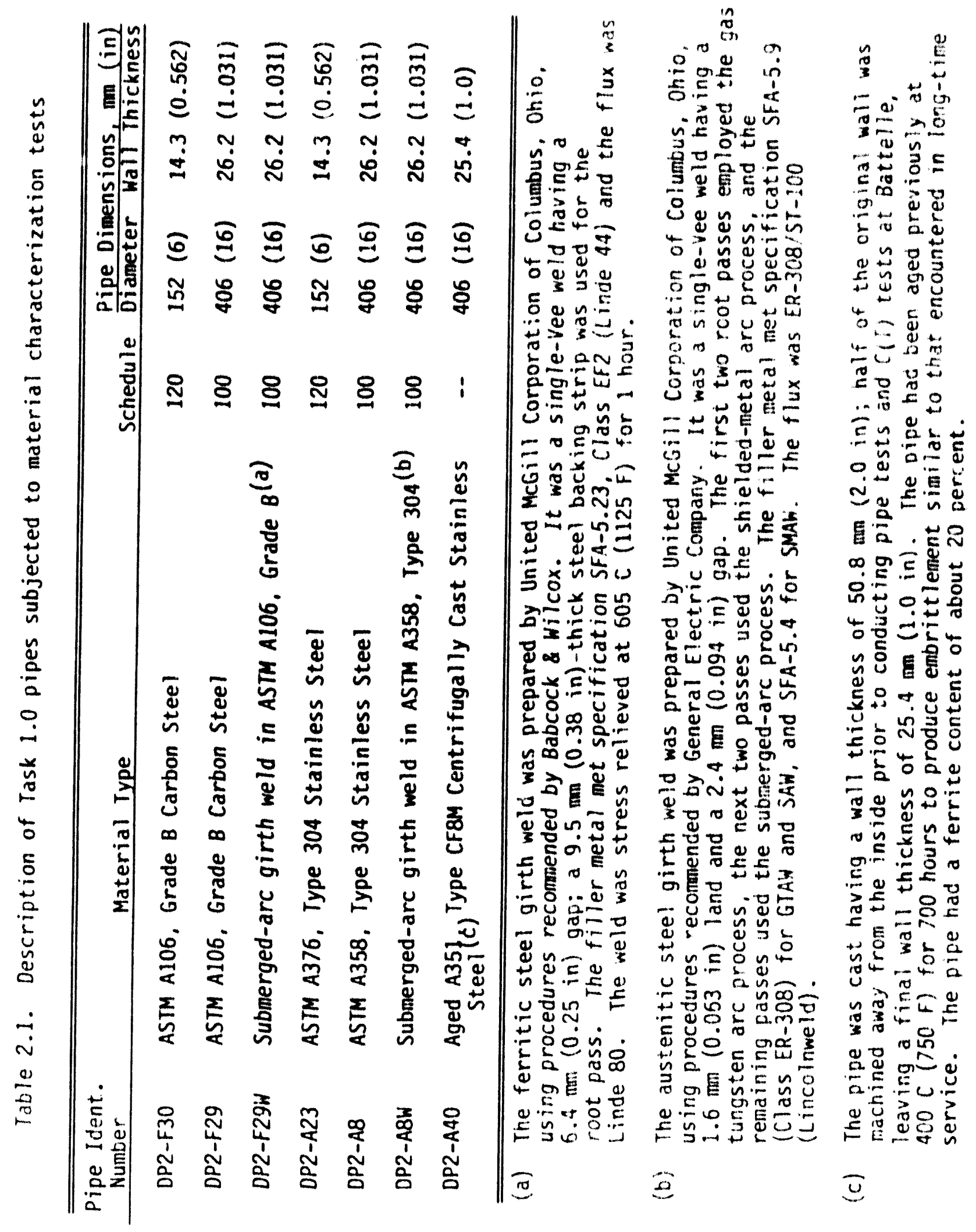




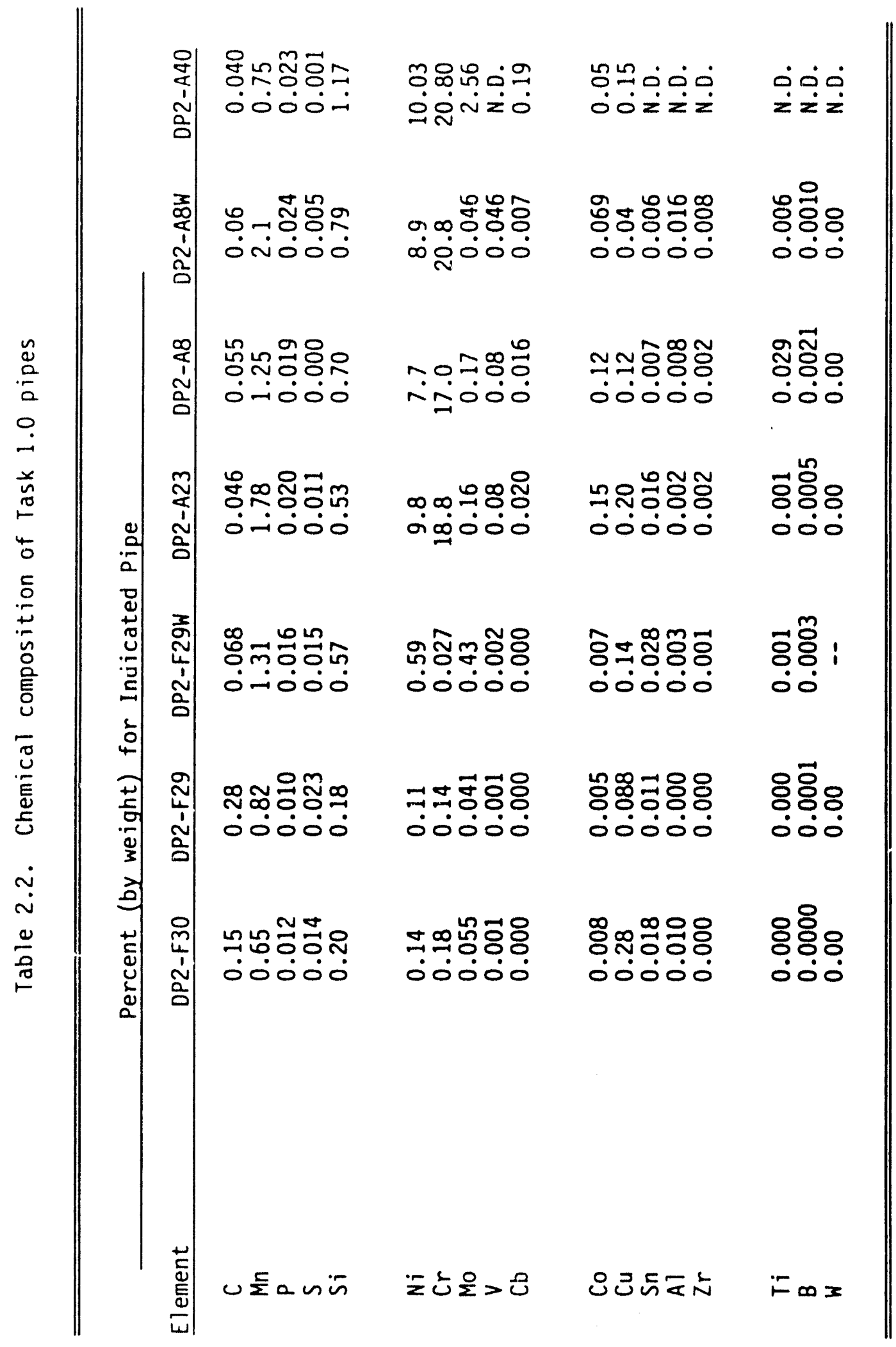




\subsection{TENSILE TESTS}

\subsection{Experimental Procedures}

Tensile specimens were machined from the pipes such that their tensile axis was parallel with the pipe axis. Base metal specimens were taken from the midwall location of the pipe but weld metal specimens were. taken from near the outside of the pipe where the girth weld was relatively wide so that the reduced section of the specimen corsisted entirely of weld metal.

Tests at the higher strain rates ( 1 to $10 \mathrm{~s}^{-1}$ ) employed flat, pin-loaded specimens of the design shown in Figure 3.1. For the austenitic weld metal specimens (DP2-ABiv), the dimensions of the reduced section had to be lessened, to $20.3 \mathrm{~mm}(0.8 \mathrm{in})$ by $5.1 \mathrm{~mm}(0.2 \mathrm{in})$, because of the relative narrowness of the fusion zone.

Tests at quasi-static rates employed both flat, pin-loaded specimens, of the type shown in Figure 3.1, and round-bar threaded-end specimens. The round-bar specimens were of two types, depending on whether they were tested at Battelle or at Materials Engineering Associates (MEA) as part of the NRC-sponsored Degraded Piping Program. Battelle specimens had a gage diameter of $6.35 \mathrm{~mm}(0.25 \mathrm{in})$, a reduced-section length of $31.8 \mathrm{~mm}$ (1.25 in), and a gage length of $25.4 \mathrm{~mm}$ (1 in). MEA specimens had a gage diameter of $5.1 \mathrm{~mm}(0.2 \mathrm{in})$, a reduced-section length of $25.4 \mathrm{~mm}$ (1 in), and a gage length of $12.7 \mathrm{~mm}(0.5 \mathrm{in})$.

Tests that employed the flat, pin-loaded specimens were conducted in a $22 \mathrm{kN}$ (5000 lb)-capacity servohydraulic testing machine. The specimens were enclosed in a circulating-air oven which haci windows in both the front and back for transmission of light. Temperatures were maintained within $+2 C(+4 F)$ of the designated test temperatures. In both the quasi-static and dynamic tests on the flat specimens, strain in the gage section was monitored using a noncontacting optical strain-measuring device (Optron Model 511), shown schematically in Figure 3.2. The specimen was back lit using a high intensity lamp to create a sharp contrast at the edges of the flags located at the extremities of the gage section. As the flags moved apart during the tensile tests, the optical device followed their movement and provided an electrical signal whose magnitude was proportional to the change in spacing of the flags. Recording of data in quasi-static tests employed an $X-Y$ recorder (Hewlett Packard Model 7004-B) to obtain curves of load versus elongation, while in dynamic tests a transient recorder (Gould Model 4074) was used to obtain curves of load, elongation, and ram displacement versus rime. Figure 3.3 is an example of the type of data obtained in a dynamic test; Figure 3.3 a shows the various quantities versus time and Figure $3.3 \mathrm{~b}$ shows load versus elongation.

Quasi-static tests on round-bar specimens were conducted in a Baldwin hydraulic testing machine and employed an electric resistance splittubular furnace to achieve the desired test temperature. Elongation during the test was measured with a clamp-on extensometer in which the 
elongation was transferred outside the furnace by a rod-in-tube arrangement and detected using a linear-variable differential transformer. Data were recorded in two ways: (1) a curve of load versus elongation was plotted autographically as the test proceeded, and (2) load and elongation data were recorded on a Compaq computer equipped with a data acquisition board.

Values of 0.2 percent offset yield strength and ultimate tensile strength were calculated from the curves of load-versus-elongation, while ductility values were obtained from measurements on the fractured specinens. Complete stress-strain curves to the point of fracture were also plotted for each specimen tested.

\subsection{Tensile Test Results}

Summary graphs and tables of tensile test results are presented in this section. Tabulated stress-strain data for individual tensile specimens were also developed for the evaluation of the full-scale pipe fracture experiments.

\subsubsection{Carbon Steel Tensile Test Results}

Pipe Number DP2-F30, [152 mm (6 inch), Schedule 120, ASIM A106 Grade B Carbon Steel Pipe]. Durirg the course of the investigation of strain rate effects, it became apparent that the carbon steels (Battelle Pipe Numbers DP2-F30, $-F 29$, and $-F 29 W$ ) were susceptible to dynamic strain aging (DSA). DSA is a phenomenon in which aging occurs simultaneously with straining at certain strain rates and temperatures (Ref. 3.1). It results from the rapid diffusion of minute quantities of nitrogen and/or carbon dissolved in the steel. DSA can produce several unusual effects, as described later. To investigate the susceptibility to DSA of the carbon steels used in nuclear piping, one of the steels, DP2-F30, was subjected to additional tensile testing beyond that used for the other materials.

The results of tensile tests on specimens from Pipe OP2-F30 at various temperatures and strain rates are summarizad in Table 3.1 and Figure 3.4. Notice in Figure 3.4 that the yield strength at room temperature was approximately 130 percent of the ASME Section III specified minimum yield strength, SMYS. The tensile strength at room temperature was approximately 120 percent of the ASME Section 111 specified minimum tensile strength. SMTS. Figure 3.4 also illustrates some of the unusual effects of DSA discussed earlier: (1) in quasi-static tests, the tensile strength rather than decreasing continuously with increasing temperature, as is typical for many metals, actually showed a strength increase over a certain range of temperatures; in fact, the tensile strength at $288 \mathrm{C}(550 \mathrm{~F})$ was greater than at room temperature, and (2) at $288 \mathrm{C}(550 \mathrm{~F})$, increasing the strain rate caused the strength to decrease, rather than to increase as it does at room temperature. Notice also in Figure 3.4 that the yield strength was relatively 
undfected by either strain rate or temperature over the ranges investigated, and that a minimum in tensile ductility coincided with a minimum in strength at the highest strain rate. The combination of low strength and low ductility suggests that toughness also is low at that comination of temperature and strain rate.

Figures 3.5 and 3.6 show engineering stress-strain curves and true stress-strain curves, respectively, for DP2-F 30 steel at three different strain rates at $288(550 \mathrm{~F})$. The curve at the intermediate strain rate in Figures 3.5 and 3.6 illustrates another feature of DSA, namely, serrated stress-strain curves which occur at certain combinations of strain rate and temperature. The serrations can be explained by hypothesizing interactions between moving dislocations in the steel (the mechanism by which plastic deformation occurs) and nitrogen and carbon atoms, whose ability to diffuse to the dislocations is governed by strain rate and temperature. Keh, Nakada, and Leslie (Ref. 3.2) have shown that the serrations occur only in a certain range of temperatures and that the temperature range is moved upward by increasing the strain rate.

Fiqure 3.7 shows the effect of strain rate on tensile properties at $288 \mathrm{C}(550 \mathrm{~F})$ for DP2-F30. As was noted earlier, the tensile strength, as well as the ductility, diminished significantly with increasing strain rate but the yield strength was not strongly affected by sirain rate. The question arises whether the tensile strength would cont inue to drop at even greater rates of strain. The shape of the curves presented in Figure 3.4 suggests that the strength would not fall continuously with increasing strain rate but would begin to rise beyond some limiting rate. Experimental evidence to support this suggestion has been reported by Manjoine (Ref. 3.3) for a mild steel tested between 0 and $650, C(32$ and $1200 \mathrm{~F})$ and at strain rates ranging from $8.5 \times 10^{-4}$ to $300 \mathrm{~s}^{-1}$.

Also noted in Figure 3.7 are the ASME Section III yield $\left(S_{y}\right)$ and ultimate strength $\left(S_{u}\right)$ values at 288 C (550 F) for Al06 Grade B pipe. The actual yield strength was approximately 175 percent of the ASME value for pipe $\mathrm{F} 30$. Although the ultimate strength decreased significantly with increasing strain rate, the actual ultimate strength at the higher strain rates was still greater than the ASME Section III value. Hence, overall this particular pipe had much higher strength values than the ASME Section III values.

The other two carbon steels investigated in IPIRG Task 1.0 (DP2-F29 and DP2-F29W) also showed evidence of susceptibility to DSA, but they were subjected to fewer tensile tests than was DP2-F30. Test results for those two steels are described separately below.

Pipe Number DP2-F29 [406 mm (16 in), Schedule 100 , ASTM A106 Grade B Carbon Steel Pipe]. Specimens fabricated from Pipe DP2-F29 were subjected to quasi-static tests at room temperature, $149 \mathrm{C}(300 \mathrm{~F})$, and $288 \mathrm{C}(550 \mathrm{~F})$, and to dynamic tests only at $288 \mathrm{C}(550 \mathrm{~F})$. The results of those tests are summarized in Table 3.2 and Figure 3.8. Notice in 
Figure 3.8 that the actual yield strength at room temperature was approximately 115 percent of the ASME Section III specified minimum yield strength, and the actual tensile strength was approximately 125 percent of the ASME Section III specified minimum tensile strength. Notice also the similarity of the curves shown in Figure 3.8 for $012-129$ to those shown in Figure 3.4 For DP2-F3n. The elevation of the tensile strength at the higher temperatures in quasi-static tests and the lowering of the strength at $288 \mathrm{C}(550 \mathrm{~F})$ with increasing strain rate are indicative of DSA.

Figures 3.9 and 3.10 show engineering stress-strain curves and true stress-strain curves, respectively, for DP2-F29 tensile tests at $288 \mathrm{C}$ $(550 \mathrm{~F})$ and three different strain rates. For the two higher rates, the curves in Figure 3.10 are terminated at the maximum load point (onset of necking). As was also the case for DP2-F30, this steel exhibited pronounced serrations on the stress-strain curves at the intermediate strain rate.

Figure 3.11 shows the variation of strength and ductility with strain rate for DP2-F29 tested at $288 \mathrm{C}(550 \mathrm{~F})$. As was noted earlier, the ultimate strength dropped significantly with increasing strain rate. However, the yield strength and ductility were relatively unaffected by increased strain rate.

The ASME Section 111 yield strength $\left(S_{y}\right)$ and ultimate strength $\left(S_{u}\right)$ value at $288 \mathrm{C}(550 \mathrm{~F})$ are also indicated in Figure 3.11. The actual yield strength was approximately 120 percent of the ASME code value for this pipe. The ultimate strength at quasi-static test rates was approximately 145 percent of the ASME code value, but decreased to approximately 105 percent of the ASME code value at a strain rate of $10 /$ second.

Pipe Number DP2-F29W [Submerged Arc Weld in 406-mm (16-inch) diameter Schedule 100 ASTM A106 Grade B Stee T Pipe]. Steel DP2-F29W, a submerged-arc girth weld in Pipe DP2-F29, was subjected to tensile tests only at $288(550 \mathrm{~F})$ at three different strain rates. Tensile properties are summarized in Table 3.3. Engineering stress-strain curves and true stress-strain curves are presented in Figures 3.12 and 3.13 . respectively. Each of the curves in Figure 3.13 is terminated at the maximum load point (onset of necking). Note that in this material also the most pronounced serrations occurred at the intermediate strain rate.

Figure 3.14 shows the tensile properties of the submerged-arc weld (DP2$\mathrm{F} 29 \mathrm{~W})$ as a function of strain rate in tests conducted at $288 \mathrm{C}(550 \mathrm{~F})$. Notice the similarity of the behavior exhibited by the carbon steel weld-metal to that exhibited by the two carbon-steel base metals in Figures 3.7 and 3.11 , in particular, the decreasing tensile strength with increasing strain rate. Thus, even though tensile tests on the pipe weld metal were conducted only at $288 \mathrm{C}(550 \mathrm{~F})$, it appears that the carbon-steel weld metal was displaying susceptibility to DSA in much the same way as were the carbon-steel base metals. 
In comparing the $\mathrm{F} 29$ base metal tensile test results to the $\mathrm{F} 29 \mathrm{~W}$ weld metal results, it was found that the weld metal yield strength at $288 \mathrm{C}$ $(550 \mathrm{~F})$ exceeded the base metal yield strength at all strain rates investigated. However, the ultimate strength of the weld metal at $288 \mathrm{C}$ $(550 \mathrm{~F})$ was below that of the base metal at quasi-static rates and approached the base metal ultimate strength at a stroin rate of $10 /$ second.

\subsubsection{Austenitic Stainless Steel Tensile Test Results}

Each of the three austenitic stainless steel pipes investigated in IPIRG lask 1.0 was tested only at $288 \mathrm{C}(550 \mathrm{H})$. However, data from quas istatic tensile tests at several other temperatures were available from the Degraded Piping Program for Pipe DP2-A23 (A376, Type 304) and Pipe DP2-A8 (A358, Type 304) (Ref. 3.4).

Pipe Number DP2-A23 [152 mm (6 in) Schedule 120, ASIM A376, Type 304 Stainless Steel pipel. Tensile properties are summarized in Table 3.4 for all tensile tests, both quasi-static and dynamic, conducted on DP2A23. Figure 3.15 shows the effect of test temperdiuie on tensile properties, using data obtained from round-bar specimens in the Degraded Piping Program. As is commonly observed in austenitic stainless steels and many other metallic materials, both the ultimate tensile strength and the yield strength of DP2-A23 were diminished significantly as the temperature was increased. The tensile ductility, as indicated by percent elongation, was also diminished with increasing temperature, for reasons that are not known.

Notice in Figure 3.15 that the actual yield strength of Pipe A23 at room temperature was approximately 115 percent of the ASME Section 111 specified minimum yield strength (SMYS). The actual tensile strength at room temperature for Pipe A23 was approximately 120 percent of the ASME Section III specified minimum tensile strength (SMTS).

In tensile tests conducted at room temperature and $288 \mathrm{C}(550 \mathrm{~F})$ on this material, round-bar specimens tested at several different laboratories at quasi-static rates showed good agreement in results. However, a single flat specimen tested at $288 \mathrm{C}(550 \mathrm{~F})$ and a quasi-static rate at Battelle exhibited both lower strength and lower elongation than did the round-bar specimens (see Table 3.4). While the smaller cross-sectional area of the flat specimen could account for a portion of the observed ductility reduction (Ref. 3.5), the only logical explanation for the lower strength of the flat specimens is material variability within the same heat of steel. Because the flat specimens gave somewhat different results than did the round-bar specimens, subsequent comparisons between dynamic tests (which employed flat specimens) and quasi-static tests will be based only on flat-specimen tests.

Figures 3.16 and 3.17 show engineering and true stress-strain curves, respectively, for flat specimens tested at several different strain rates at $288 \mathrm{C}(550 \mathrm{~F})$. Figure 3.18 summarizes the effect of strain 
rate on tensile properties. Notice in Figure 3.18 that the 2 percent offset yield strength values have been used because the quality of the strain data at small strains for this material was inadequate to permit. measurement of the 0.2 percent of fset yield strength. The results indicate that increasing the strain rate by four orders of magnitude raised the yield strength of Pipe DP2-A23 significantly but had only a modest effect on ultimate tensile strength and fracture elongation.

The ASME Section 111 yield strength $\left(S_{y}\right)$ and ultimate strength $\left(S_{u}\right)$ value at $288 \mathrm{C}(550 \mathrm{~F})$ are also indicated in Figure 3.18. Notice that the actual yield strengths were above the ASME $S_{y}$ value for all strain rates, but the actual ultimate strengths were betow the ASME. $S_{u}$ values for all strain rates.

Pipe Number DP2-A8 [406 mm (16 inch), Schedule 100, ASTM A358, Type 304 staintess Steel pipel. Tensile properties are summarized in table 3.5 for all tensile tests, both quasi-static and dynamic, conducted on material from Pipe Number DP2-AB. Figure 3.19 shows the effect of test temperature on tensile properties. The results in Figure 3.19 are similar to those for austenitic Pipe Number DP2-A23, shown in Figure 3.15 , that is, the tensile strength, yield strength, and fracture elongation were decreased by increasing the test temperature in both pipes. As was noted earlier, strength decreases are the expected result of increasing the test temperature; however, the reason for the decrease in fracture elongation as temperature was raised is not known.

Notice in Figure 3.19 that the actual yield strength of Pipe $A 8$ at room temperature was approximately 140 percent of the ASME Section III specified minimum yield strength (SMYS). The actual tensile strength at room temperature for $P$ ipe $A B$ was approximately 140 percent of the ASME. Section III specified minimum tensile strength (SMTS).

Figures 3.20 and 3.21 show engineering and true stress-strain curves, respectively, for Pipe DP2-A8 tensile specimens tested at $288 \mathrm{C}(550 \mathrm{~F})$ at several different strain raies. Table 3.5 and Figure 3.22 summarize the effect of strain rate on tensile properties.

The results for Pipe DP2-A8 differed slightly from those shown for another austenitic stainless steel pipe, DP2-A23, discussed in this section. In Pipe DP2-A8, ultimate tensile strength showed a slight decrease, rather than a slight increase, and yield strength showed a slight increase, rather than a significant increase, with increasing strain rate. In both materials strain-rate effects on fracture elongation were modest.

The ASME Section III yield strength $\left(S_{y}\right)$ and ultimate strength $\left(S_{u}\right)$ values at $288 \mathrm{C}(550 \mathrm{~F})$ are also indicated in Figure 3.22. Not ice that the actual yield strength was above the ASME $S_{y}$ value for all strain rates investigated. The actual ultimate strengths were above the ASME $S_{4}$ value at low strain rates, and at the higher strain rates the actual ultimates were very close to the ASME $S_{u}$ value. This result shows that 
the A8 pipe had a higher strength than the $A 23$ pipe, especially at room temperature.

Pipe Number DP2-A8W [Submerged-Arc Weld in 406-mm (16-inch) diameter, Schedule 100 , type 304 Stainless Steel Pipe. Figures 3.23 and 3.24 show engineering stress-strain and true-stress-strain curves, respectively, for submerged-arc weld metal (DP2-A8W) in Type 304 austenitic stainless steel tested at $288 \mathrm{C}(550 \mathrm{~F})$ at several different strain rates. No tensile test results are available at other temperatures for this material. Table 3.6 and Figure 3.25 summarize the effect of strain rate on tensile properties at $288 \mathrm{C}(550 \mathrm{~F})$.

The results for the weld metal are similar to those for the base metal in this pipe. Both materials showed slightly lower ultimate tensfle strength, slightly higher yield strength, and little change in fracture elongation with increasing strain rate.

In comparing the $A B$ base metal tensile test results to the $A B$ weld metal results, it was found that the weld metal yield strength values and ultimate strength values at $288 \mathrm{C}(550 \mathrm{~F})$ exceeded those of the base metal at all strain rates investigated.

\subsubsection{Cast Stainless Steel Tensile Test Results}

Pipe Number DP2-A40 (406-mm (16-inch) Diameter, $25.4 \mathrm{~mm}(1.0 \mathrm{in}) \mathrm{Wall}$ Artificially Aged CFBM Centrifugally Cast Stainless Steel Pipe]. Figures 3.26 and 3.27 show engineering stress-strain and true stressstrain curves, respectively, for Pipe DP2-A40 tensile specimens tested at $300 \mathrm{C}(572 \mathrm{~F})$. No Battelle tensile test results are available at other temperatures for this material, but additional data have been developed at Framatome, who donated this pipe to the NRC's Degraded Piping Program (see data for Heat Y4331 in Reference 3.6). Table 3.7 and Figure 3.28 summarize the effect of strain rate on tensile properties at $300 \mathrm{C}(572 \mathrm{~F})$.

The results shown in Figure 3.28 indicate that the artificially aged cast stainless steel displayed significant increases in yield strength and fracture elongation but little change in ultimate tensile strength as the strain rate was increased.

Since there were no room temperature data developed at Battelle, comparisons cannot be made to the ASME specified minimum strength values.

The ASME Section 111 yield strength $\left(S_{y}\right)$ and ultimate strength $\left(S_{u}\right)$ values for CF8M at $300 \mathrm{C}(572 \mathrm{~F})$ are indicated in Figure 3.28. Notice, that the actual yield strength was a minimum of 150 percent of the ASME $S_{y}$ value for all strain rates evaluated. The actual ultimate strengths were a minimum of 125 percent of the ASME $S_{u}$ values at all strain rates tested. 


\subsection{References}

3.1 Baird, J. D., "Strain Aging of Steel .. A Critical Review", Iron and Steel, Sept. 1963, pp 450-457.

3.2 Keh, A. S., Nakada, Y., and Leslie, W. C., "Dynamic Strain Aging in Iron and Steel", in Dislocation Dynamics, A. R. Rosenfield et al., Eds., McGraw-Hill, New York, 1968, Pp 381-408.

3.3 Manjoine, M. J., "Influence of Rate of Strain and Temperature on Yield Stresses of Mild Steel", J. of Applied Mechanics, December, 1944, PP A211-A218.

3.4 Wilkowski, G. M. and others, "Degraded Piping Program - Phase II, Sumary of Technical Results and Their Significance to Leak-BeforeBreak and In-Service Flaw Acceptance Criteria", March 1984 . January 1989, NUREG/CR-4082, Volume 8, March 1989.

3.5 Dieter, G. E., "Introduction to Ductillity". Chapter 1 in Ductility, American Society for Metals, Metals Park, Ohio, 1968.

3.6 Meyzaud, V., Ould, P., Balladon, P., Bethmont, M., and Soulat, P., "Tearing Resistance of Aged Cast Austenitic Stainiess Steels", presented at NUCSAFE 88, Avignon, France, October, 1988. 
Table 3.1. Tensile test results for specimens machined from Pipe DP2-F30, Type A106 Grade B carbon steel.

Tensfle axis was parallel with pipe axis;

Flat, pin-loaded specimens were used, except as noted

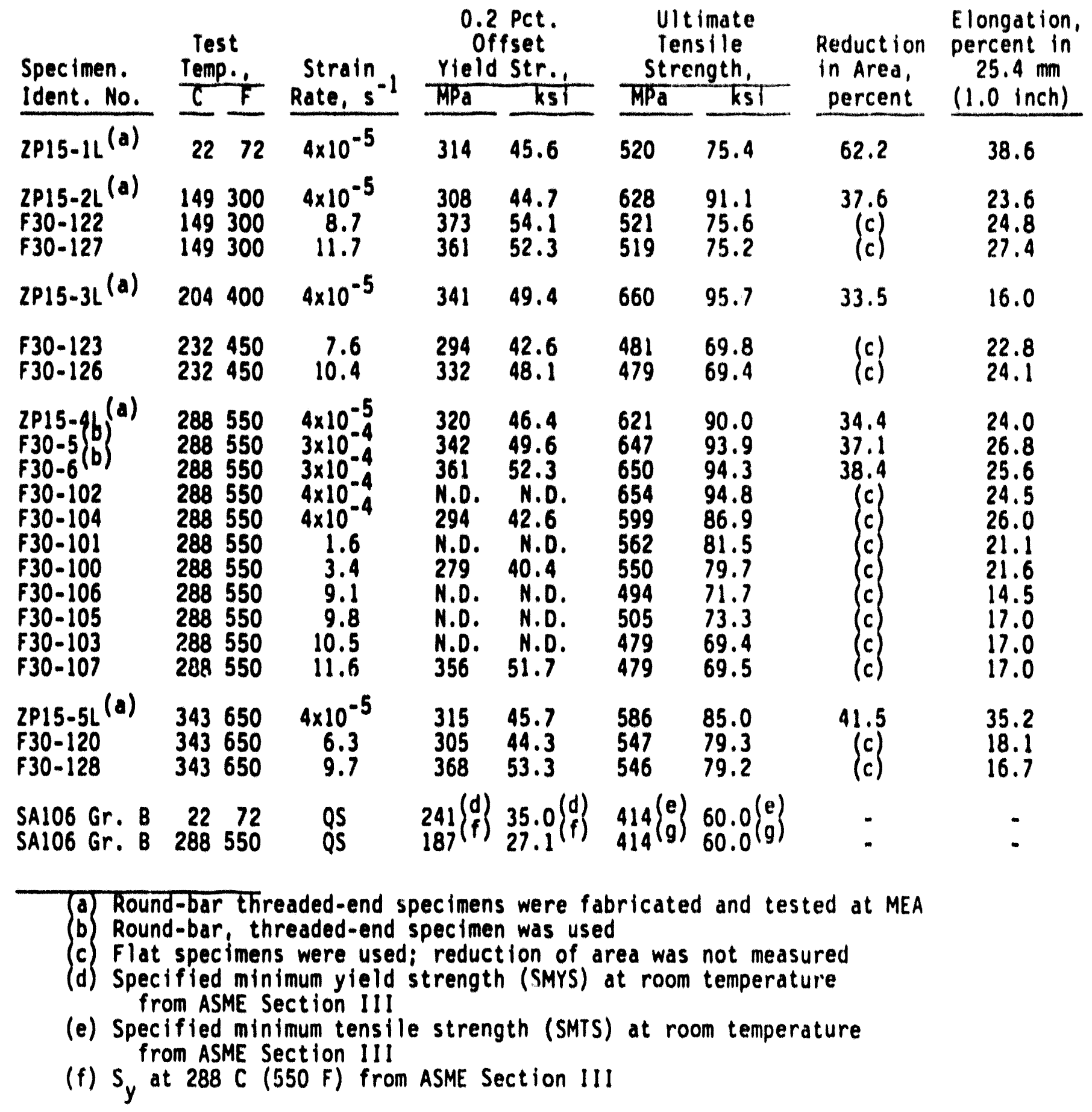


Table 3.2. Tensile properties of Pipe DP2-F29 (ASTM A106 Grade B Carbon Steel)

\begin{tabular}{|c|c|c|c|c|c|c|c|c|}
\hline $\begin{array}{l}\text { Spec. } \\
\text { Ident. } \\
\text { No. }\end{array}$ & \multicolumn{2}{|c|}{ Temp. } & $\begin{array}{l}\text { Strain, } \\
\text { Rate, } s\end{array}$ & \multicolumn{2}{|c|}{$\begin{array}{c}0.2 \text { Pct. } \\
\text { Offset } \\
\text { Yield Str. }\end{array}$} & \multicolumn{2}{|c|}{$\begin{array}{r}\text { Ult. } \\
\text { Tensile } \\
\text { Strength, }\end{array}$} & $\begin{array}{l}\text { Elongation, } \\
\text { Pct. in } \\
25.4 \mathrm{~mm} \\
(1.0 \mathrm{inch}) \\
\end{array}$ \\
\hline $\begin{array}{l}F 29-1 \\
F 29-2\end{array}\left(\begin{array}{l}a \\
a\end{array}\right)$ & $\begin{array}{l}22 \\
22\end{array}$ & $\begin{array}{l}72 \\
72\end{array}$ & $\begin{array}{l}2 \times 10^{-4} \\
2 \times 10^{-4}\end{array}$ & $\begin{array}{l}277 \\
276\end{array}$ & $\begin{array}{l}40.2 \\
40.0\end{array}$ & $\begin{array}{l}524 \\
513\end{array}$ & $\begin{array}{l}76.0 \\
74.4\end{array}$ & $\begin{array}{l}29.6 \\
29.6\end{array}$ \\
\hline $\begin{array}{l}F 29-3(a) \\
F 29-4\end{array}$ & $\begin{array}{l}149 \\
149\end{array}$ & $\begin{array}{l}300 \\
300\end{array}$ & $\begin{array}{l}2 \times 10^{-4} \\
2 \times 10^{-4}\end{array}$ & $\begin{array}{l}252 \\
251\end{array}$ & $\begin{array}{l}36.6 \\
36.4\end{array}$ & $\begin{array}{l}610 \\
596\end{array}$ & $\begin{array}{l}88.5 \\
86.4\end{array}$ & $\begin{array}{l}18.1 \\
19.1\end{array}$ \\
\hline 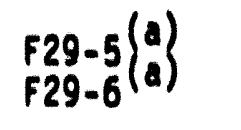 & $\begin{array}{l}288 \\
288\end{array}$ & $\begin{array}{l}550 \\
550\end{array}$ & $\begin{array}{l}2 \times 10^{-4} \\
2 \times 10^{-4}\end{array}$ & $\begin{array}{l}241 \\
234\end{array}$ & $\begin{array}{l}34.9 \\
33.9\end{array}$ & $\begin{array}{l}618 \\
601\end{array}$ & $\begin{array}{l}89.7 \\
87.2\end{array}$ & $\begin{array}{l}24.0 \\
24.0\end{array}$ \\
\hline $\begin{array}{l}F 29-101 \\
F 29-103\end{array}$ & $\begin{array}{l}288 \\
288\end{array}$ & $\begin{array}{l}550 \\
550\end{array}$ & $\frac{1}{1}$ & $\begin{array}{l}235 \\
230\end{array}\left(\begin{array}{l}b \\
b\end{array}\right)$ & $\begin{array}{l}34.1 \\
33.3\end{array}$ & $\begin{array}{l}503 \\
511\end{array}$ & $\begin{array}{l}72.9 \\
74.1\end{array}$ & $\begin{array}{l}19.6 \\
23.0\end{array}$ \\
\hline $\begin{array}{l}F 29-102 \\
F 29-104\end{array}$ & $\begin{array}{l}288 \\
288\end{array}$ & $\begin{array}{l}550 \\
550\end{array}$ & $\begin{array}{l}10 \\
10\end{array}$ & $\begin{array}{l}234(b) \\
228\end{array}$ & $\begin{array}{l}34.0 \\
33.0\end{array}$ & $\begin{array}{l}443 \\
435\end{array}$ & $\begin{array}{l}64.2 \\
63.1\end{array}$ & $\begin{array}{l}24.1 \\
19.6\end{array}$ \\
\hline $\begin{array}{l}\text { SALOG Gr. B } \\
\text { SALOG Gr. B }\end{array}$ & $\begin{array}{r}22 \\
288\end{array}$ & $\begin{array}{r}72 \\
550\end{array}$ & $\begin{array}{l}\text { QS } \\
\text { QS }\end{array}$ & 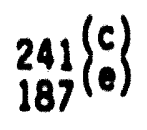 & $\begin{array}{l}35.0 \\
27.1\end{array}\left(\begin{array}{l}c \\
e\end{array}\right)$ & $\begin{array}{l}414 \\
414\end{array}\left(\begin{array}{l}d \\
f\end{array}\right)$ & $\begin{array}{l}60.0 \\
60.0\end{array}\left(\begin{array}{l}d \\
f\end{array}\right)$ & : \\
\hline
\end{tabular}

\footnotetext{
(a) Round-bar, threaded-ends specimens; all others were flat pin-loaded specimens.

(b) Approximate value only, due to uncertainties in stress-strain curves at small strains.

(c) Spectfied minimum yield strength (SMYS) at room temperature from ASME Section III

(d) Specified minimum tensile strength (SMTS) at room temperature frnm ASME Section III

(e) $S_{\text {S }}$ at 288 C (550 F) from ASME Section III

(f) $S_{u}^{y}$ at $288 \mathrm{C}(550 \mathrm{~F})$ from ASME Section III
} 
Table 3.3. Tensile properties of submerged-arc weld (OP2-F29W) in Pipe DP2-F29 (ASTM A106 Grade B Carbon Steel) at 288 C (550 F)

\begin{tabular}{|c|c|c|c|c|c|c|}
\hline \multirow{2}{*}{$\begin{array}{l}\text { Spec. } \\
\text { Ident. } \\
\text { No. } \\
\end{array}$} & \multirow{2}{*}{$\begin{array}{r}\text { Strain } \\
\text { Rate, } s^{-1} \\
\end{array}$} & \multicolumn{2}{|c|}{$\begin{array}{c}0.2 \text { Pct. } \\
\text { Offset } \\
\text { Yield Str. }\end{array}$} & \multicolumn{2}{|c|}{$\begin{array}{l}\text { Ult. } \\
\text { Tensile } \\
\text { Strength. }\end{array}$} & \multirow[t]{2}{*}{$\begin{array}{c}\text { Elongation, } \\
\text { Pct. in } \\
25.4 \mathrm{~mm} \\
(1.0 \text { inch }) \\
\end{array}$} \\
\hline & & $\underline{M a}$ & ksi & $\mathrm{MPa}$ & kst & \\
\hline F29W-107 & $2 \times 10^{-4}$ & 356 & 51.7 & 556 & 80.7 & 20.4 \\
\hline $\begin{array}{l}F 29 W-101 \\
F 29 W-104\end{array}$ & 1 & $\begin{array}{l}368 \\
396\end{array}$ & $\begin{array}{l}53.4 \\
57.4\end{array}$ & $\begin{array}{l}487 \\
495\end{array}$ & $\begin{array}{l}70.6 \\
71.8\end{array}$ & $\begin{array}{l}14.8 \\
14.5\end{array}$ \\
\hline $\begin{array}{l}F 29 W-103 \\
F 29 W-106\end{array}$ & $\begin{array}{l}10 \\
10\end{array}$ & $\begin{array}{l}347 \\
345\end{array}$ & $\begin{array}{l}50.3 \\
50.0\end{array}$ & $\begin{array}{l}446 \\
454\end{array}$ & $\begin{array}{l}64.7 \\
65.8\end{array}$ & $\begin{array}{l}21.8 \\
21.9\end{array}$ \\
\hline
\end{tabular}

(a) Approximate values on $y$, due to uncertainties in stress-strain curves at small strains. 
Table 3.4. Tensile test results for specimens machined from Pipe DP2-A23, Type 304 stainless steel.

(Tensile axis was parallel with pipe axis)

\begin{tabular}{|c|c|c|c|c|c|c|c|c|c|}
\hline \multirow{2}{*}{$\begin{array}{l}\text { Specimen } \\
\text { Ident. No. }\end{array}$} & \multicolumn{2}{|c|}{ Temp. } & \multirow{2}{*}{$\begin{array}{l}\text { Strain }: 1 \\
\text { Rate, } s^{-1} \\
\end{array}$} & \multicolumn{2}{|c|}{$\begin{array}{c}0.2 \text { Pct. } \\
\text { Offset } \\
\text { Yield Str., }\end{array}$} & \multicolumn{2}{|c|}{$\begin{array}{c}\text { Ultimate } \\
\text { Tensile } \\
\text { Strength, }\end{array}$} & \multirow{2}{*}{$\begin{array}{c}\text { Elongation, } \\
\text { Pct. in } \\
25.4 \mathrm{~mm} \\
(1.0 \text { inch }) \\
\end{array}$} & \multirow{2}{*}{$\begin{array}{l}\text { Reduction } \\
\text { in Area, } \\
\text { percent } \\
\end{array}$} \\
\hline & $c$ & $F$ & & $\mathrm{MPa}$ & ksi & $\mathrm{MPa}$ & kst & & \\
\hline $\begin{array}{l}2 P 17-1 L(a) \\
2 P 17-15 L(d)\end{array}$ & $\begin{array}{l}21 \\
26\end{array}$ & $\begin{array}{l}69 \\
78\end{array}$ & $\begin{array}{l}4 \times 10^{-5} \\
4 \times 10^{-5}\end{array}$ & $\begin{array}{l}248 \\
250\end{array}$ & $\begin{array}{l}35.9 \\
36.2\end{array}$ & $\begin{array}{l}601 \\
607\end{array}$ & $\begin{array}{l}87.2 \\
88.1\end{array}$ & $\begin{array}{r}92.8 \\
102.6\end{array}$ & $\begin{array}{l}64.0 \\
83.2\end{array}$ \\
\hline $\begin{array}{l}2 P 17-17 L(a) \\
2 P 17-11 L\end{array}$ & $\begin{array}{l}149 \\
149\end{array}$ & $\begin{array}{l}300 \\
300\end{array}$ & $\begin{array}{l}4 \times 10^{-5} \\
4 \times 10^{-5}\end{array}$ & $\begin{array}{l}170 \\
182\end{array}$ & $\begin{array}{l}24.6 \\
26.4\end{array}$ & $\begin{array}{l}466 \\
467\end{array}$ & $\begin{array}{l}67.6 \\
67.8\end{array}$ & $\begin{array}{l}72.8 \\
46.6\end{array}$ & $\begin{array}{l}79.3 \\
64.0\end{array}$ \\
\hline $\begin{array}{l}A 23-1 \\
A 23-2 \\
2 P 17-16 L(a) \\
2 P 17-13(a) \\
A 23-105(b)\end{array}$ & $\begin{array}{l}288 \\
288 \\
288 \\
288 \\
288\end{array}$ & $\begin{array}{l}550 \\
550 \\
550 \\
550 \\
550\end{array}$ & $\begin{array}{l}3.7 \times 10^{-4} \\
3.7 \times 10^{-4} \\
3.7 \times 10^{-5} \\
4.1 \times 10^{-5} \\
5.5 \times 10^{-4}\end{array}$ & $\begin{array}{c}134 \\
128 \\
147 \\
145(c) \\
\text { N.D. }\end{array}$ & $\begin{array}{l}19.4 \\
18.6 \\
21.3 \\
21.1 \\
N .0 .\end{array}$ & $\begin{array}{l}451 \\
447 \\
448 \\
453 \\
400\end{array}$ & $\begin{array}{l}65.4 \\
64.8 \\
65.0 \\
65.7 \\
58.0\end{array}$ & $\begin{array}{l}53.5 \\
53.5 \\
51.0 \\
57.0 \\
46.0\end{array}$ & $\begin{array}{l}73.4 \\
74.5 \\
62.6 \\
75.0 \\
N .0 .\end{array}$ \\
\hline $\begin{array}{l}A 23-101 \\
A 23-104\end{array}(b)$ & $\begin{array}{l}288 \\
288\end{array}$ & $\begin{array}{l}550 \\
550\end{array}$ & $\begin{array}{l}1.1 \\
0.9\end{array}$ & $\begin{array}{l}\text { N.D. } \\
\text { N.D. }\end{array}$ & $\begin{array}{l}\text { N.D. } \\
\text { N.D. }\end{array}$ & $\begin{array}{l}413 \\
421\end{array}$ & $\begin{array}{l}59.9 \\
61.0\end{array}$ & $\begin{array}{l}47.0 \\
46.0\end{array}$ & $\begin{array}{l}\text { N.D. } \\
\text { N.D. }\end{array}$ \\
\hline $\begin{array}{l}A 23-102 \\
A 23-103 \\
A 23-108\end{array}\left(\begin{array}{l}b \\
b\end{array}\right)$ & $\begin{array}{l}288 \\
288 \\
288\end{array}$ & $\begin{array}{l}550 \\
550 \\
550\end{array}$ & $\begin{array}{r}10.0 \\
8.9 \\
9.0\end{array}$ & $\begin{array}{l}\text { N.D. } \\
N .0 . \\
N . D .\end{array}$ & $\begin{array}{l}\text { N.D. } \\
\text { N.D. } \\
\text { N.D. }\end{array}$ & $\begin{array}{l}413 \\
423 \\
396\end{array}$ & $\begin{array}{l}59.9 \\
61.3 \\
57.4\end{array}$ & $\begin{array}{l}52.0 \\
47.5 \\
47.0\end{array}$ & $\begin{array}{l}\text { N.D. } \\
\text { N.D. } \\
\text { N.D. }\end{array}$ \\
\hline $\begin{array}{ll}\text { SA376 TP304 } \\
\text { SA376 TP304 }\end{array}$ & $\begin{array}{l}22 \\
288\end{array}$ & $\begin{array}{l}72 \\
550\end{array}$ & $\begin{array}{l}Q S \\
Q S\end{array}$ & $\begin{array}{l}207 \\
130\end{array}\left(\begin{array}{l}d \\
f\end{array}\right)$ & $\begin{array}{l}30.0 \\
18.8\end{array}\left(\begin{array}{l}d \\
f\end{array}\right)$ & ${ }_{438}^{517}\left(\begin{array}{l}e \\
g\end{array}\right)$ & $\begin{array}{l}75.0 \\
63.5\end{array}(\mathrm{~g})$ & - & - \\
\hline $\begin{array}{l}\text { (a) Speci } \\
\text { (b) Flat } \\
\text { speci } \\
\text { (c) N.o. } \\
\text { (d) Speci } \\
\text { from } \\
\text { (e) Speci } \\
\text { from } \\
\text { (f) } S_{y} a t \\
\text { g) } S_{u} \text { at }\end{array}$ & $\begin{array}{l}\text { Not } \\
\text { ied m } \\
\text { isME S } \\
\text { ied m } \\
\text { SSME S } \\
288 \mathrm{C} \\
288 \mathrm{C}\end{array}$ & $\begin{array}{l}\text { deter } \\
\text { inimu } \\
\text { ectio } \\
\text { inimu } \\
\text { ectio } \\
550 \\
550\end{array}$ & $\begin{array}{l}\text { mined } \\
\text { im yield str } \\
\text { on lll } \\
\text { im tensile s } \\
\text { olll } \\
\text { F) from ASI } \\
\text { F) from ASI }\end{array}$ & trength & $\begin{array}{l}\text { MYS) at } \\
\text { (SMTS) } \\
\text { on III } \\
\text { on III }\end{array}$ & $\begin{array}{l}\text { om tem } \\
\text { room } t\end{array}$ & $\begin{array}{l}\text { perature } \\
\text { emperatur }\end{array}$ & $\begin{array}{l}\text { sociates } \\
\text { end }\end{array}$ & \\
\hline
\end{tabular}


Table 3.5. Tensile properties of Pipe DP2-A8 (ASTM A358, Type 304 Stainless Steel)

\begin{tabular}{|c|c|c|c|c|c|c|c|}
\hline $\begin{array}{l}\text { Spec. } \\
\text { Ident. } \\
\text { No. }\end{array}$ & $\stackrel{\text { Temp. }}{c} \mathbf{F}$ & $\frac{\text { Strain }}{\text { Rate, s }}$ & $\begin{array}{r}0.2 \\
\text { of } \\
\text { Yield } \\
\text { Mpd }\end{array}$ & $\begin{array}{l}\text { Pct. } \\
\text { fset } \\
\text { Str. } \\
\text { ksi }\end{array}$ & $\begin{array}{c}U \\
T e \\
\text { Str } \\
\mathrm{MPa}\end{array}$ & $\begin{array}{l}\text { it. } \\
\text { nsile } \\
\text { ength, } \\
\text { ksi }\end{array}$ & $\begin{array}{l}\text { Elongation, } \\
\text { PCt. in } \\
25.4 \mathrm{~mm} \\
(1.0 \text { inch })\end{array}$ \\
\hline $\begin{array}{l}A 8-48\left(\begin{array}{l}b \\
A 3-35 \\
A \\
A 8-36\end{array}(b)\right. \\
(b)\end{array}$ & $\begin{array}{ll}22 & 72 \\
22 & 72 \\
22 & 72\end{array}$ & $\begin{array}{l}4 \times 10^{-4} \\
4 \times 10^{-4} \\
4 \times 10^{-4}\end{array}$ & $\begin{array}{l}287 \\
295 \\
303\end{array}$ & $\begin{array}{l}41.6 \\
42.8 \\
43.9\end{array}$ & $\begin{array}{l}698 \\
743 \\
736\end{array}$ & $\begin{array}{l}101.2 \\
107.8 \\
106.7\end{array}$ & $\begin{array}{l}79.4 \\
75.9 \\
74.3\end{array}$ \\
\hline $\begin{array}{l}A 8-37(b) \\
A 8-38(b)\end{array}$ & $\begin{array}{l}149300 \\
149300\end{array}$ & $\begin{array}{l}4 \times 10^{-4} \\
3 \times 10^{-4}\end{array}$ & $\begin{array}{l}225 \\
202\end{array}$ & $\begin{array}{l}32.6 \\
29.3\end{array}$ & $\begin{array}{l}481 \\
476\end{array}$ & $\begin{array}{l}69.8 \\
69.1\end{array}$ & $\begin{array}{l}43.5 \\
54.8\end{array}$ \\
\hline $\begin{array}{l}A B-105(b) \\
A 8-39(b) \\
A B-40\end{array}(b)$ & $\begin{array}{l}288550 \\
288550 \\
288550\end{array}$ & $\begin{array}{l}5 \times 10^{-4} \\
3 \times 10^{-4} \\
4 \times 10^{-4}\end{array}$ & $\begin{array}{l}200^{(a)} \\
180 \\
171\end{array}$ & $\begin{array}{l}29.0 \\
26.1 \\
24.8\end{array}$ & $\begin{array}{l}443 \\
461 \\
456\end{array}$ & $\begin{array}{l}64.3 \\
66.8 \\
66.2\end{array}$ & $\begin{array}{l}45.7 \\
45.0 \\
47.0\end{array}$ \\
\hline $\begin{array}{l}A 8-100 \\
A B-101 \\
A 8-102\end{array}$ & $\begin{array}{ll}288 & 550 \\
288 & 550 \\
300 & 572\end{array}$ & $\frac{1}{1}$ & $\begin{array}{c}N \cdot P(a) \\
200 \\
190\end{array}(a)$ & $\begin{array}{l}\text { N.D. } \\
29.0 \\
27.5\end{array}$ & $\begin{array}{l}430 \\
420 \\
423\end{array}$ & $\begin{array}{l}62.4 \\
60.9 \\
61.3\end{array}$ & $\begin{array}{l}47.0 \\
47.1 \\
46.5\end{array}$ \\
\hline $\begin{array}{l}A B-103 \\
A B-104\end{array}$ & $\begin{array}{ll}288 & 550 \\
288 & 550\end{array}$ & $\begin{array}{l}10 \\
10\end{array}$ & $\begin{array}{l}200\left(\begin{array}{l}\text { a } \\
194\end{array}\right) \\
\text { a }\end{array}$ & $\begin{array}{l}29.0 \\
28.1\end{array}$ & $\begin{array}{l}429 \\
423\end{array}$ & $\begin{array}{l}62.2 \\
61.4\end{array}$ & $\begin{array}{l}49.8 \\
50.8\end{array}$ \\
\hline $\begin{array}{l}\text { SA358 TP304 } \\
\text { SA358 TP304 }\end{array}$ & $\begin{array}{rr}22 & 72 \\
288 & 550\end{array}$ & $\begin{array}{l}Q S \\
Q S\end{array}$ & $\left.\begin{array}{l}207(c) \\
130\end{array}\right)$ & $\left.\begin{array}{l}30.0(c) \\
18.8\end{array}\right)$ & $\begin{array}{l}517)^{(d)} \\
438\end{array}$ & $\begin{array}{l}75.0(d) \\
63.5\end{array}$ & - \\
\hline
\end{tabular}

\footnotetext{
(a) Approximate value only, due to uncertainties in stress-strain curves at small strains.

(b) Round-bar, threaded-ends specimen; all others were flat, pin-loaded specimens.

(c) Specified minimum yield strength (SMYS) at room temperature from ASME Section III

(d) Specified minimum tensile strength (SMTS) at room temperature from ASME Section III

(e) $S_{y}$ at 288 C (550 F) from ASME Section III

(f) $s_{u}^{y}$ at $288 \mathrm{C}(550 \mathrm{~F})$ from ASME Section III
} 
Table 3.6. Tensile properties of SA weld (DP2-ABW) in Pipe DP2-AB (ASTM A358, Type 304 Stainless Steel) at 288 C (550F)

\begin{tabular}{|c|c|c|c|c|c|c|}
\hline $\begin{array}{l}\text { Spec. } \\
\text { Ident. } \\
\text { No. }\end{array}$ & $\begin{array}{r}\text { Strain } \\
\text { Rate, } \mathrm{s}^{-1} \\
\end{array}$ & $\begin{array}{r}0.2 \\
0 f \\
Y i e l c \\
\mathrm{MPa} \\
\end{array}$ & $\begin{array}{l}\text { Pct. } \\
\text { set } \\
\text { Str. } \\
\text { ksi } \\
\end{array}$ & $\begin{array}{r}1 \\
\text { Ter } \\
\text { Stre } \\
\mathrm{MPa} \\
\end{array}$ & $\begin{array}{l}\text { t. } \\
\text { ile } \\
\text { gth, } \\
k s i\end{array}$ & $\begin{array}{l}\text { Elonyation, } \\
\text { Pct. in } \\
20.3 \mathrm{~mm} \\
(0.8 \text { inch })\end{array}$ \\
\hline$A 8 W-106$ & $2.0 \times 10^{-4}$ & 258 & 37.4 & 469 & 68.0 & 26.4 \\
\hline $\begin{array}{l}A B W-105 \\
A B W-101(a) \\
A B W-102\end{array}$ & $\begin{array}{l}0.9 \\
1.0 \\
1.1\end{array}$ & $\begin{array}{l}283 \\
288 \\
270\end{array}$ & $\begin{array}{l}41.0 \\
44.8 \\
39.1\end{array}$ & $\begin{array}{l}430 \\
443 \\
436\end{array}$ & $\begin{array}{l}62.3 \\
64.2 \\
63.2\end{array}$ & $\begin{array}{l}19.4 \\
23.3 \\
30.1\end{array}$ \\
\hline $\begin{array}{l}A 8 W-103 \\
A B W-104\end{array}$ & $\begin{array}{r}8.0 \\
13.7\end{array}$ & $\begin{array}{l}308 \\
266\end{array}$ & $\begin{array}{l}44.6 \\
38.6\end{array}$ & $\begin{array}{l}442 \\
444\end{array}$ & $\begin{array}{l}64.1 \\
64.4\end{array}$ & $\begin{array}{l}22.8 \\
24.5\end{array}$ \\
\hline
\end{tabular}

(a) Tested at $300 \mathrm{C}(572 \mathrm{~F})$

Table 3.7. Tensile properties of Pipe DP2-A40 (aged CF8M cast stainless steel) at $300 \mathrm{C}(572 \mathrm{~F})$

\begin{tabular}{|c|c|c|c|c|c|c|}
\hline \multirow{2}{*}{$\begin{array}{l}\text { Specimen } \\
\text { Ident. No. }\end{array}$} & \multirow{2}{*}{$\begin{array}{l}\text { Strain } \\
\text { Rate, } s^{-1} \\
\end{array}$} & \multicolumn{2}{|c|}{$\begin{array}{c}0.2 \text { Pct. } \\
\text { offset } \\
\text { Yield Str., }\end{array}$} & \multicolumn{2}{|c|}{$\begin{array}{l}\text { Ultimate } \\
\text { Tensile } \\
\text { Strength, }\end{array}$} & \multirow{2}{*}{$\begin{array}{c}\text { Elongation, } \\
\text { Pct. in } \\
25.4 \mathrm{~mm} \\
(1.0 \text { inch }) \\
\end{array}$} \\
\hline & & $\mathrm{MPa}$ & ksi & $\mathrm{MPa}$ & ksi & \\
\hline$A 40-106^{(a)}$ & $1.6 \times 10^{-4}$ & 201 & 29.2 & 578 & 83.9 & 20.2 \\
\hline $\begin{array}{l}\text { A40-104 } \\
\text { A40-101 }\end{array}$ & $\begin{array}{l}1.0 \\
1.2\end{array}$ & $\begin{array}{l}228 \\
231\end{array}$ & $\begin{array}{l}33.1 \\
34.0\end{array}$ & $\begin{array}{l}563 \\
578\end{array}$ & $\begin{array}{l}81.6 \\
83.8\end{array}$ & $\begin{array}{l}28.3 \\
25.4\end{array}$ \\
\hline $\begin{array}{l}\text { A40-105 } \\
\text { A40-102 } \\
\text { A40-103 }\end{array}$ & $\begin{array}{l}6.8 \\
7.6 \\
8.1\end{array}$ & $\begin{array}{l}259 \\
252 \\
232\end{array}$ & $\begin{array}{l}37.6 \\
36.6 \\
33.7\end{array}$ & $\begin{array}{l}571 \\
581 \\
574\end{array}$ & $\begin{array}{l}82.8 \\
84.3 \\
83.3\end{array}$ & $\begin{array}{l}24.7 \\
26.9 \\
33.1\end{array}$ \\
\hline SA351 (CF8M) & QS & $134^{(b)}$ & $19.4^{(b)}$ & $462^{(c)}$ & $67.0^{(c)}$ & - \\
\hline
\end{tabular}

(a) Tested at $288 \mathrm{C}(550 \mathrm{~F})$
(b) $S_{\text {at }} 300 \mathrm{C}(572 \mathrm{~F})$ from ASME Section III
(c) $S_{u}^{y}$ at $300 \mathrm{C}(572 \mathrm{~F})$ from ASME Section III 


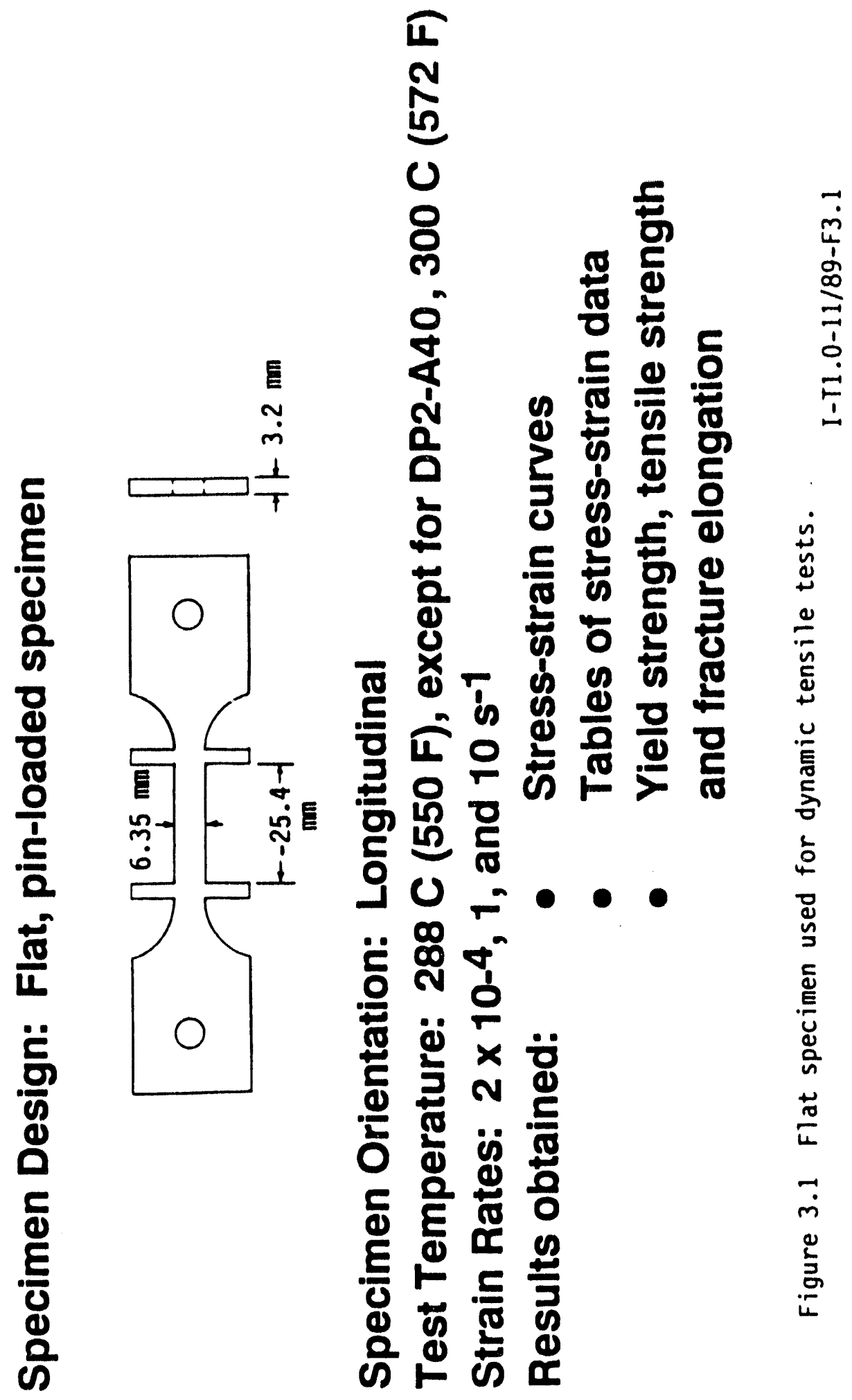




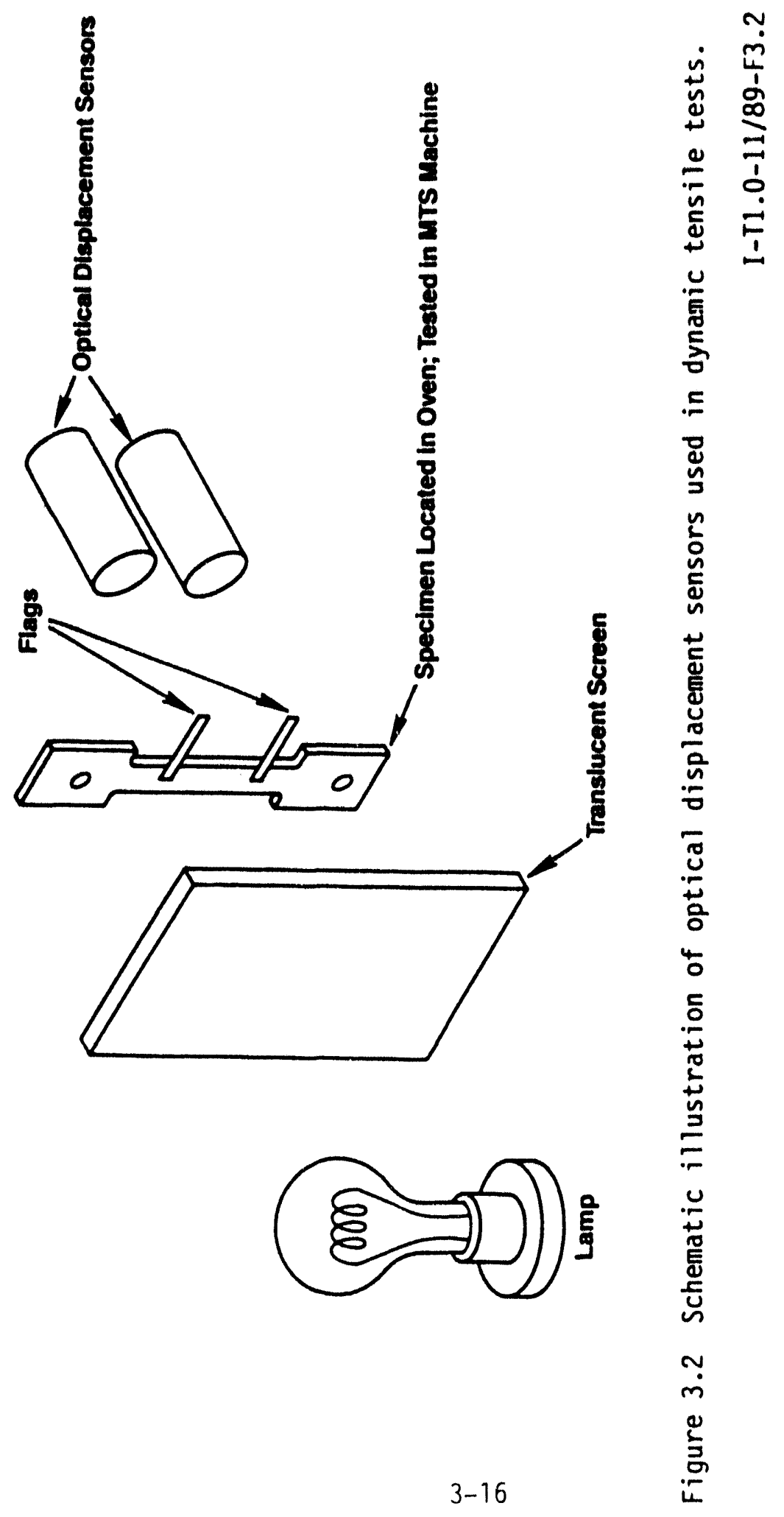




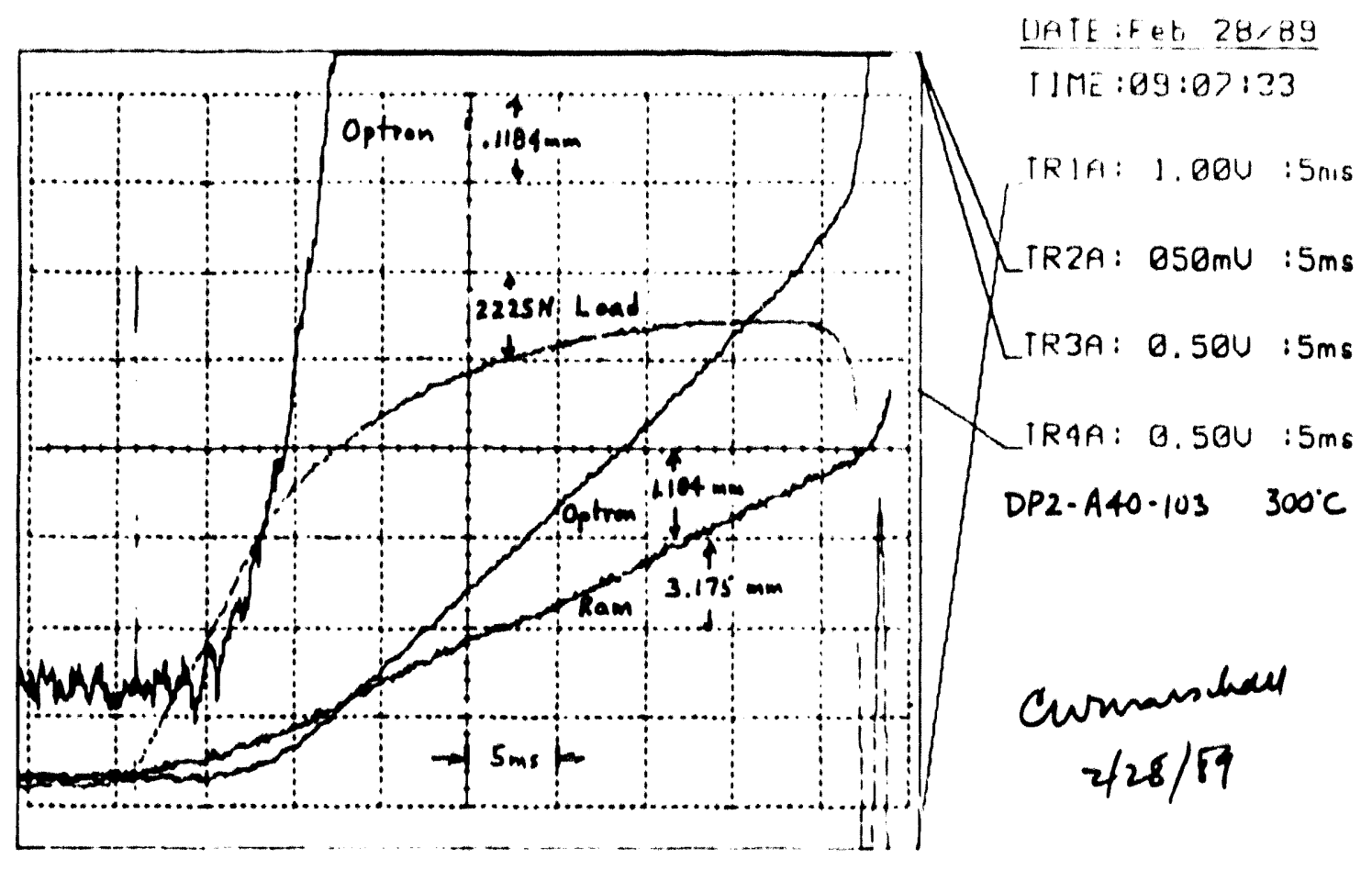

(a) Indicated quantities versus time

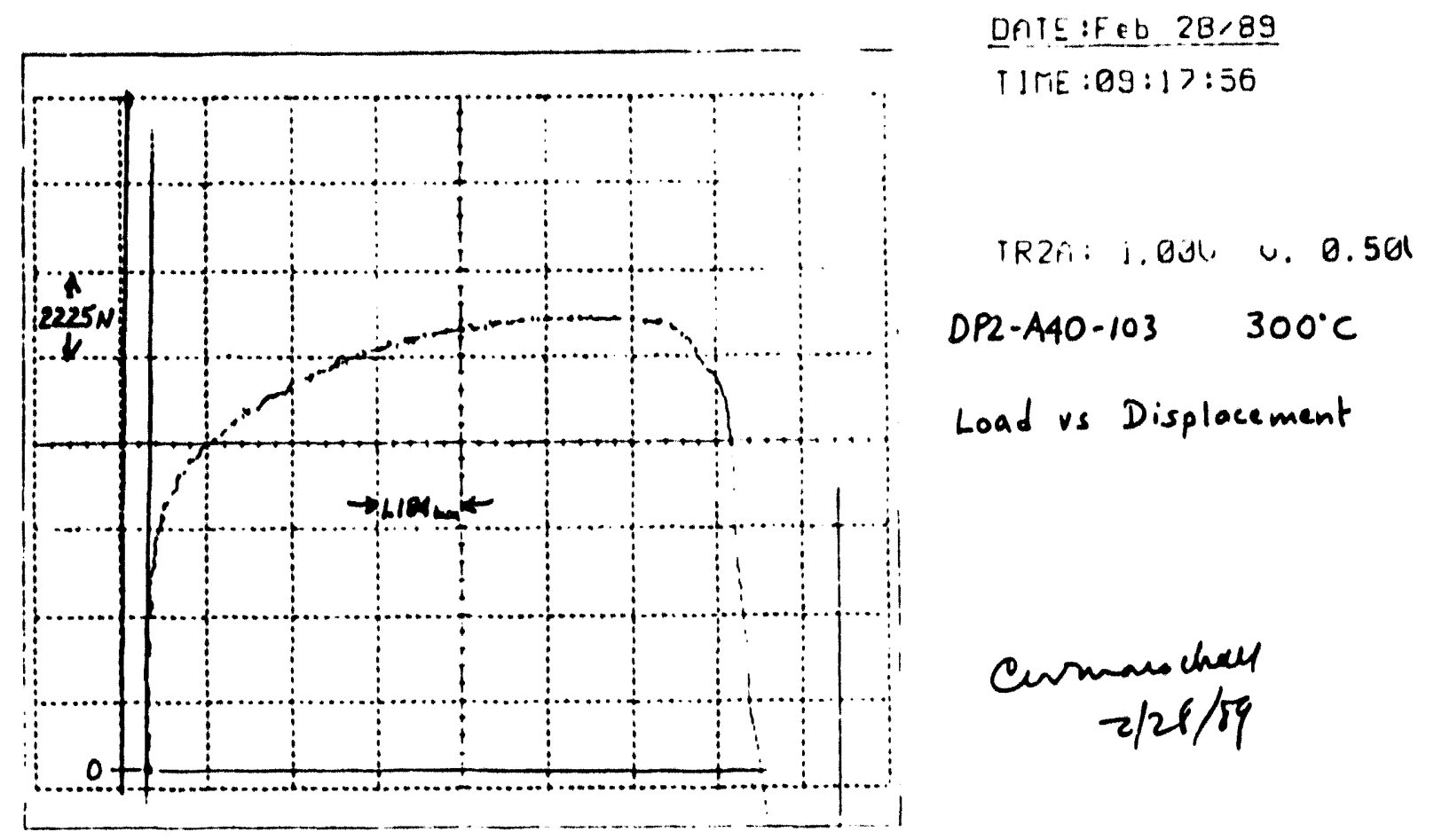

(b) Load versus displacement

Figure 3.3 Example of dynamic tensile test data; Pipe DP2-A40 (Aged A351 Type CF8M Cast Staigless Steel) tested at 300 C (572 F) at a strain rate of 8.1

$1-T 1.0-11 / 89-F 3.3$ 


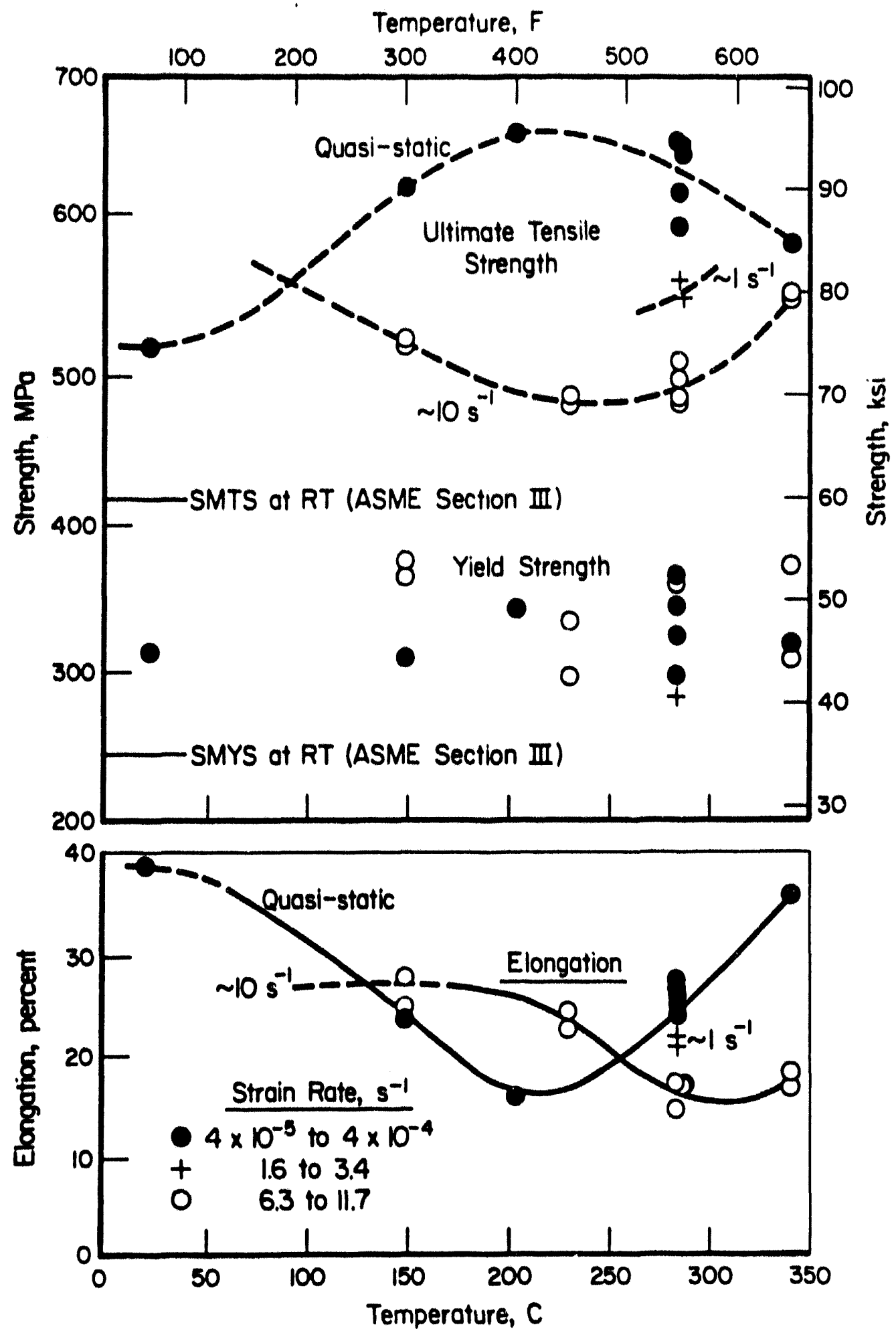

Figure 3.4 Effect of strain rate and test temperature on tensile properties of Pipe DP2-F30 (A106 Grade B carbon steel).

I-T1.0-11/89-F3.4 


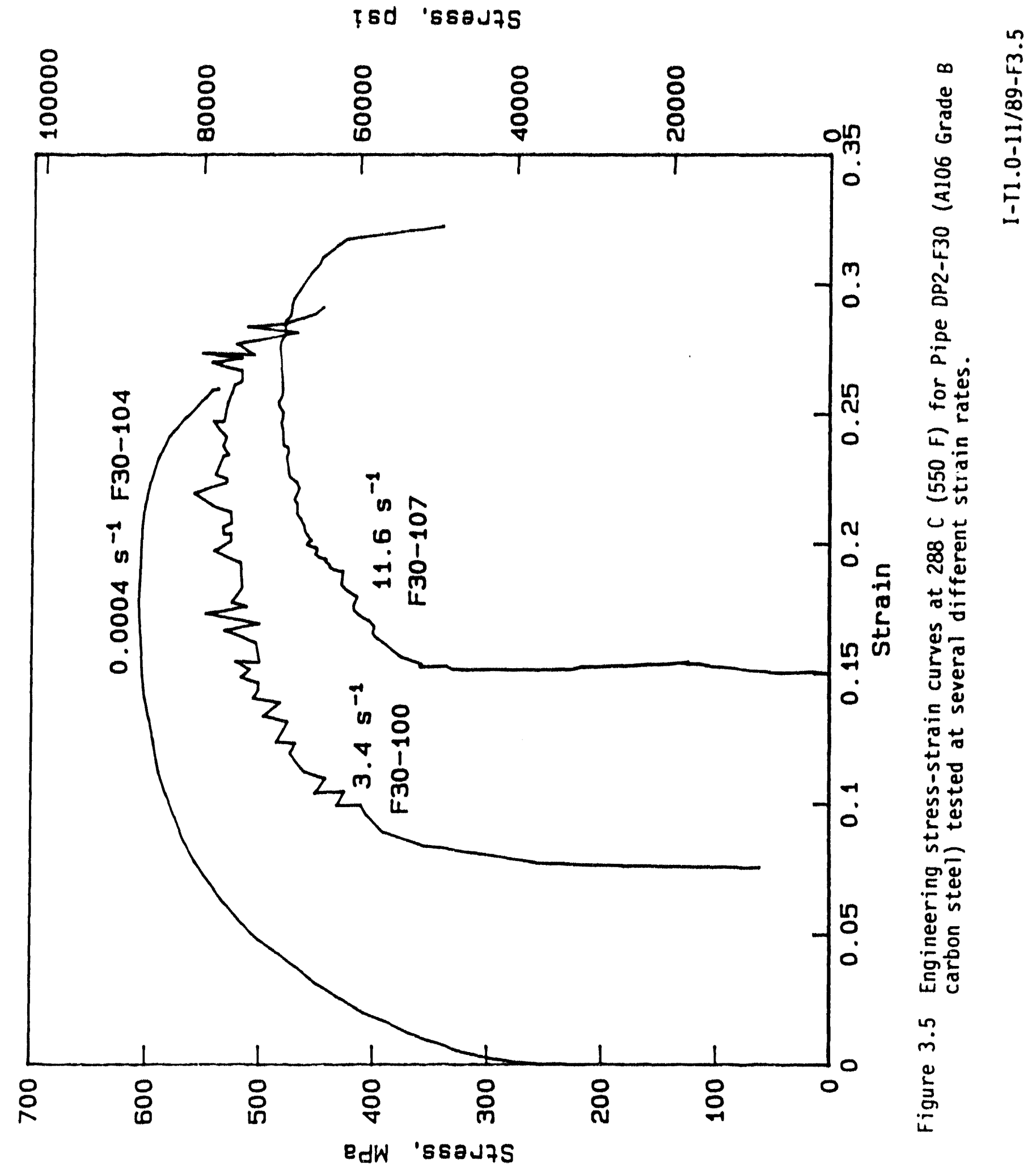


โรत्र 's50נ75 0nd

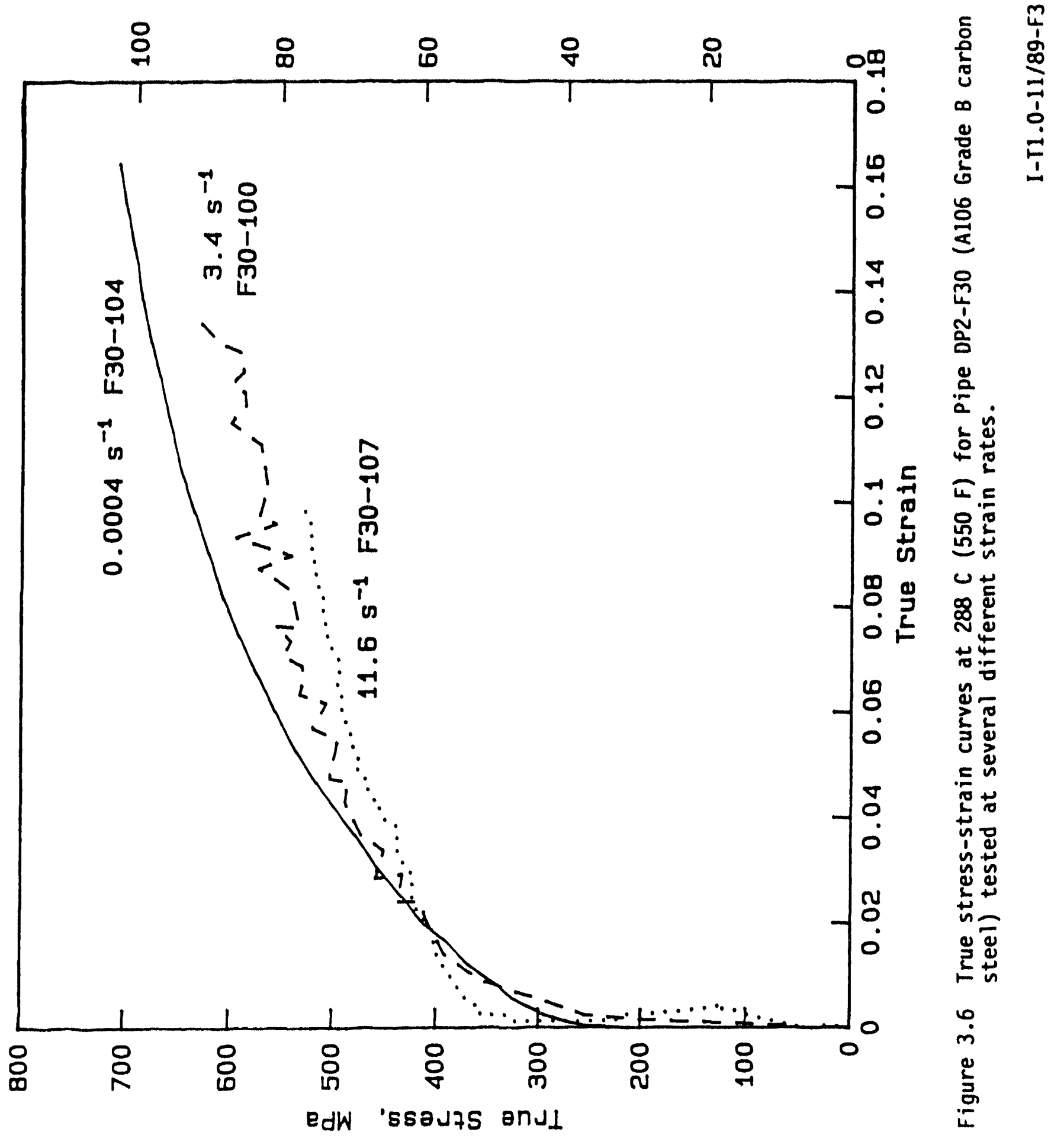




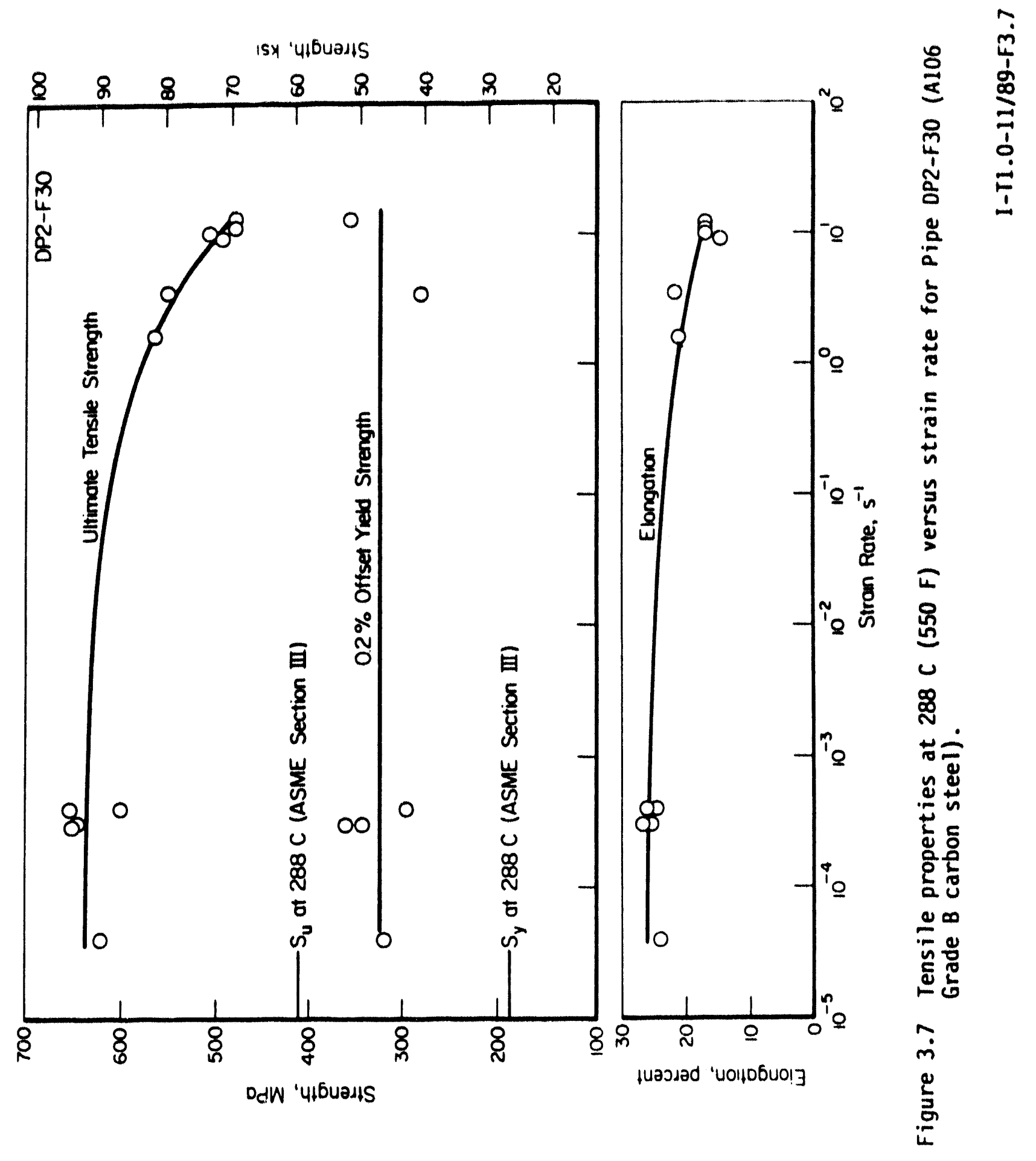




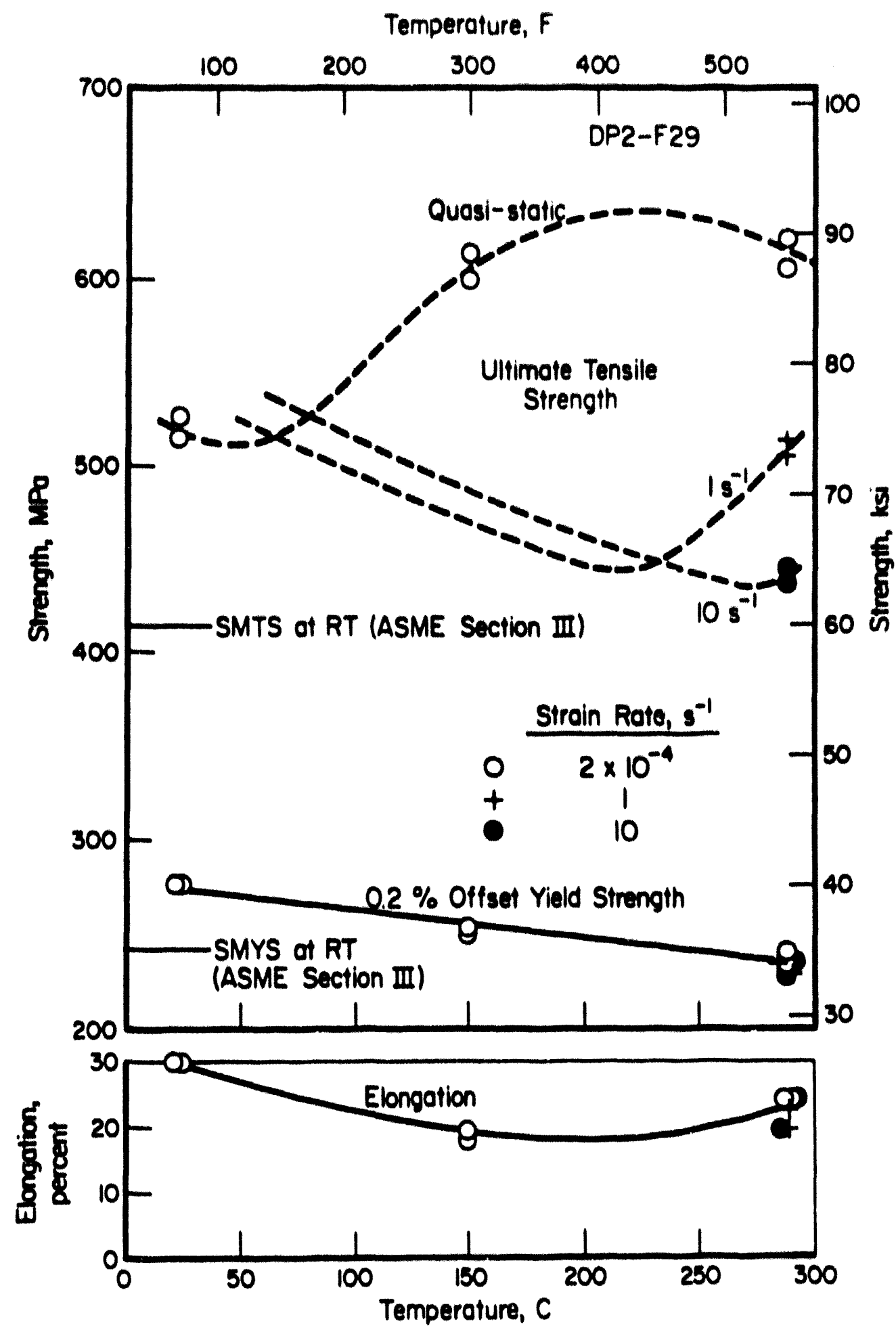

Figure 3.8 Tensile properties versus temperature for Pipe DP2-F29 (A106 Grade B carbon steel).

I-T1.0-11/89-F3.8 


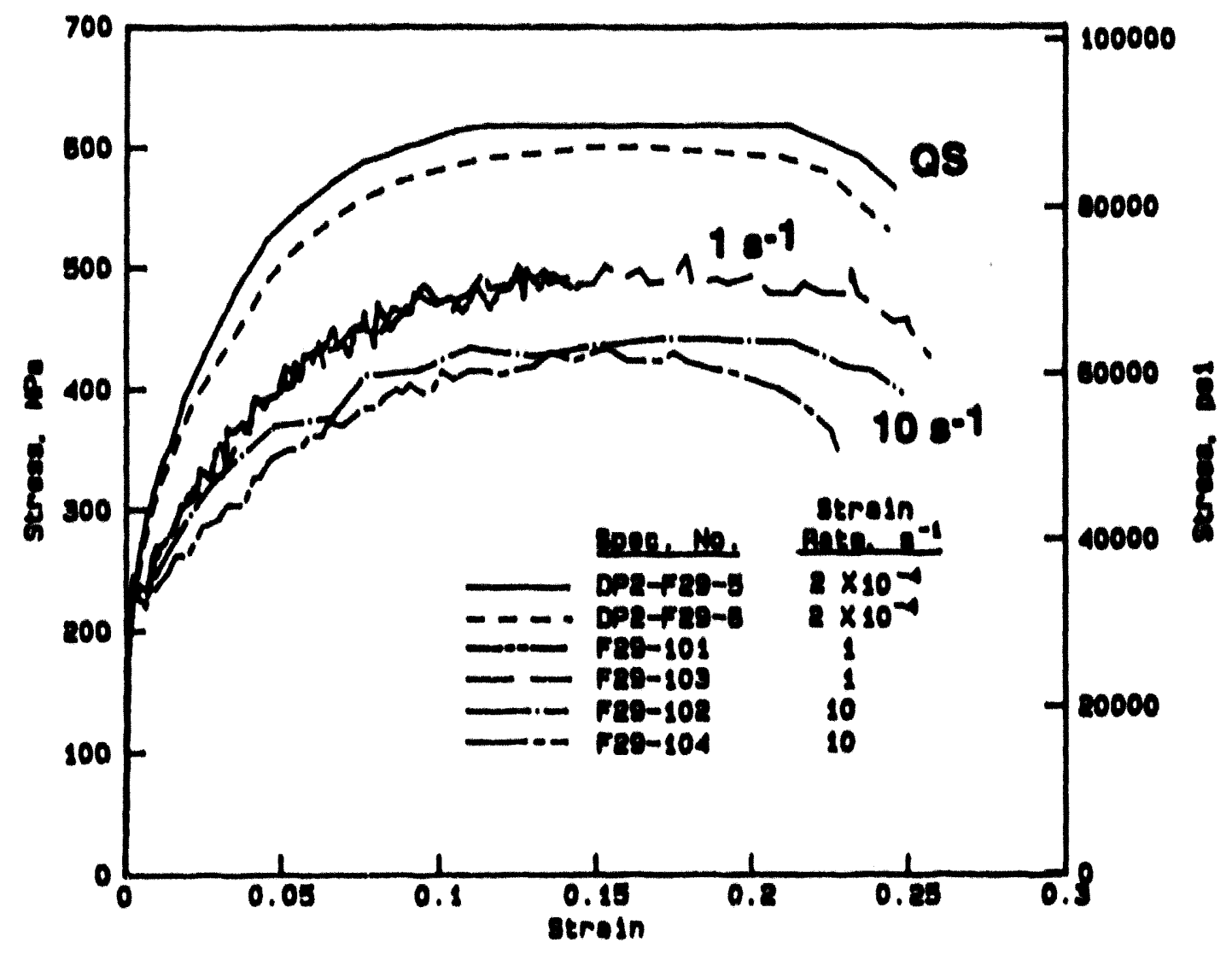

Figure 3.9 Engineering stress-strain curves at $288 \mathrm{C}(550 \mathrm{~F})$ for Pipe DP2-F29 (Al06 Grade B carbon steel) tested at several different strain rates.

$1-T 1.0-11 / 89-F 3.9$ 


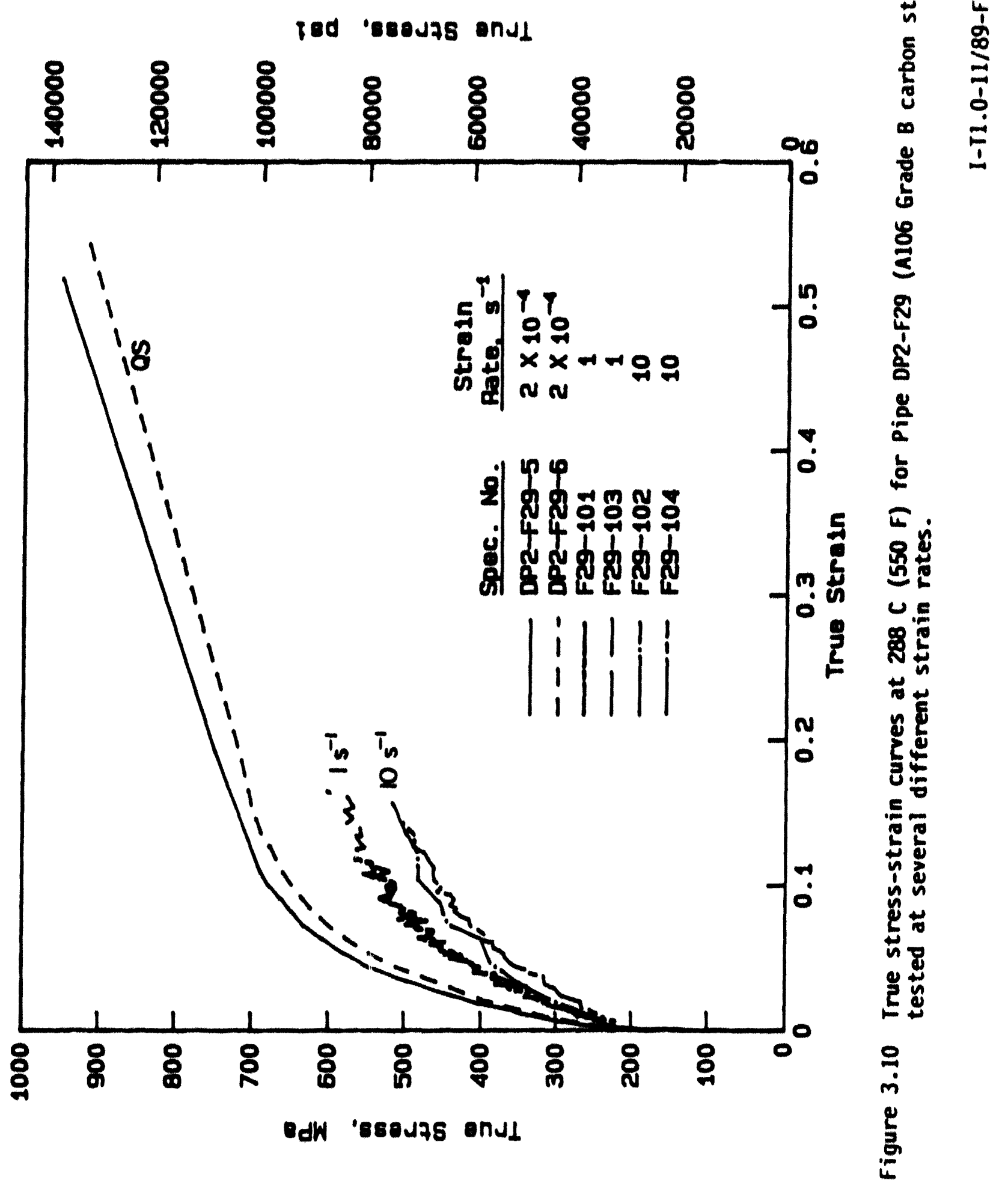




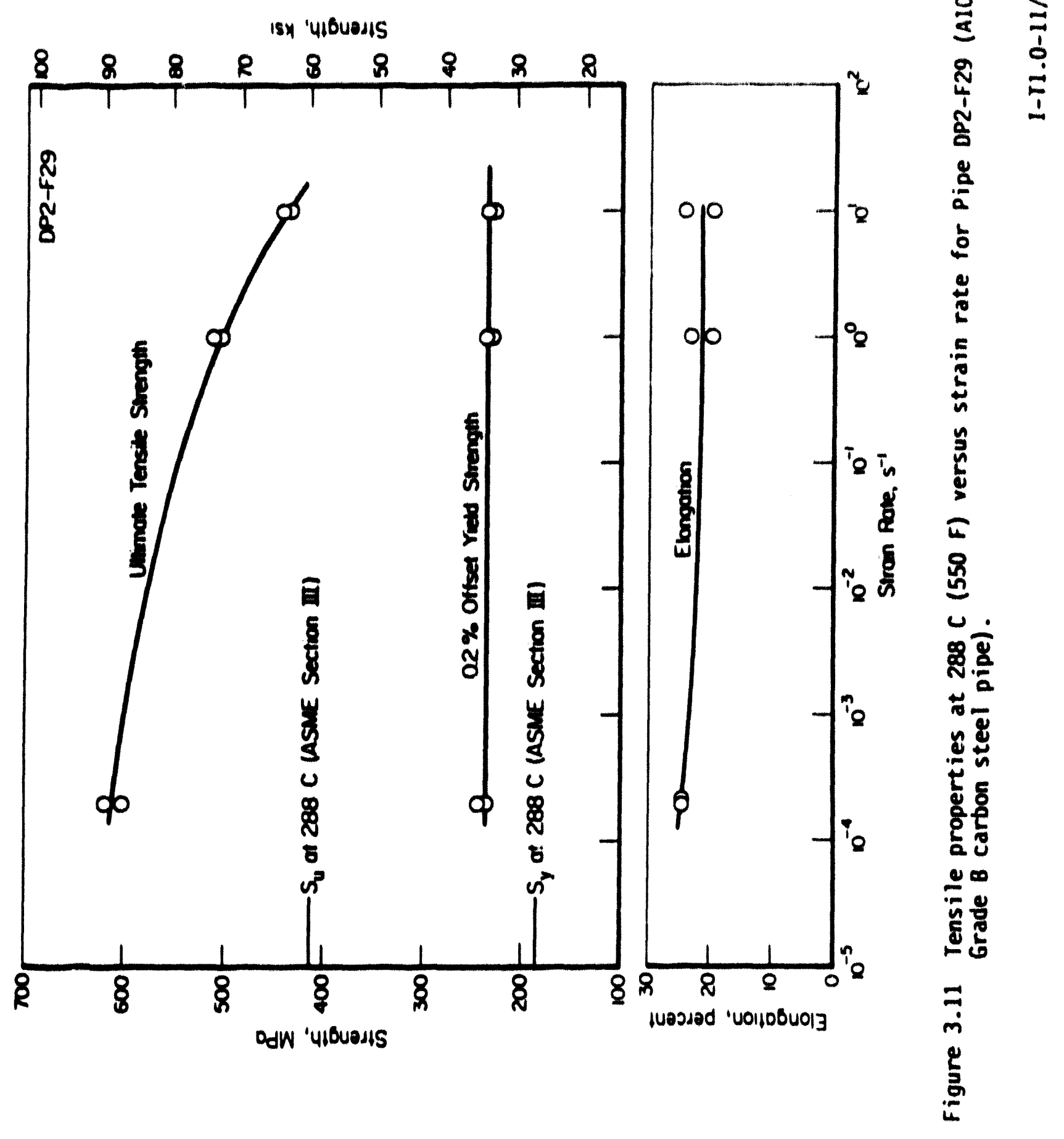




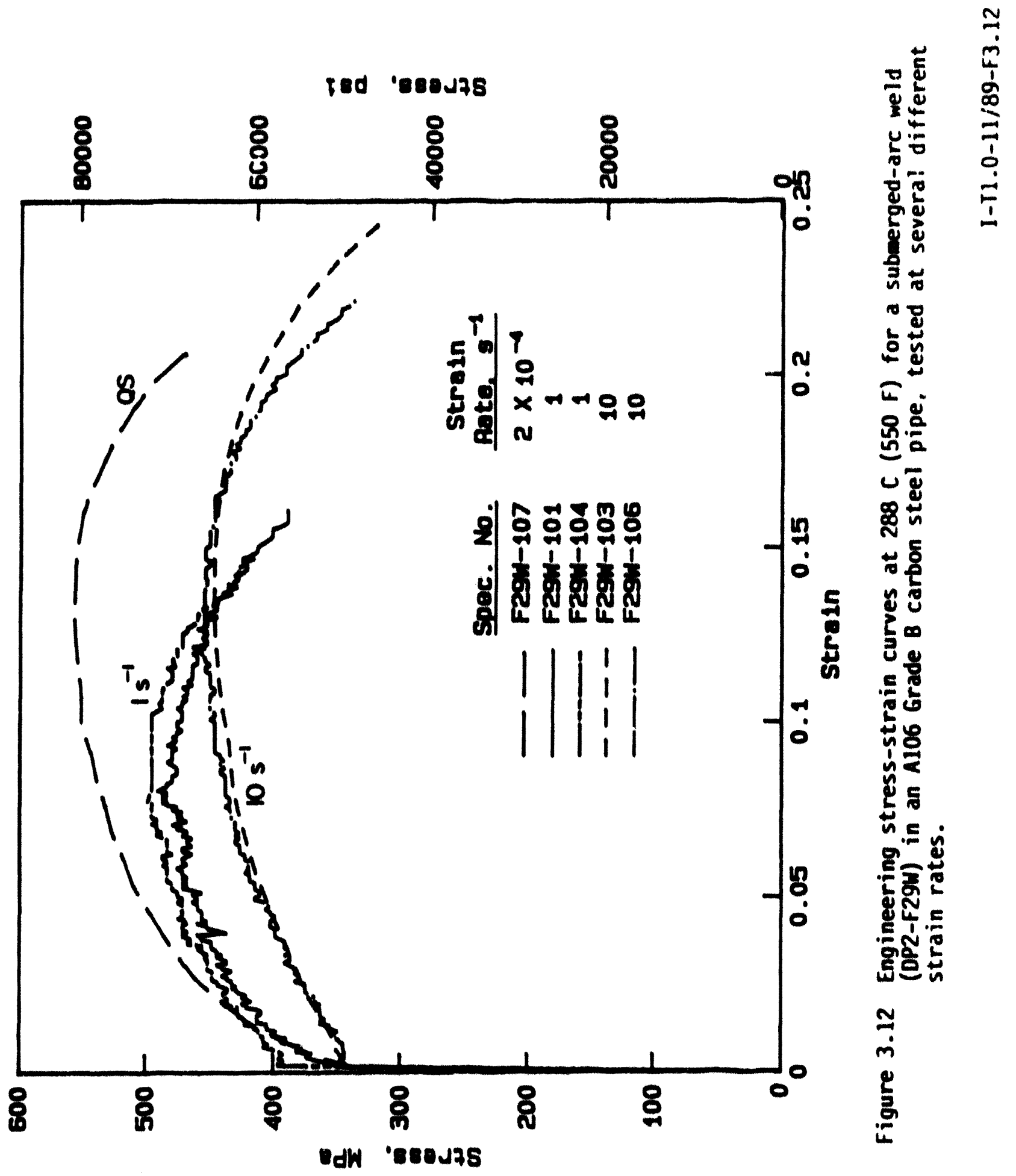




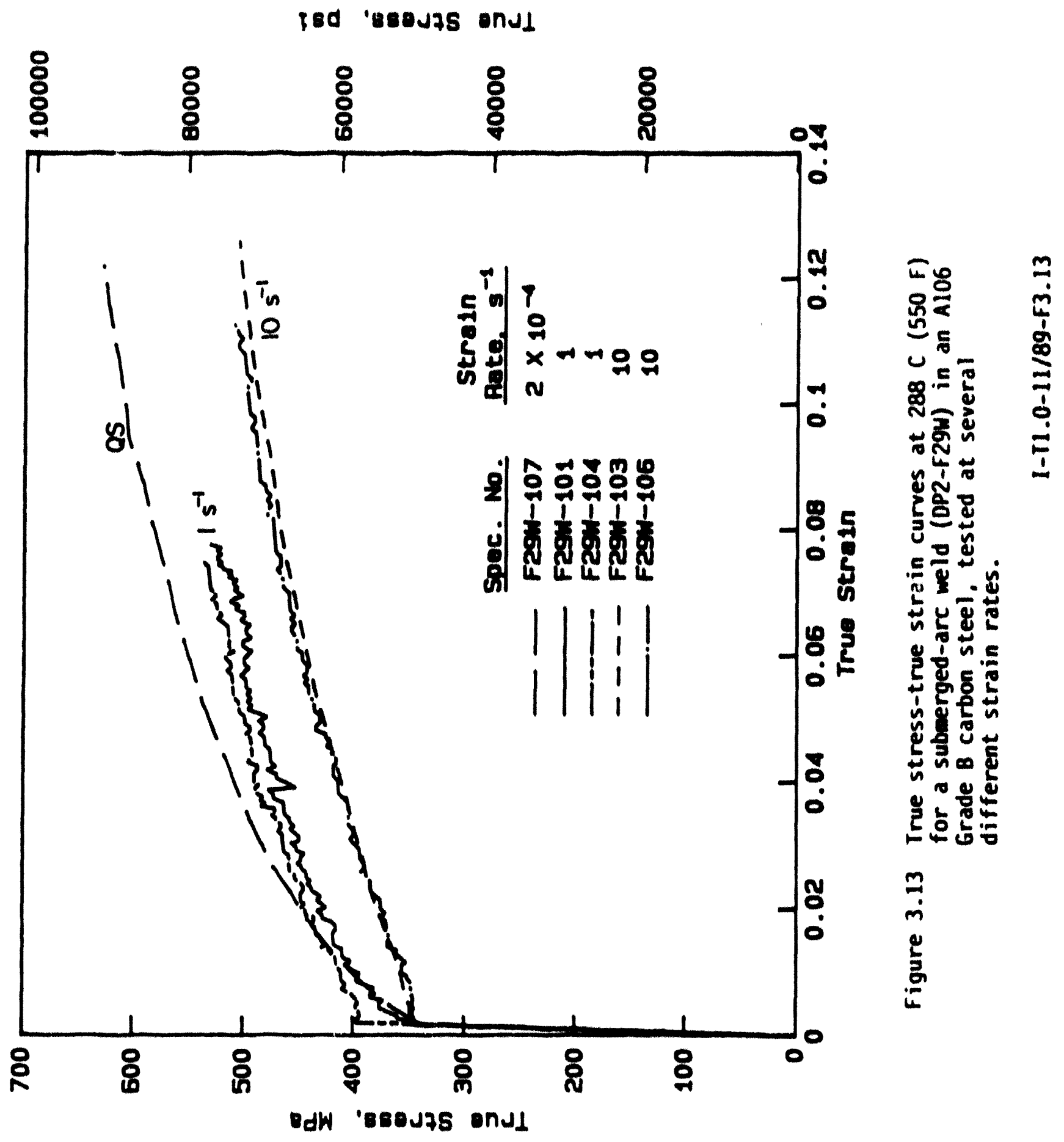




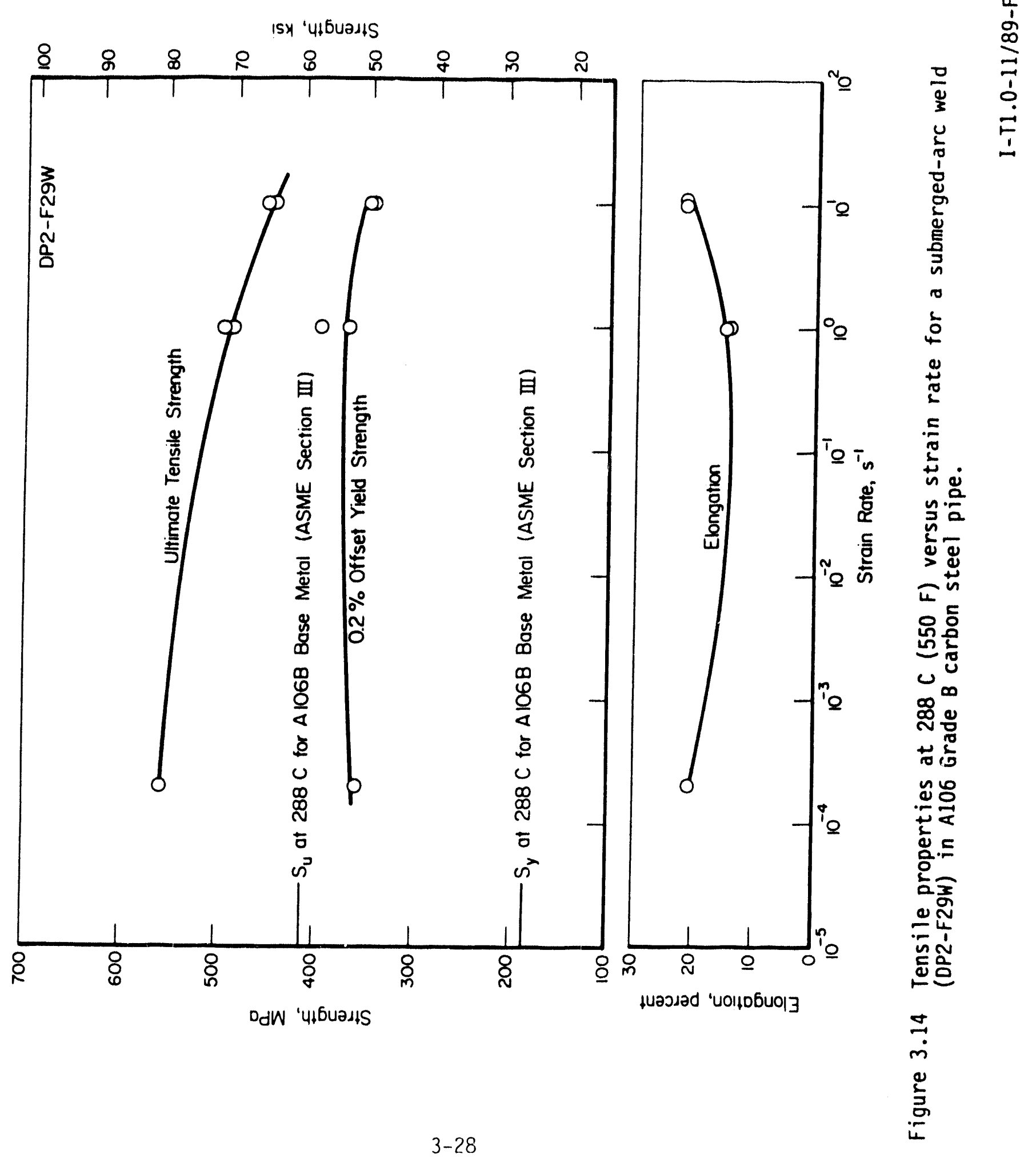




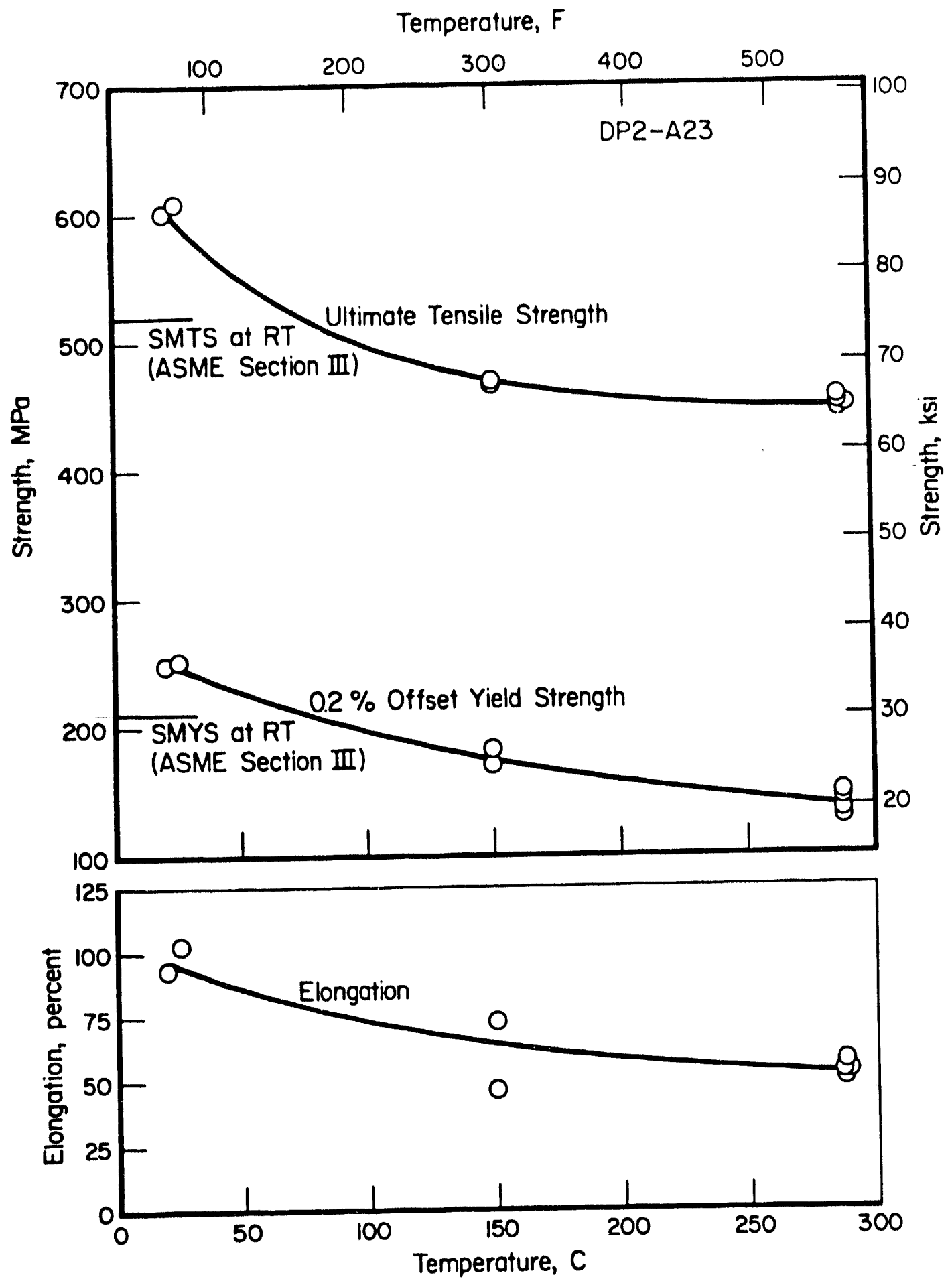

Figure 3.15 Tensile properties versus temperature for Pipe DP2-A23 (A376 Type 304 stainless steel).

I-T1.0-11/89-F3.15 


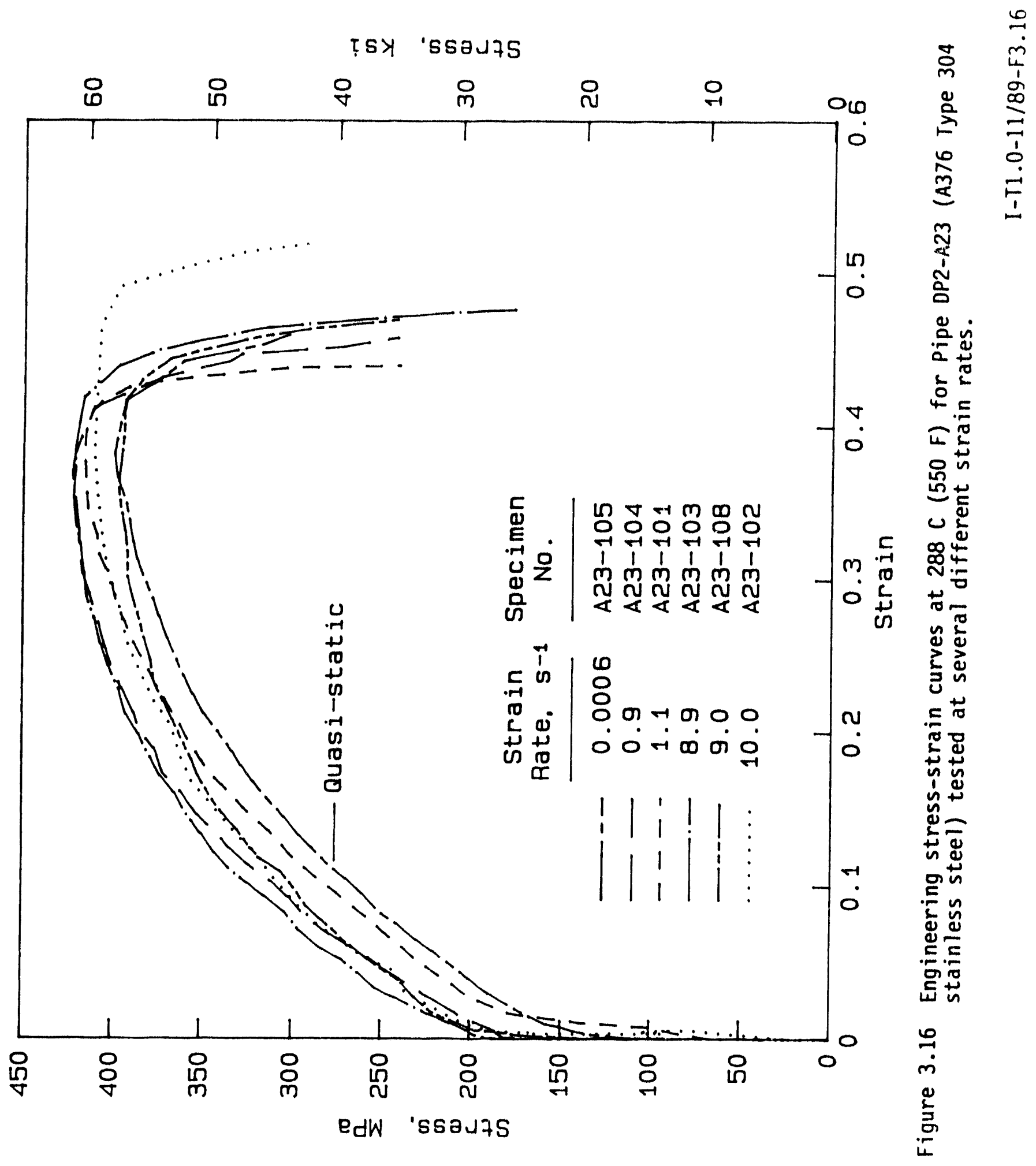




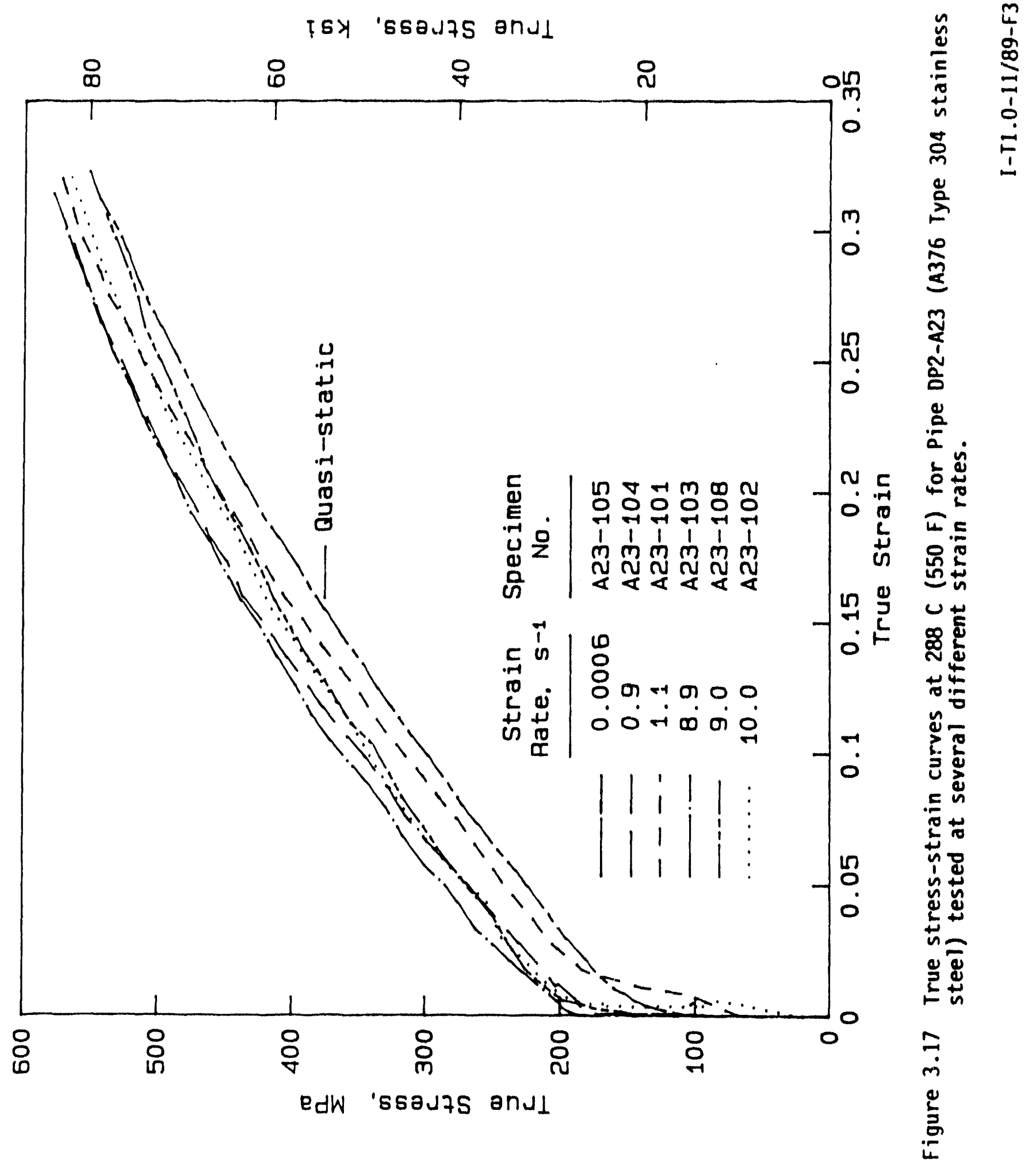




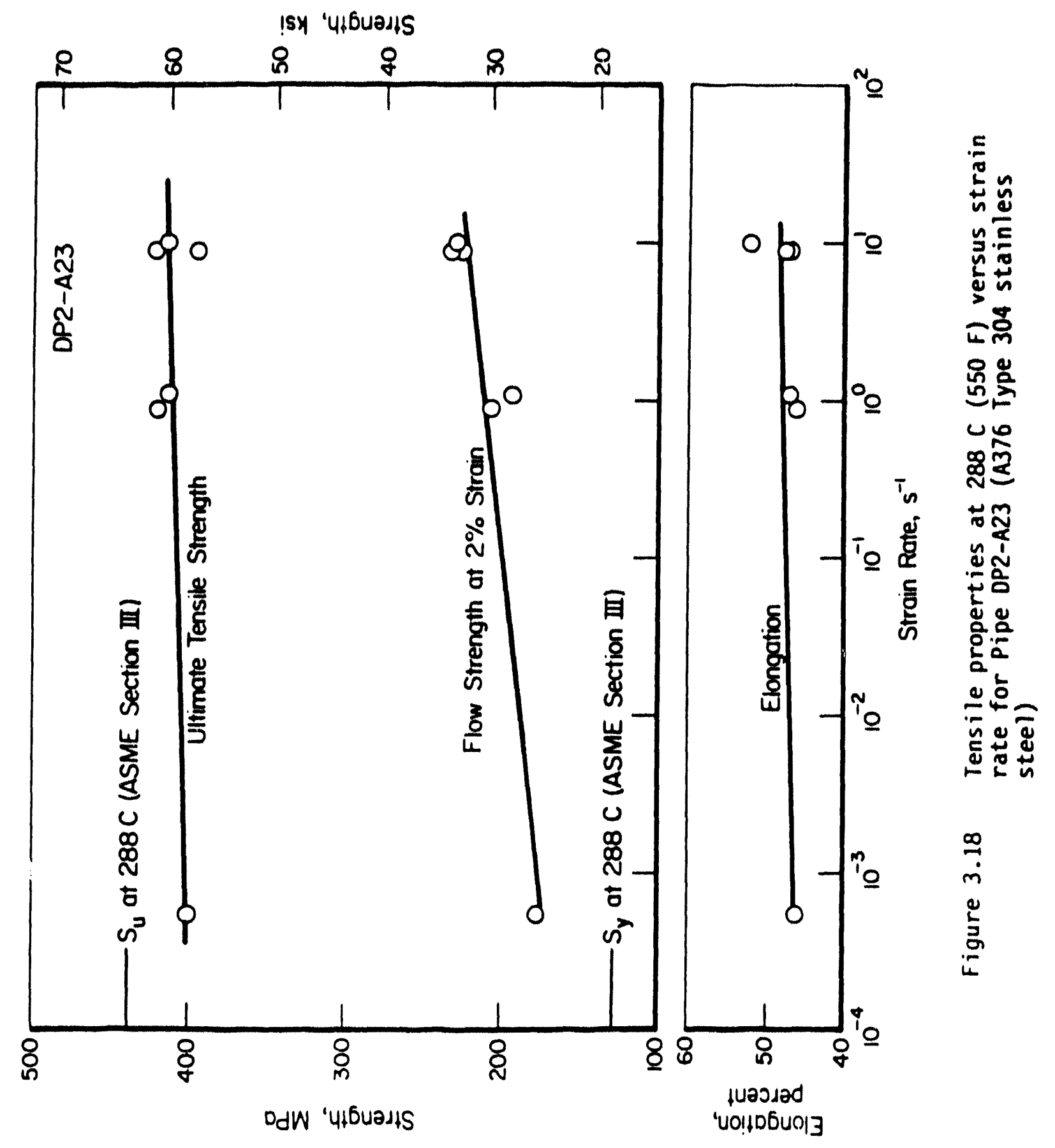




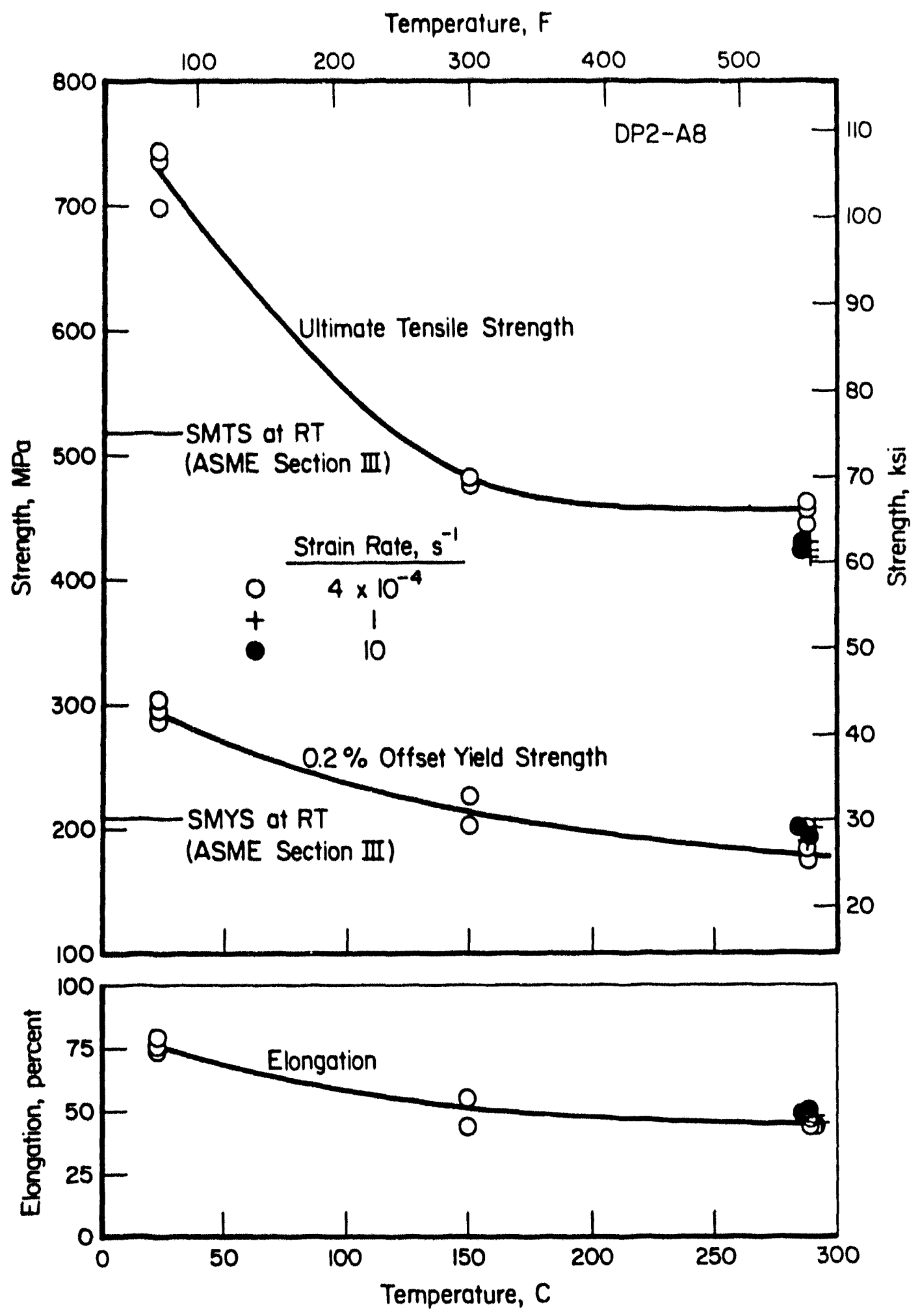

Figure 3.19 Tensile properties versus temperature for Pipe DP2-A8 (A358 Type 304 stainless steel).

I-T1.0-11/89-F3.19 


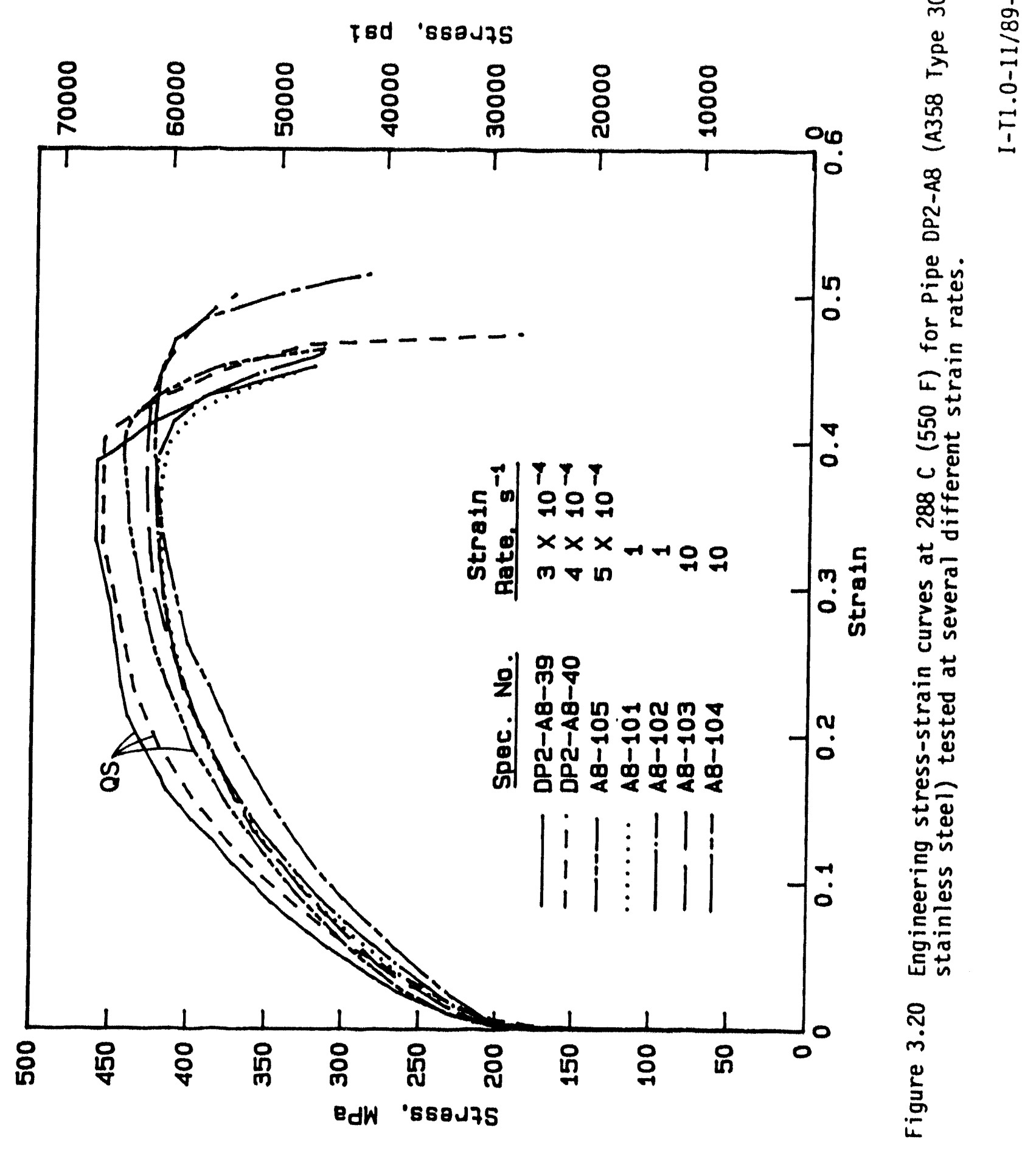




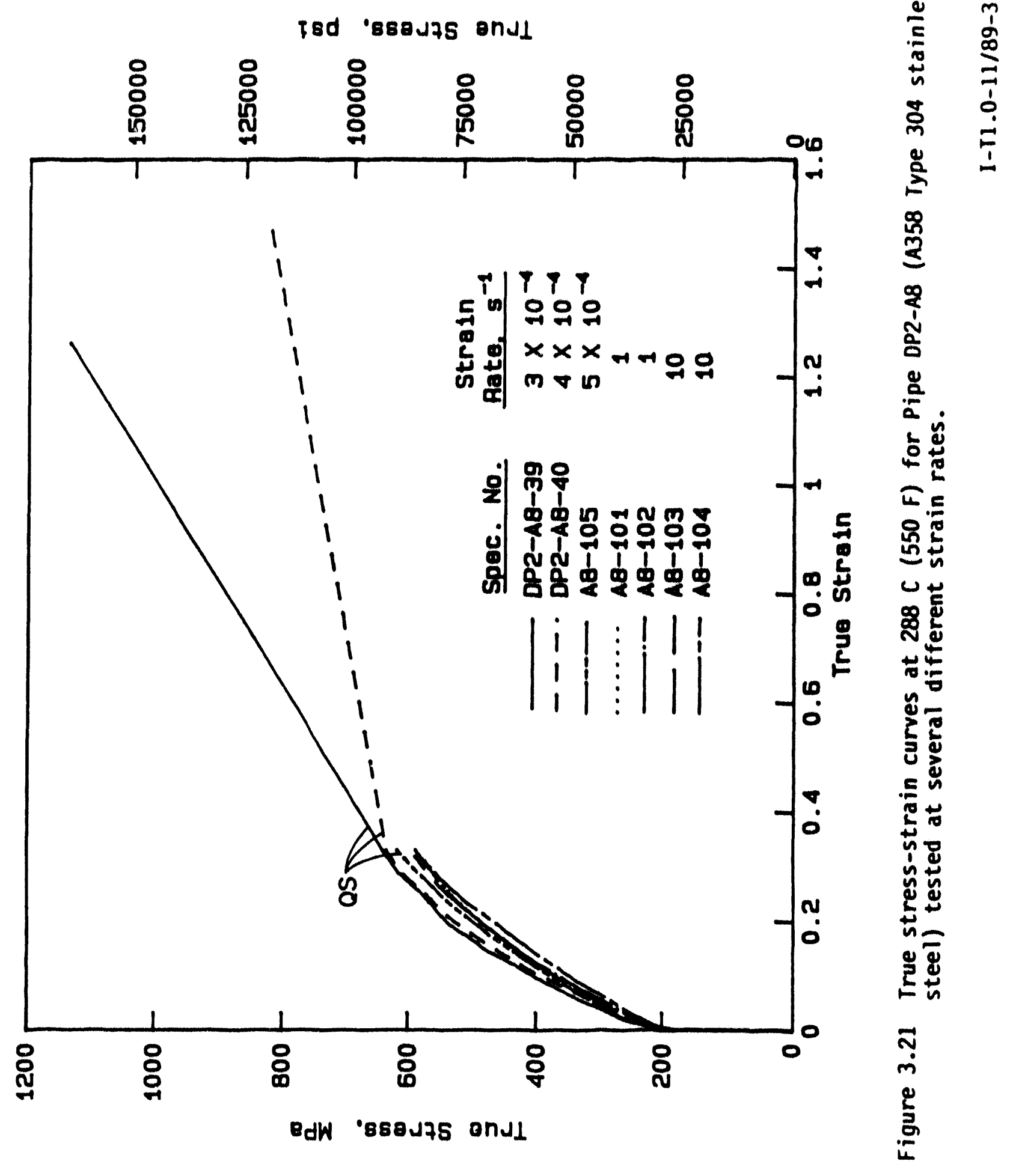




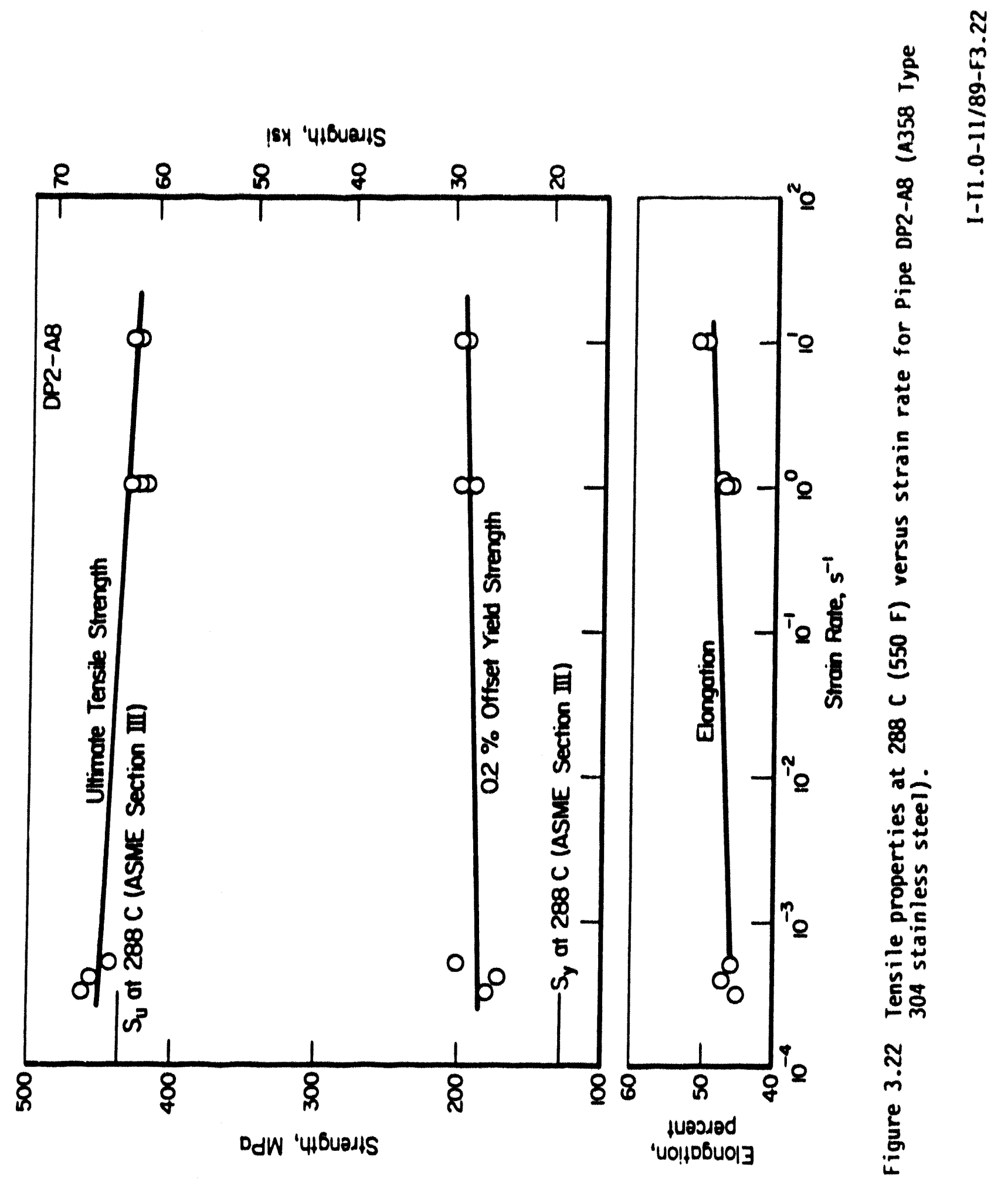




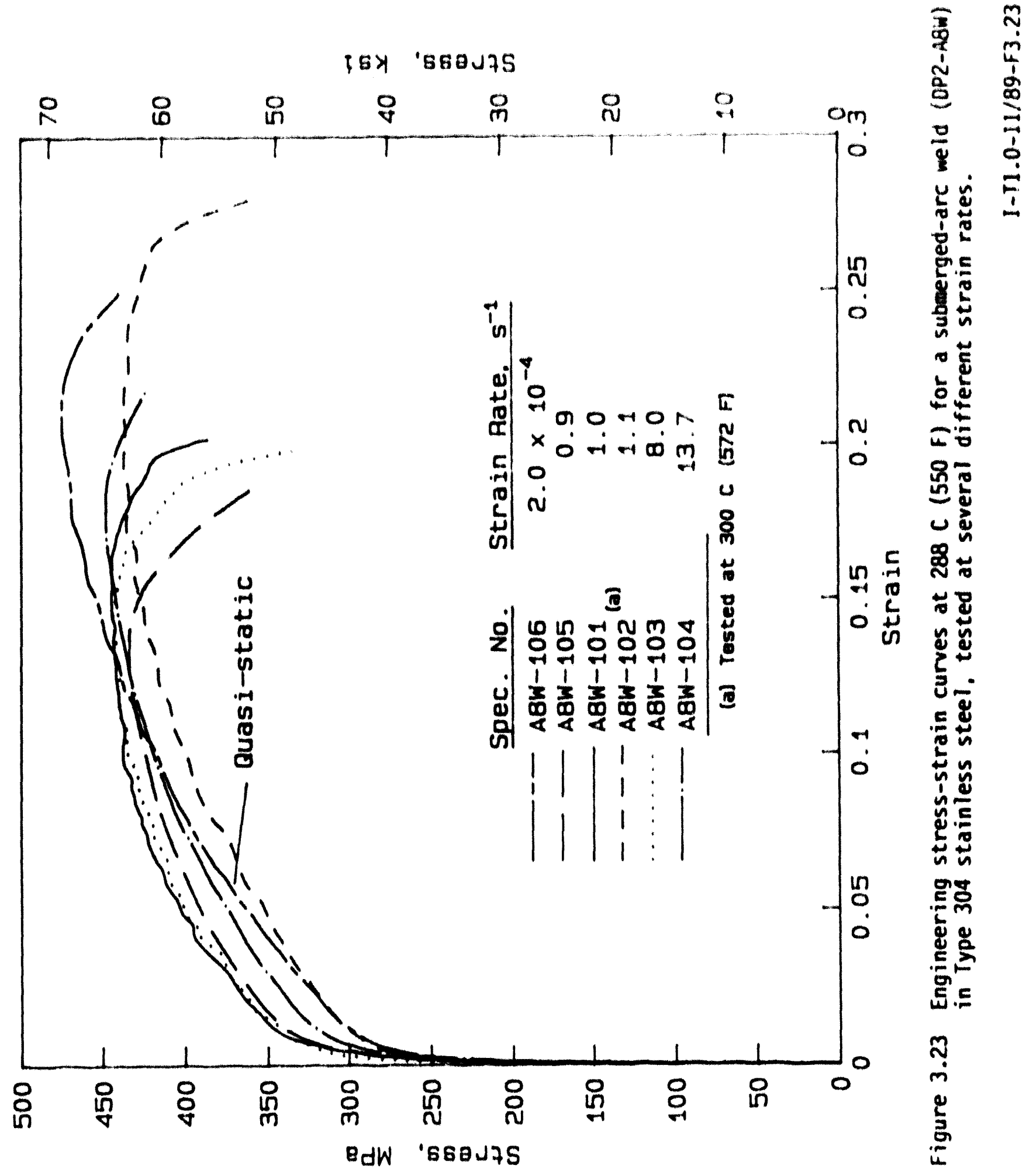




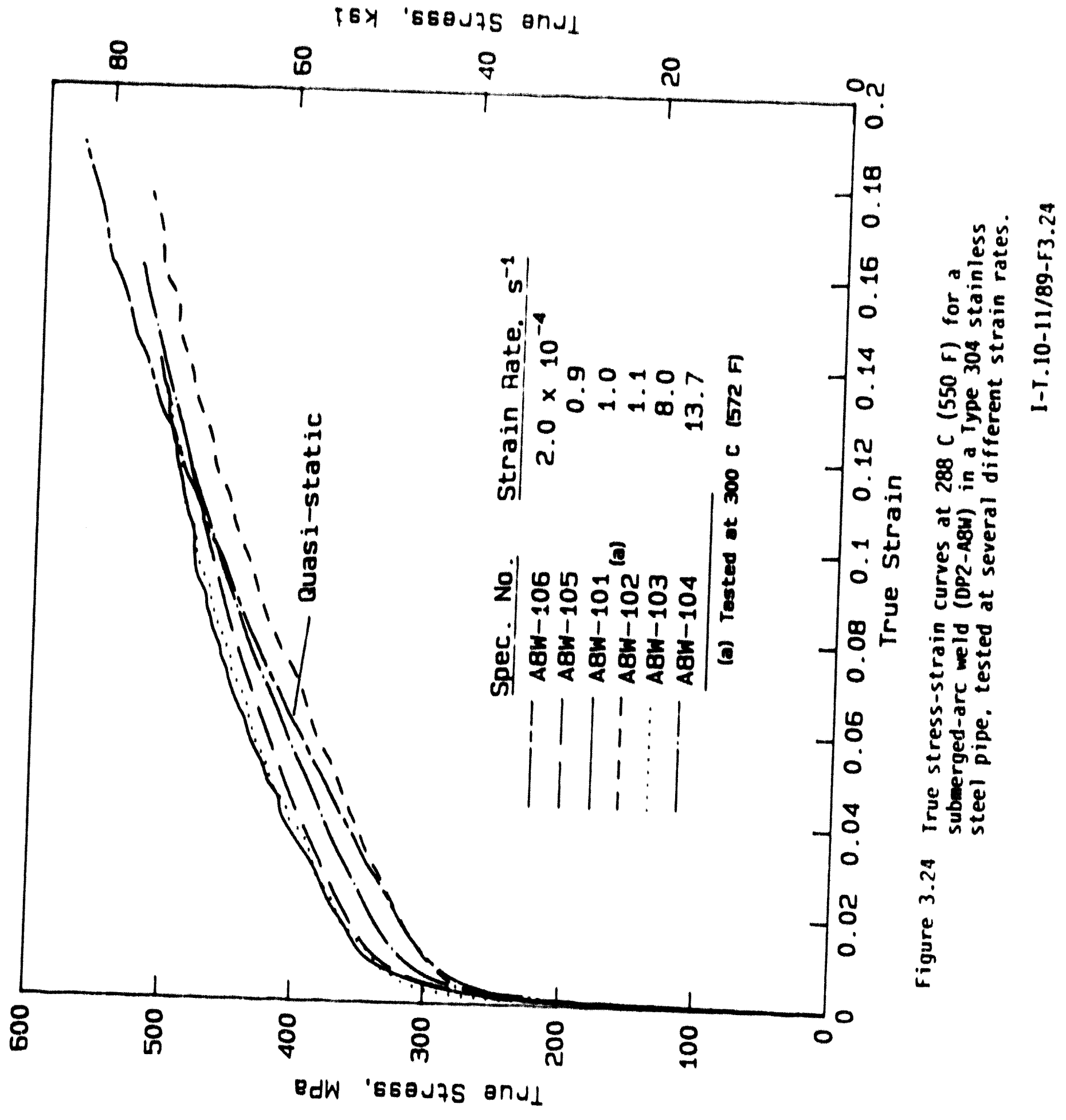




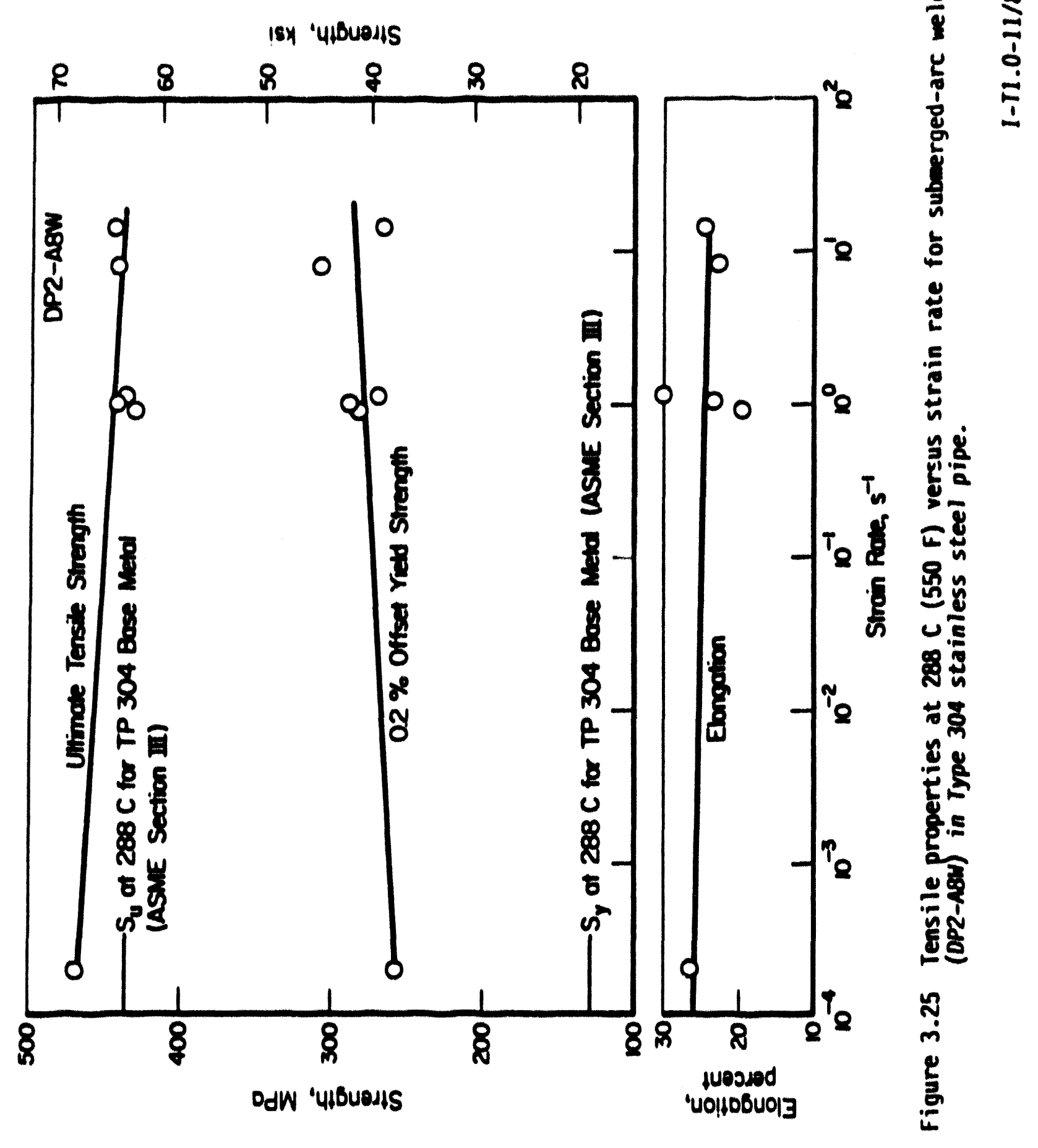




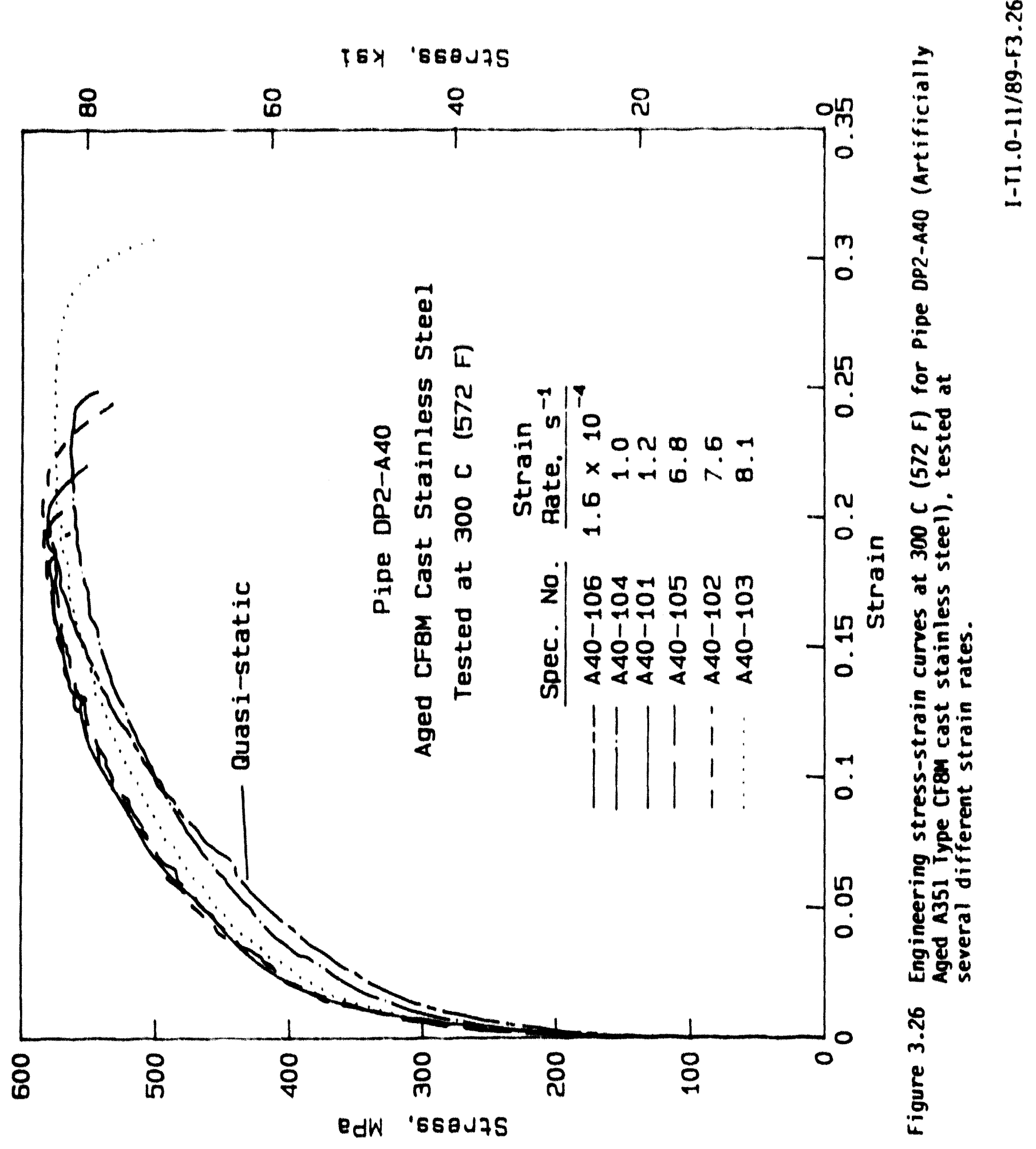




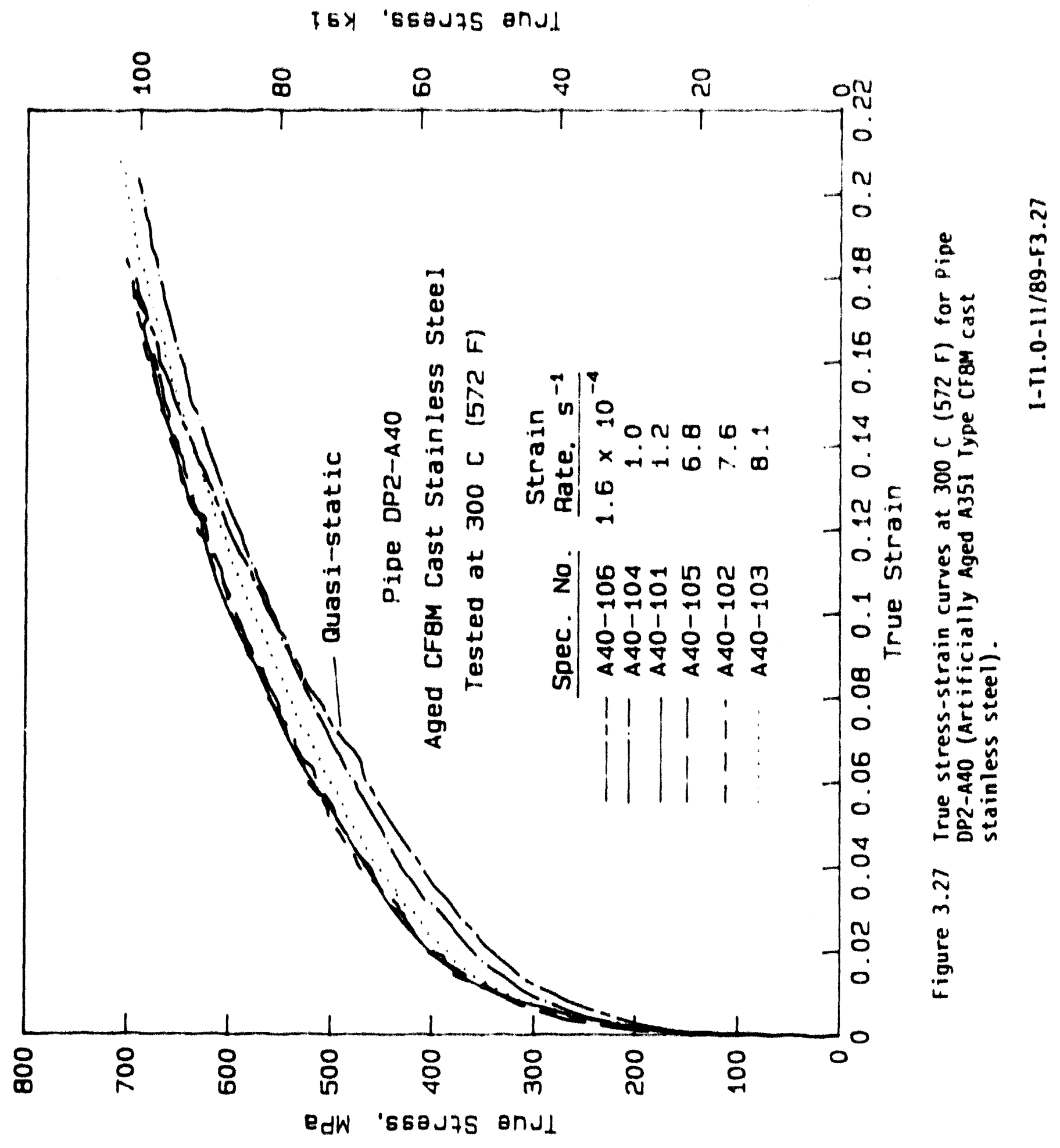




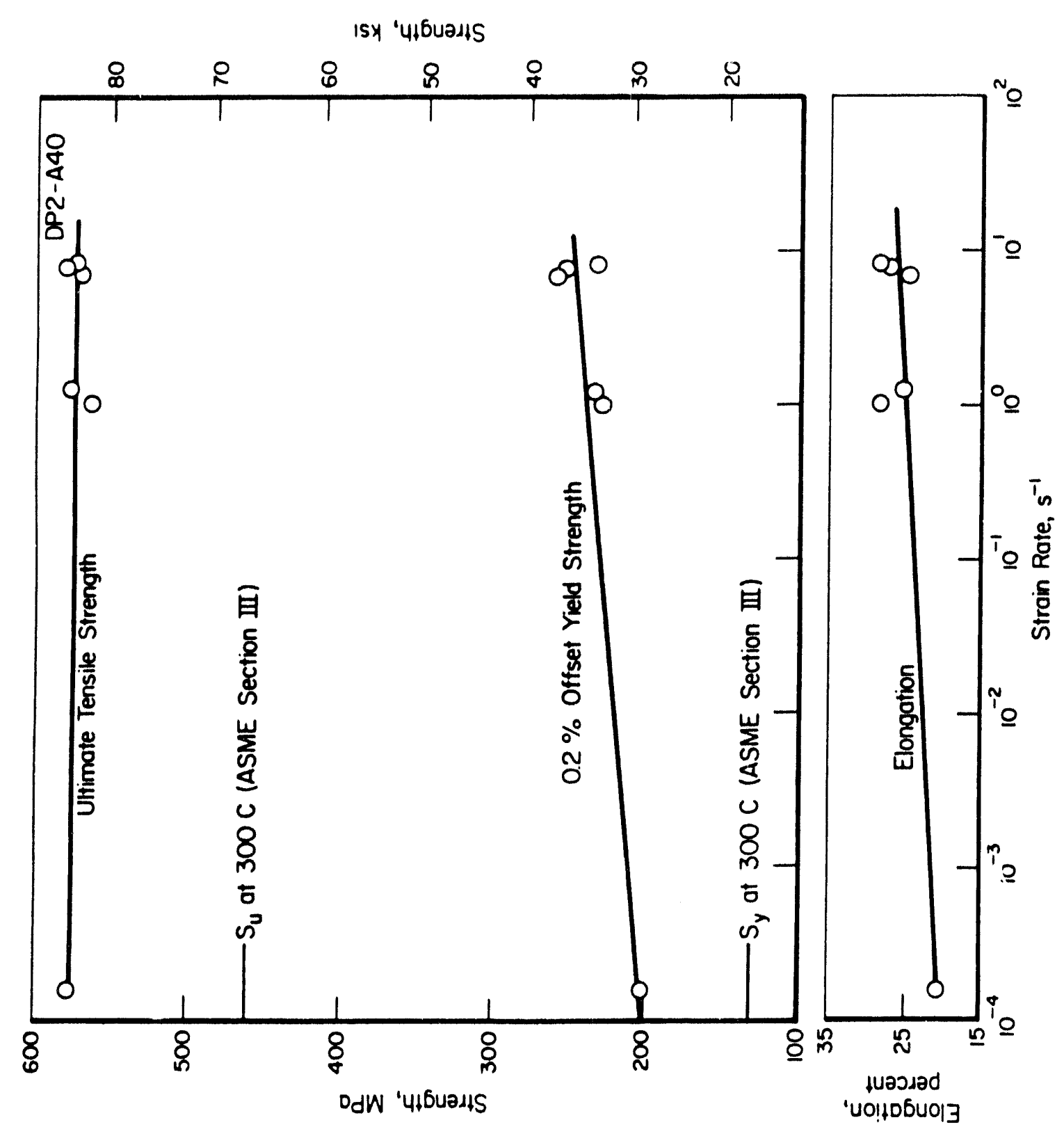

웅

음

$\stackrel{\varrho}{\Omega}$

ธำ

茎

$=\frac{\pi}{8}$

结出

竞

气ู

ตั้

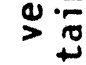

部

N

กี

这

음

m들

o<

怘导

$+<$

क्ष

各尔

电

जั

这

品 


\subsection{J-R CURVE TESTS}

\subsection{Experimental Procedures}

\subsubsection{Fabrication and Testing of Compact Specimens}

All fracture toughness specimens were of the compact (tension), $C(T)$, design. They were machined from sections of pipe without mechanical flattening and were in the L-C orientation, i.e., loads were applied in the direction of the pipe axis and the crack growth direction was circumferential.

The $C(T)$ specimens were of two different sizes--0.5T and $1 T$. The $1 T$ specimens were only about 80 percent of the standard thickness of $25.4 \mathrm{~mm}$ ( 1 inch) because of pipe curvature. The smaller specimens were machined from the $152 \mathrm{~mm}$ ( 6 inch) diameter pipes and the larger specimens from the $406 \mathrm{~mm}$ (16 inch) diameter pipes.

The specimens were fatigue precracked according to the specifications in ASTM E1152-87, Standard Test Method for Determining J-R Curves, to produce an initial crack length of $0.52 w$ to $0.57 w$, where $w$ is specimen width. Except for a few nonside-grooved specimens that were fabricated and tested as part of the Degraded Piping Program, each specimen tested in this program was side grooved to a depth of $0.1 \mathrm{~B}$ on each side after precracking, where $B$ is thickness.

Both quasi-static and dynamic tests were conducted at $288 \mathrm{C}(550 \mathrm{~F})$ or, in the case of Pipe DP2-A40, at $300 \mathrm{C}(572 \mathrm{~F})$. Some of the quasi-static testing was done at Materials Engineering Associates (MEA) and at Battelle as part of the Degraded Piping Program.

Quasi-static tests conducted at MEA as part of the Degraded Piping Program employed the unloading compliance method to estimate crack extension at regular intervals during the test. From the measured loads and load-line displacements and the calculated crack lengths, values of $\mathrm{J}$ were calculated for each unloading point. The methods employed by MEA to obtain $\mathrm{J}$ at crack initiation $\left(\mathrm{J}_{i}\right)$ were identical to those described in ASTM E813-81, Standard Method for $J_{I C}$, a Measure of Fracture Toughness, except that the J- $\Delta$ a graphs submitted by MEA to Battelle employed Modified-J $\left(J_{M}\right)$ values (Ref. 4.1) rather than Deformation-J $\left(J_{0}\right)$ values. For use in this report, MEA's data were reanalyzed at Battelle in the manner described in ASTM E1152-87 to provide Deformation-J (symbolized in this case simply as $\mathrm{J}$ ) values. These values of $\mathrm{J}$ were used in constructing $\mathrm{J}$-resistance curves for the MEA tests.

Quasi-static and dynamic tests conducted at Battelle employed the direct-current electric potential (d-C EP) method to monitor crack initiation and growth. That procedure was selected for several reasons. First, it is a single-specimen method, i.e., it permits determination of a complete J-R curve in each specimen tested, thus making it more economical to perform than the multiple-specimen method. Although the 
unloading-compliance method (Ref. 4.2) also is a single-specimen method, the $d-c$ EP method was preferred for this program because it does not require periodic unloadings. Such unloadings are impractical for rapid displacement-rate tests. As was discovered during the course of this study, the periodic unloadings of the unloading-compliance method may also have a significant effect on the load-displacement curve in $288 \mathrm{C}$ $(550 \mathrm{~F})$ tests on carbon-steel $\mathrm{C}(\mathrm{T})$ specimens.

Another reason for selecting the d-C EP method was the favorable experience gained with that method in the Degraded Piping Program. In that program, the d-c EP method provided reasonable estimates of the point of crack initiation and, in most cases, good agreement between calculated and actual crack extension, even for relatively large amounts of crack growth (Refs. 4.3 and 4.4).

The d-C EP procedure adopted at Battelle was similar to one employed by Schwalbe and Hellmann (Refs. 4.5 and 4.6) in which constant current leads were attached to the top and bottom edges at $w / 2$ from the load line (Locations $A$ and $B$ in Fig. 4.1), and the potential was measured across the notch mouth (Locations $C$ and $D$ in Figure 4.1 ). The load cell in the testing machine was electrically isolated to prevent a current path through the load train. The potential leads were iron wires in the case of carbon-steel specimens and Type 304 stainless steel wires in the case of stainless steel specimens, to minimize thermally induced voltages that can arise when dissimilar metals are in contact. As can be seen in the edge view in Figure 4.1, Location $C$ was near one side and Location $D$ was near the other side, in an attempt to detect average crack length in those cases where the crack front might not be straight.

For quasi-static tests on carbon steel specimens and for both quasistatic and dynamic tests on stainless steel specimens, the directcurrent magnitude was adjusted to give a potential of 400 to $500 \mu \mathrm{V}$ at the start of a test. For the dynamic tests on carbon steel, however, the current was increased to provide a starting potential of 4000 to $5000 \mu \mathrm{V}$. The larger potential in the dynamic tests was used to minimize the effect of a voltage pulse that is generated within ferromagnetic materials when they are subjected to rapid loading (Ref. 4.4). The voltage pulse phenomenon and the method for minimizing its effects were investigated in a separate Battelle-funded study.

Displacement rates in quasi-static tests were selected to cause crack initiation in 5 to 20 minutes. In dynamic tests, the displacement rate was selected to cause crack initiation in approximately 0.2 seconds. As was discussed in Section 1.1, the time of 0.2 seconds to reach crack initiation was based on an analysis of IPIRG Task 1.0 dynamic pipe fracture experiments which involved cyclic loading; that analys is determined an "average equivalent monotonic time to crack initiation" of approximately 0.2 seconds in the various pipe tests.

Tests on the two different specimen sizes were conducted in two different servohydraulic testing machines that employed different data acquisition systems. The $0.5 \mathrm{~T}$ specimens were tested in a Materials 
Testing System servohydraulic machine that had a capacity of $22 \mathrm{kN}$ $(5,000 \mathrm{lb})$, whereas the $1 T$ specimens were tested in an Instron servohydraulic machine that had a capacity of $220 \mathrm{kN}(50,000 \mathrm{lb})$. In both cases, data recorded during a test included load, ram displacement, load-line displacement, and direct-current electric potential. For the $0.5 T$ specimens, these data were recorded using a Gould Model 4074 digital oscilloscope, whereas for the $1 T$ specimen, data were recorded using a Masscomp Model MC 500 computer. Examples of data obtained on the Gould oscilloscope and on the Masscomp computer are shown in Figures 4.2 and 4.3 , respectively.

\subsubsection{Calculation of $\mathrm{J}$ at Crack Initiation and the J-Resistance Curve}

An example of the type of data obtained in each test of a $C(T)$ specimen is shown schematically in Figure 4.4a. Curves of load versus load-line displacement $\left(P-V_{L L}\right)$ and $d-c$ electric potential versus load-line displacement ( $U-V(U)$ provide all the information needed to determine $J$ at crack initiation, referred to as $\mathrm{J}_{j}$ in this report, and a complete $\mathrm{J}$ resistance curve.

The procedure followed at Battelle in analyzing the $C(T)$ results in the IPIRG program was as follows. First, the point of crack initiation was estimated from the point of departure from linearity of the $U-V_{U}$ curve, based on work described in References 4.7, 4.8, and 4.9. In some cases, selection of that point was not as obvious as in Fig. 4.4a. In those cases, a graph of load versus electric potential $(P-U)$ was also examined for evidence of a slope change that might be indicative of crack initiation. When necessary, engineering judgment was employed in final selection of the crack-initiation point, making certain that it lay somewhat beyond the linear-elastic part of the $P-V_{L}$ curve and before the maximum-load point.

Once a decision was made on the crack initiation point, the value of $U$ at that point was called $U_{0}$. Approximately 30 to 50 data sets ( $P, V_{L L}$, and $U)$ were then selected from the continuous test records of the type shown in Fig. 4.4a. Some of these data sets were from the part of the test prior to crack initiation and some were from the growing crack part of the test. Because the crack had not actually grown prior to the initiation point, the increase in $U$ during the early part of the test (due to plastic strain near the crack tip) was misleading in that it implied that the crack was growing. For that reason, $U$ was assigned a constant value of $U_{0}$ prior to initiation. Beyond the crack initiation point, new values of crack length were calculated from the ratio $U / U_{O}$, using the Johnson equation (Ref. 4.5):

$$
a=(2 w / \pi) \cos -1 \frac{\cosh (\pi y / 2 w)}{\cosh \left\{\left(U / U_{0}\right) \cosh ^{-1}\left[\cosh (\pi y / 2 w) / \cos \left(\pi a_{0} / 2 w\right)\right]\right\}}
$$


where a is crack length, a is original crack length, w is specimen width, and $2 y$ is the spacing of the potential probes (see fig. 4.1). Battelle has modified Eq. 4.1 to permit $2 y$ to increase in proportion to $V_{U L}$ during a test because experience has shown that this modification provides a more accurate estimate of the actual crack extension (Ref. 4.3 and 4.4). As has been shown by Schwalbe and Hellmann (Ref. 4.5). Equation 4.1 has several desirable features--it can be used on all compact specimens, regardless of materials or dimensions, it is independent of test temperature, and it is independent of current magnitude (assuming, of course, that the current remains constant throughout a test).

Once the crack length values were available from the calculations that employed Equation 4.1, J values were calculated from each data set to obtain a curve of $\mathrm{J}$ versus crack extension. The procedures used to calculate $J$ were those specified in ASTM E1152-87, Standard Test Method for Determining J-R Curves.

$J$ was separated into elastic and plastic components, as indicated in Eqs. 4.2, 4.3, and 4.4 , below:

$$
\begin{aligned}
& J=J_{e l}+J_{p l} \\
& J_{e l}=K_{e l}{ }^{2}\left(1-\nu^{2}\right) / E \\
& J_{p \ell(i)}=\left[J_{p \ell(i-1)}+\eta_{i}\left(A_{p \ell(i)}-A_{p \ell(i-1)}\right) / b_{i} B_{N}\right]\left[1-\gamma_{j}\left(a_{i}-a_{i-1}\right) / b_{i}\right]
\end{aligned}
$$

where $K$ is the stress-intensity parameter, $\nu$ is Poisson's ratio, $E$ is Young's modulus of elasticity, a is crack length, $b$ is ligament length, $B_{N}$ is net thickness at the side grooves, $A$ is area under the loaddisplacement curve, $\eta=2+0.522 \mathrm{~b} / \mathrm{w}, \eta=1+0.76 \mathrm{~b} / \mathrm{w}$, and the subscripts $i$ and $i-1$ relate to consecutive test record increments. The results of the $\mathrm{J}$ calculations were presented graphically, as is illustrated schematically in Fig. 4.4b. J Jenotes the value of $J$ at crack initiation.

The curve shown schematically in Fig. $4.4 \mathrm{~b}$ differs in form from $J-R$ curves in ASTM E1152-87 and ASTM E813-87 (a revised version of E813-81), as well as in a 1987 draft standard (EGF-P1-870) prepared by the European Group on Fracture. Each of those includes a so-called blunting line, illustrated schematically in Fig. 4.5.* The points that lie along the blunting line represent apparent, rather than real, crack extension.

In each of the procedures that employ a blunting line as the early portion of the $J-R$ curve, the blunting line is used in estimating the point of crack initiation. For example, in ASTM E813-87, the value of $\mathrm{J}$ at crack initiation, $J_{J_{c}}$ is defined as the intersection of the $0.2 \mathrm{~mm}$ offset line (parallel to the blunting line) and a power-law regression

Methods for calculating the blunting line differ between ASTM and EGF but both are based on tensile flow properties. 
Iine calculated from data heetween the 0.15 man and 1.5 man exclusion lines, (sec $1 \mathrm{ig} .4 .5)$.

The flit draft standard on the other hand, offers several methods to select a crack-initiation point. One method, which yields a value termed $J_{j}$, defines initiation as the intersection of the blunting line and an offset power law regression line calculated for data between the exclusion lines." A second method, which yields a value termed $J_{0.2 / B 1}$. defines initiation in the same way a. ASIM F813-87 except that it specifies an of set. power-law regression line rather than simply a power law. Clearly, the value termed $J_{i}$ is less than the value of $J$ measured at an offset of $0 . ?$ min. It represents an attempt to define the crack initiation point as accurately as possible, whereas the offset method attempts to provide an engineering definition of crack initiation in the same way as the 0.2 percent offset yield strength defines the onset of plastic deformation in an engineering sense.

The method used at Battelle to define the point of crack initiation, based on $d-c$ tP as described previously, thus differs from both the ASIM standard method and the $\mathrm{LGt}$ draft standard method. However, $J_{i}$ values as determined in the Battelle tests are believed to be very similar to $\mathrm{J}_{i}$ values as determined by the EGf guidelines, i.e., they represent estimates of the $J$ value at the actual onset of crack extension. Furthermore, to obtain $J$ values at crack initiation in the Battelle method that would be virtually identical to those defined by ASTM E81387 or by the EGF J $2 / B L$ value, it would be necessary only to draw a line parallel to the $\mathrm{e}_{-a x}$ is in $\mathrm{fig} .4 .4 \mathrm{~b}$ and of set by $0.2 \mathrm{~mm}$. The intersection of that line with the $J-R$ curve would provide that comparable value of $\mathrm{J}$.

\subsection{Experimental Results}

Summary graphs and tables of $J-R$ curve tests are presented in this section. Tabulated data for individual $C(T)$ specimens were developed for analysis of full-scale pipe experiments, and may be put in the NRC PIFRAC database in the future (Ref. 4.10).

Actual rates of loading in $C(T)$ tests, expressed as $1 \mathrm{~J} / \mathrm{dt}$ up to the point of crack initiation, are summarized in Table 4.1. Loading rates in rapid loading tests were about 2500 to 6000 times faster and averaged approximately 4,000 times faster than those in quasi-static tests.

$\mathrm{J}_{j}$ in the EGF draft standard may also be determined on the bas is of stretch-zone width measurements in a scanning electron microscope examination of the fracture surface. 


\subsubsection{Carbon Steels J-R Curve Results}

Pipe Number DP2-F30 [152 mm (6 inch), Schedule 120 , Al06 Grade B Carbon steel pipe]. It should be noted at the outset of this section that several differences were observed between the quasi-static tests conducted at MEA and the quasi-static tests conducted at Battelle on specimens from Pipe DP2-F30. In the MEA tests, which employed the unloading compliance method to monitor crack extension, maximum loads tended to be significantly lower than in the Battelle tests, which employed the d-C EP method, even after allowing for the different thicknesses and crack lengths.* Furthermore, specimens tested at MEA exhibited only stable tearing, whereas those tested at Battelle showed distinct crack instabilities.

A graph of $J$ versus crack extension for the two side-grooved specimens tested at MEA is shown in Figure 4.6. A blunting line was constructed through the data points near the origin (the solid line in Figure 4.6) and exclusion lines were drawn parallel with the blunting line (the two dashed lines in Figure 4.6). A straight line was fitted to the data points between the exclusion lines and extrapolated back to the blunting line. The slope of that straight line gave the value of $\mathrm{dJ} / \mathrm{da}$ and the intersection of that line with the blunting line gave the value of $J_{i} \cdot{ }^{*}$ Table 4.2 provides a summary of $J_{i}$ and $d J / d a$ values obtained from the MEA tests.

As was noted above, the quasi-static $C(T)$ tests conducted at Battelle exhibited crack instabilities interspersed with periods of stable tearing. Similar behavior was observed in the dynamic tests. Examples of data obtained in dynamic tests at $288 \mathrm{C}(550 \mathrm{~F})$ are given in Figures $4.2,4.7$, and 4.8 for Specimen F30-109. Figure 4.2 shows load, loadline displacement $\left(V_{1}\right)$, ram displacement, and direct-current electric potential (U) as functions of time. A graph of load versus $V_{U L}$ is shown in Figure 4.7, and of $U$ versus $V_{1}$ in Figure 4.8. Examination of the three graphs indicates that crack initiation probably occurred at the point indicated by a small load drop in Figures 4.2 and 4.7 . That point is shown also on the $U$ versus $V_{1}$ curve in Figure 4.8 and represents the earliest point on that curve that could be considered as a departure from linearity, usually taken as evidence of the onset of crack extension. Notice from Figure 4.2 that the time to achieve crack initiation was approximately 0.24 seconds, a time that was reasonably close to the desired time of 0.2 seconds.

* For the Battelle and MEA specimens, respectively, thicknesses were $12.7 \mathrm{~mm}(0.5 \mathrm{in})$ and $9.1 \mathrm{~mm}(0.36 \mathrm{in})$ and crack lengths were approximately $0.56 \mathrm{w}$ and $0.53 \mathrm{w}$.

* The method used to determine $\mathrm{J}_{i}$ for the MEA tests was that specified in ASTM E813-81, which was the recommended practice at the time of the Degraded Piping Program. 
It appears from the data in Figures $4.2,4.7$, and 4.8 that the crack exhibited several periods of rapid, unstable growth--a short period right after maximum load and a longer period shortly thereafter. The strongest evidence for this assumption is the appearance of the

electrical noise on the $V_{1}$ signal in Figures 4.7 and $4.8 ;$ only a few cycles of noise are evident during much of the falling-load (Figure 4.7) and rising-electric-potential (Figure 4.8) part of the test, indicating that the crack was growing at an unusually high rate. The velocity of the ductile crack during the large apparent instability was estimated from the data in the figures to be approximately $200 \mathrm{~mm} / \mathrm{s}(8 \mathrm{in} / \mathrm{s})$. The velocity of the ductile crack during the period of stable growth immediately following the instability was estimated to be approximately $55 \mathrm{~mm} / \mathrm{s}(2 \mathrm{in} / \mathrm{s})$.

The quasi-static $C(T)$ tests conducted at Battelle at $288 \mathrm{C}(550 \mathrm{~F})$ likewise showed distinct crack instabilities. Figure 4.9 shows that these instabilities occurred for both monotonic-displacement tests and tests that employed periodic partial unloadings, similar to those used in MEA tests. Such instabilities were not observed in the quasi-static tests conducted at MEA, for reasons that are not clearly evident at this time. There is some thought that the use of clip-gage control in the tests at MEA was better able to suppress cracking instability than was crosshead control used in the Battelle tests. Also, the fact that the MEA specimens were much thinner than the Battelle specimens may have played a role in the differences in behavior. In any event, inasmuch as all the Battelle tests, both quasi-static and dynamic, exhibited significant crack instabilities, graphs of $\mathrm{J}$ versus crack extension for the Battelle tests were terminated at the point in the test at which the first major crack instability started because there is no agreed upon method for calculating a J-R curve during the unstable crack growth.

Figure 4.10 is a graph of load-displacement data for four quasi-static tests and four dynamic tests conducted at Battelle on $0.5 T$ compact specimens at $288 \mathrm{C}(550 \mathrm{~F})$. It does not include data for periodic unloadings or crack instabilities. Figure 4.11 shows the corresponding $J-R$ curves for these eight specimens up to the point of the first major crack instability. Values of $J_{j}$ and $d J / d a$ are summarized in Table 4.3.

Several observations from Figures 4.10 and 4.11 and Table 4.3 are noteworthy:

(1) In specimens that were subjected to monotonically increasing displacement, the quasi-static and dynamic load-displacement curves (Figure 4.10) were nearly identical. The main exception to that observation is that the quasi-static tests produced slightly higher maximum loads than did the dynamic tests. The observed similarity bethuen quasi-static and dynamic tests seen in Figure 4.10 differs from the behavior displayed by other ferritic steels tested in the IPIRG program. In a larger diameter A106B pipe (DP2-F29), the loaddisplacement curve for a dynamic test was significantly lower 
than for a quasiostatic test. Conversely, the opposite was true for a submerged-arc weld in that pipe (DP?-F29W).

(2) On average, the quasi-static J-R curves were slightly higher than the dymamic curves, and the slopes (i.e., tearing modulus) for the two displacement rates were comparable (see figure 4.11 and lable 4.3 ).

(3) Specimens that underwent periodic partial unloadings exhibited significantly lower maximum loads and greater displacements at maximum loads (see figure 4.10) than did their monotonically loaded counterparts. A similar observation was made when comparing MEA and Battelle tests. However, the effect of periodic partial unloadings on $J_{j}$ and $d J / d a$ appeared to be small (see Table 4.3 and Figure 4.11).

The first two observations suggest that, in the $C(T)$ tests on this steel, changing the displacement rate by a factor of about 2,500 has not caused a large change in the overall resistance to ductile crack extension in this steel. Using average values from Table $4.3, J_{1}$ was decreased approximately 15 percent and dJ/da was increased approximately 15 percent in dynamic versus quasi-static tests.

It should be noted that $J_{j}$ values from quasi-static tests at Battelle (Table 4.3) are somewhat less than $J_{j}$ values from quasi-static tests at MEA (Table 4.2). The reasons for this difference are not known with certainty, but may reflect material variability, differences in specimen thickness, or the different methods used for determining the point of crack initiation. The Battelle method of determining crack initiation, which is based on departure from linearity of the $d-c$ EP versus displacement curve, tends to give a somewhat earlier indication of initiation than does extrapolation of the $\mathrm{J}-\Delta \mathrm{a}$ curve to a blunting line.

In order to provide comparisons between the J-R curve data for Pipe DP2. F30 and other results, the J-R curves used in ASME IWB-3650 ferriticpipe flaw eveluations are shown in figure 4.12. The curve shown for A516 Grade 70 is considered by the ASME to be a reasonable lower bound for all base metal ferritic pipe steels in the L-C orientation. Portions of the two curves in Figure 4.12 are superposed on the J-R curve data for Pipe DP2-F30 in Figure 4.11. Notice that the data for Pipe DP2-F30 lie slightly below the curve for $A 516$ Grade 70 and considerably below the curve for Al06 Grade B.

To summarize the results of the tests reported here for Pipe DP2-F30, increasing the rate of displacement at $288 \mathrm{C}(550 \mathrm{~F})$ produced the following effects:

- Neither the load-displacement curve nor the J-R curve from $0.5 \mathrm{I} C(\mathrm{~T})$ tests was influenced strongly by a factor of 2,500 increase in displacement rate. Although, on average, $J_{j}$ values were slightly lower at the higher displacement rate, tearing modulus values were slightly higher. 
- Crack instabilities observed in quasi-static tests at Battelle were also observed in the dynamic tests. (No crack

instabilities were observed in the quasi-static tests at MEA.)

- J-R curves for both quasi-static and dynamic tests tended to

lie below J-R curves used in ASME IWB-3650 ferritic-pipe flaw evaluations.

Pipe Number DPZ-F29 $4406 \mathrm{~mm}$ (16 inch) Diameter, Schedule 100, A106 Grade $\bar{B}$ Carbon Steel Pipe]. [oad-displacement curves for $C(T)$ specimens machined from Pipe DP2-F29 are shown in Figure 4.13. They reveal that the effect of dynamic loadiny was markedly different for this large diameter Al06 Grade B pipe than for the smaller diameter pipe (DP2-F30) discussed in Section 4.2.1.1. In the smaller pipe, dynamic effects were relatively small, both on the load-displacement curve and on the occurrence of crack jumps. In Pipe DP2-F29, however, dynamic tests resulted in a substantial lowering of the load-displacement curve and virtual elimination of significant crack jumps that were observed in the quasi-static tests. The curve that lies above all the others in Fig. 4.13 was for a specimen that was not side-grooved (Spec. No. F29-17).

$J$-reststance curves are shown in Figure 4.14 and values of $J_{j}$ and $d J / d a$ are summarized in Table 4.4. For the quasi-static tests, the J-R curves were terminated at the point of the first significant crack jump, because there is no agreed-upon method for calculating $J$ during and after a crack instability. It is evident from the results in figure 4.14 and Table 4.4 that both $J_{j}$ and $d J / d a$ were lowered as a result of increasing the displacement rate by a factor of approximately 2,$500 ; \mathrm{J}$ values decreased by approximately 35 percent and $d J /$ da values decreased by approximately 45 percent as the displacement rate was increased.

Included for comparison in Figure 4.14 are the ASME IWB-3650 reference J-R curves for A106 Grade B and A516 Grade 70 steel. Notice that the quasi-static test results for Pipe DP2-F29 lie slightly below the ASME. curve for Al06 Grade B steel, and the dynamic test results lie approximately on the ASME curve for $A 516$ Grade 70 steel.

Pipe DP2-F29W, Submerged Arc Weld in ASIM A106, Grade B Carbon Steel. Load-displacement curves are shown in Figure 4.15 for $C 7$ ( ) specimens machined from a submerged-arc weld in an AlO6 Grade B pipe; the welded pipe is referred to as Pipe DP2-F29W. Unlike the result obtained for the base metal (see Figure 4.13 for Pipe DP2-F29) in which dynamic testing lowered the load-displacement curve, dynamic testing of the weld metal raised the load-displacement curve significantly. In addition, whereas quasi-static tests on base metal specimens produced significant crack jumps (see Figure 4.13), the single quasi-static test conducted on a weld metal specimen produced only very small jumps that are barely perceptible on the load-displacement curve in figure 4.15.

$J$-resistance curves are shown in Figure 4.16 and values of $J_{j}$ and $d J / d a$ are summarized in rable 4.5 . These results show that both $J_{i}$ and $d J / d a$ 
were increased approximately 50 percent as a result of increasing the displacement rate by a factor of approximately 4,000 .

Also shown in Figure 4.16 are the ASME IWB-3650 J-R curves for ferritic steel base metals and a ferritic steel submerged-arc weld. The ASME curve for the submerged-arc weld in Figure 4.16 is based on results obtained in the Degraded Piping Program in which a weld was prepared in a $25.4 \mathrm{~mm}$ (1 inch) plate of A5I6 Grade 70 steel, using the same procedures as for the weld studied here (F29W). J-R curves for $11 \mathrm{C}(1)$ specimens machined from that earlier weld can be found in Figures 3.3.17 and 3.3 .18 of Reference 4.1 ? . Note in Figure 4.16 that the data from both quasi-static and dynamic tests on specimens machined from Pipe DP2F29W lie above the ASME curve for a ubmerged-arc weld and, even in the worst case (quasi-static test:), are approximately equal to the ASMI curve for A516 Grade 70 base metal.

\subsubsection{Austenitic Stainless Steels}

Pipe Number DP2-A23 [152 mm (6 inch) Diameter, Schedule 120, A376 Type 304 Stainless Steel Pipe]. Two quasi-static tests on C(T) specimens at $288(C(550)$ were performed at MEA and one was performed at Battelle. The MEA tests were conducted in conjunction with the NRC's Degraded Piping Program. In MEA's original analysis of their test data, they constructed a blunting line from the formula recommended in ASTM E81381:

$$
J=20_{f} \Delta a \quad,
$$

where $o_{f}$ is the average of the yield and ultimate tensile strength and $\Delta a$ is crack extension. That blunting line provided a poor match for the experimentally determined blunting line and yielded $J_{1}$ values that were unreasonably high. Battelle reanalyzed the data using a blunting line constructed from the relation:

$$
J=40_{f} \Delta a \quad \text {. }
$$

Equation 4.6 has been suggested by several investigators [for example. see (Ref. 1.13)] as appropriate for highly ductile metals such as austenitic stainless steels. That equation was found to provide yood agreement between the calculated and experimentally determined blunting line and to bring the $J_{j}$ value close to the value observed in the Battelle quasi-static test. Figure 4.17 shows the J-R curves from the MEA tests in which Eq. 4.6 was used to calculate the blunt ing line. A summary of $J_{i}$ and $d j / d a$ values for the MEA tests can be found in lable 4.6. As was noted for MEA's results for carbon steel, Battelle's reanalys is of MEA's results for stainless steel employed the methods of ASIM E1152-87 to calculate J-resistance curves.

In the $C(I)$ tests at Battelle, both quasi-static and dynamic, the $d-C F$ results gave very poor agreement between calculated and actual crack growth. The reasons for this occurrence are not known; in the vast 
majority of other (C(1) tests conducted at Battelle on austenitic stainless steels, ayreement between calculated and actual crack growth has been good (see Refs. 4.3 and 4.4). Because of the poor agreement, the d-c fo data were used only for determining the crack initiation point; crack growth was est imated by the following method.

In the single quasi-static test conducted at Battelle, crack growth during the test was estimated by constructing a smooth curve, on a crack extension versus displacement graph, between the crack initlation point (determined from $d-c$ EP data) and the final crack extension (measured directly on the specimen after testing). Results of the quasi-static test at Battelle are shown in Figure 4.18 (load and crack extension versus displacement) and in Figure 4.19 (J-R curve). Values of $J_{i}$ and dJ/da are given in Table 4.6. Note that the Battelle results and the MIA results in Table 4.5 are in reasonable agreement.

In the dynamic tests, in which crack initiation occurred in approximately 0.1 seconds" five nominally identical specimens were tested, each to a different final displacement and final crack length. A composite graph of load-displacemeri-crack extension was constructed from the data obtained in the five cests; that composite graph is shown in Figure 4.18. The curve of crack extension versus displacement in Figure 4.18 was constructed from the estimated initiation point (from d-C EP data) and the final values of crack extension (measured directly on the tested specimens). The J-R curve constructed from the results in Figure 4.18 is shown in Figure 4.19. Also included in Figure 4.19 are $J-R$ curves from quasi-static tests at MEA (see Figure 4.17), drawn without a blunting line. $J_{i}$ and $d J / d a$ values are shown in Table 4.6.

It is evident from figures 4.18 and 4.19 and from table 4.6 that dynamic tests of specimens from Pipe DP2-A23 show moderately greater fracture resistance than do quasi-static tests. This trend was anticipated and has been observed previously in tests on another austenitic stainless steel (see Ref. 4.14).

No comparison curves are shown in Figure 4.20 because there are no ASME. Section XI reference J-R curves for type 304 stainless steel in the technical bas is document for the IWB-3640 austenitic pipe flaw evaluation criteria.

Pipe Number DP2-A8 1406 mm (16 inch) Diameter, Schedule 100, A358 Type 304 staintess steel plpe]. Load displacement curves for If $C(T)$ specimens machined from Pipe DP2-A8 are shown in Figure 4.20. As was observed for the smaller diameter austenitic stainless steel pipe (see

$C(I)$ tests on this material were conducted prior to prescribing a time of 0.2 seconds to reach crack initiation (see Section 1.1). However, based on experience with strain rate effects, it is unlikely that a factor of 2 difference in displacement rate would have a significant effect on the $J-R$ curve. 
Figure 4.18 for Pipe Number $(1,2+N 3)$, the load-displacement curve for a dynamic tost was above that for a quasi-static test.

$J$-resistance curves a presented in Higure 4.21 and values of $J_{i}$ and dJ/da are sumbriced in tahlo 4.\%. The results show that increasing tho displacement rate by a factor of approximately 4000 rassed $d_{i}$

significantly but had little effect on $\mathrm{dJ} / \mathrm{da}$.

Also shown for comparison in figure 4.21 are results for the smaller diameter lype 304 stainless steel pipe tested in the IPIRG Program (DP2-A23). Notice that the larger pipe (DP2-AB) exhibited somewhat greater toughness than did the smaller pipe.

Pipe Number DP2-ABW (Subierged-Arc Weld in $406 \mathrm{~mm}$ (16 inch) Diameter A358, Type 371 staintess steel Pipe]. [oad-displacement curves are shown in Thure 4.52 for 11 C.(I) specimens machined from a submerged-are weld in an A358, Type 304 stainless steel pipe; the welded pipe is referred to as Pipe Number DP?-ABW. Considerable variation was observed among the three specimens tested at a dynamic rate, but each of the three displayed higher load-displacement curves than did the single specimen tested at a quasi-static rate.

$J$-resistance curves are presented in rigure 4.23 and values of $J_{i}$ and dJ/da are sumnarlzed in Table 4.8. Only two J-resistance curves are shown for dynamic tests because one of the tests falled to provide electric potential data, needed to provide crack initiation and crack growth data. The results indicate that the submerged-arc weld was affected somewhat more than either of the base metals by increasing the displacement rate by a factor of approximately 4400 . J was more than doubled and $\mathrm{dJ} / \mathrm{da}$ was increased by about 40 percent as a result of dynamic loading. Notice also in Figure 4.23 that the toughness of the submeryed-arc weld metal (ABW) was much lower than that of the base metal $(A B)$. That finding is in agreement with results obtained for Type 304 plate material, both base metal and submerged-arc weld metal, in the Degraded Piping Program (Ref. 4.12). The submerged-arc weld in Reference 4.12 was made by the same procedures as were used in this program and exhibited quasi-static J-R curves in $11 C(T)$ specimens that were very similar to the $A B W$ quas $i-5$ tatic $J-R$ curve shown in figure 4.23 (see Figures 3.3 .14 and 3.3 .15 in Reference 4.12).

\subsubsection{Centrifugally Cast Stainless Steel}

Pipe Number DPF-A4O $1406 \mathrm{~mm}$ (16 inch) Diameter $25.4 \mathrm{~mm}$ (1 inch) Wall, Artificially Aged CFBM Pipe]. Only a few small pleces of inaterial were avallable for tabrication of $C(I)$ specimens from Pipe OP2-A4O. The size of the pieces was such that three full-size 0.81 specimens and one 11 planform-size specimen, $22.9 \mathrm{~mm}$ (0.9 inch) thick could be obtained.

load-displacement curves for the $C(1)$ specimens are shown in figure 4.24; the curve for Spec. No. A40-4 lies above those for Spec. No.'s A40-1 and $A 40-2$ because that specimen was larger than the other two. As 
was observed for the autenitie stainless steels, dymanic loading raised the load-displacement curve for the centrifugally cast stainless steel.

$J$-resistance curves are presented in figure 4.25 and values of $J_{1}$ and $\mathrm{dJ} / \mathrm{da}$ are summarized in lable 4.9. The results indicate that increasing the displacement rate by a factor of about 4,300 increased $\mathrm{J}_{i}$ by approximately 30 percent and $d \mathrm{~J} / \mathrm{da}$ by nearly 60 percent.

For comparison, the wrought stainless steel (DP2-AB) and the stainless steel subinerged-arc weld (DP2-ABW) J-R curve scatter bands are also given in Fiqure 4.25. This comparison shows that the artificially aged cast stainless material (OP2-F40) exhibited a toughness level that was comparable to that of submerged-arc weld metal in lype 304 stainless steel (ABW), but significantly lower than that of lype 304 stainless steel base metal (AB). Note that ASME Section $X I$ does not have a reference $J-R$ curve for cast stainless steel, but only requires the ferrite number to be less than 20. Under those requirements, a limitload analysis is used for cast stainless steel in Article IWB-3640.

\subsection{References}

4.1 Ernst, H., "Materials Resistance and Instabillty Beyond JControlled Crack Growth". Elastic-Plastic Fracture, ASTM STP 803 Testing and Materials, 1983, Dp T-191- 1213.

4.2 Clarke, G. A., Andrews, W. R., Paris, P. C., and Schmidt, D. W., "Single Specimen Tests for J Determination". Mechanics of Crack Growth, ASIM STP 590, American Society for lesting and Materials, 1976, pp 27-42.

4.3 Marschall, C.W., Held, P. R., Landow, M. P., and Mincer, P. N., "Use of the Direct-Current Electric Potential Method to Monitor Large Amounts of Crack Growth in Highly Ductile Metals", presented at 21 st National Symposium on Fracture Mechanics in Annapolis, MD., June 1988 .

4.4 Landow, M. P., and Marschall, C. H., "Experience in Using Direct Current Electric Potential to Monitor Crack Growth in Ductile Metals", presented at Second ASIM Symposium on User Experience with Elastic-plastic Test Methods, Orlando, Fl, November 8, 1989.

4.5 Schwalbe, K. H. and Hellman, D., "Application of the Electric Potential Method to Crack Length Measurements Using Johnson's Formula", Journal of lesting and Evaluation, Vol, 9, No. 3, 1981, pp 218-2?1.

4.6 Schwalbe, K.-H., Hellmann, D., Herrens, J., Knaack, J., and Muller-Roos, J., "Measurement of Stable Crack Growtn Including Detection of Initiation of Growth Using the DC Potential Drop and the Partial Unloading Methods", Hastic-Plastic Fracture Test Methods: The User's Ixperience, ASIM SIP 856, F. T. Wessel and $f$. 
J. Loss, Eds., American Society for Testing and materials, 1985, pp 338-362.

4.7 Lowes, J. M., and Fearnehough, G. D., "The Detection of Slow Crack Growth in Crack Opening Displacement Specimens Using an Electrical Potential Method, Engineering Fracture Mechanics, Vol. 3, 1971, pp 103-108.

4.8 Wilkowski, G. M., Wambaugh, J. 0., and Prabhat, K., "Single Specimen J-Resistance Curve Evaluations using the Direct-Current Electric Potential Method and a Compu+arized Data Acquisition System", Fracture Mechanics: Fifteenth Symposium, ASTM STP 833, R. J. Sanford, Ed., ASTM, Philadelphia, 1984, pp 553-576.

4.9 Wilkowski, G. M., and Maxey, W. A., "Review and Applications of the Electric Potential Method for Measuring Crack Growth in Specimens, Flawed Pipes, and Pressure Vessels", Fracture Mechanics: Fourteenth Symposium-Volume II: Testing and Applications, ASTM STP 791, J. C. Lewis and G. Sines, Eds., American Society for Testing and Materials, 1983, pp II -266 - II294.

4.10 Hiser, A. L. and Callahan, G. M., "A User's Guide to the NRC's Piping Fracture Mechanics Data Base (PIFRAC)", Materials Engineering Associates, Inc. report to the U.S. Nuclear Regulatory Commission, NUREG/CR-4894, May, 1987.

4.11 Zahoor, A., Gamble, R. M., Mehta, H. S., Yukawa, S., Ranganath, S., "Evaluation of Flaws in Carbon Steel Piping" NOVETECh Corporation and General Electric Company report to Electric Power Research Institute, EPRI NP-4824M, October, 1986.

4.12 Wilkowski, G. M. and others, "Degraded Piping Program - Phase II", Sixth Program Report, October 1986-September 1987, by Battelle Columbus Laboratories, NUREG/CR-4082, Vol. 6, April 1988.

4.13 Balladon, P. and Foucault, M., "Comparison of Potential Drop, Acoustic Emission, and Partial Unloading Methods for the Evaluation of J-R Curves of Austenitic Stainless Steels", Proc. of 2nd CSNI Workshop on Ductile Fracture Test Methods, Report No. NUREG/CP-0064, CSNI Report No. 105, Aug. 1988.

4.14 Kanninen, M. F., Zahoor, A., Wilkowski, G., Abou-Sayed, I., Marschal1, C., Broek, D., Sampath, S., Rhee, H., and Ahmad, J., "Instability Predictions for Circumferentially Cracked Type 304 Stainless Steel Pipes Under Dynamic Loading", Battelle Final Report to Electric Power Research Institute, NP-2347, Vol. 1, April 1982. 


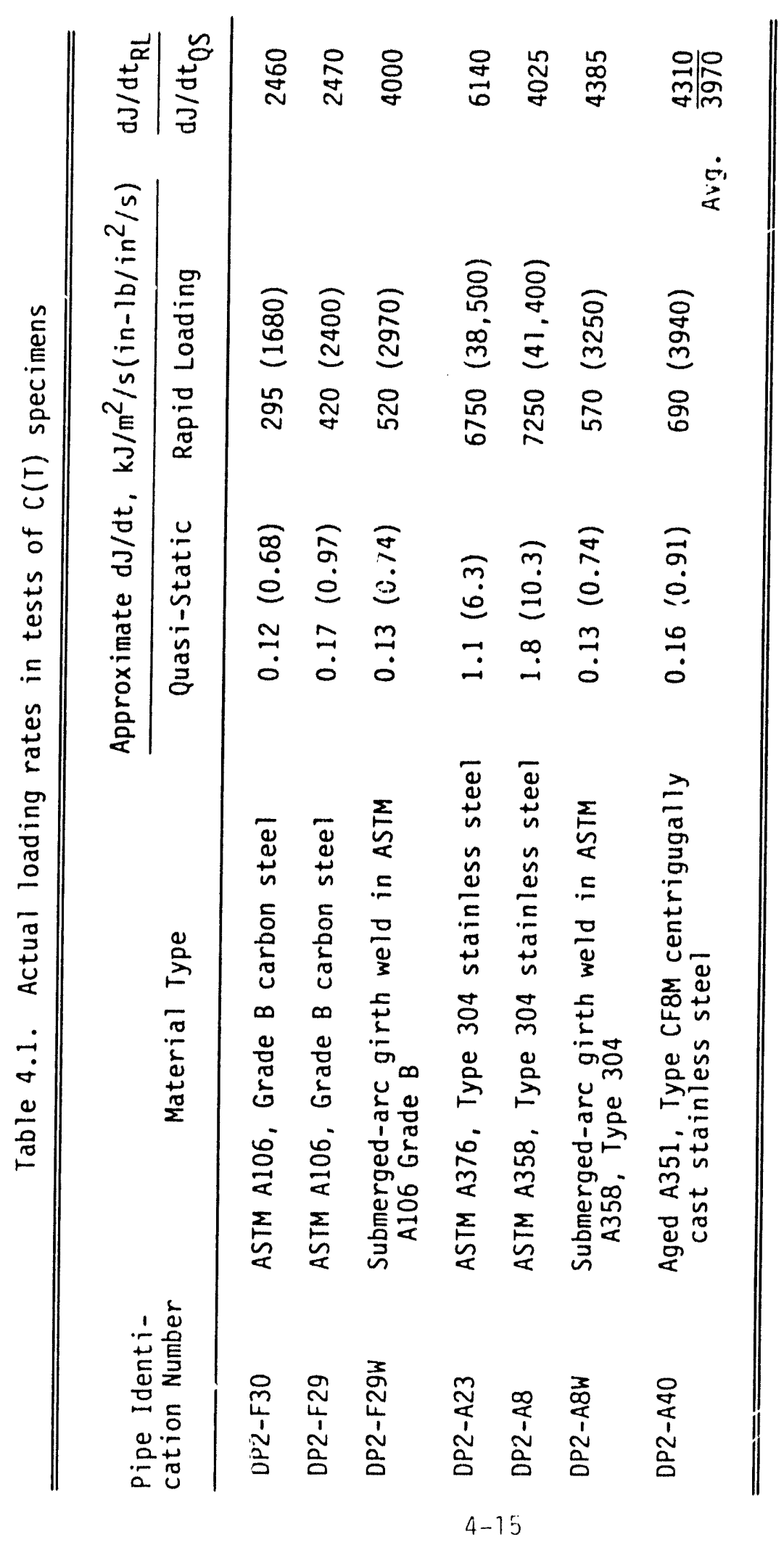


Table 4.2. Summary of $J_{j}$ and $d J / d a$ values for Pipe DP2-F30 obtained from compact specimens tested at $288 \mathrm{C}(550 \mathrm{~F})$ at Materials Engineering Associates.

( $L-C$ orientation; 20 percent side grooves)

\begin{tabular}{|c|c|c|c|c|c|}
\hline \multirow[b]{2}{*}{$\begin{array}{l}\text { Specimen } \\
\text { Ident. No. }\end{array}$} & \multirow[b]{2}{*}{ Rate } & \multicolumn{2}{|c|}{$J$ at Initiation } & \multicolumn{2}{|c|}{$d J / d a(a)$} \\
\hline & & $\mathrm{kJ} / \mathrm{m}^{2}$ & $i n-1 b / i n^{2}$ & $\mathrm{MJ} / \mathrm{m}^{3}$ & $i n-1 b / i n^{3}$ \\
\hline $\begin{array}{l}\text { ZP15-5LC } \\
\text { ZP15-6LC }\end{array}$ & $\begin{array}{l}\text { Quasi-static } \\
\text { Quasi-static }\end{array}$ & $\begin{array}{r}103 \\
97\end{array}$ & $\begin{array}{l}590 \\
555\end{array}$ & $\begin{array}{l}89 \\
92\end{array}$ & $\begin{array}{l}12900 \\
13300\end{array}$ \\
\hline
\end{tabular}

(a) Determined for crack extension between 0.15 and $1.5 \mathrm{~mm}$ (0.006 and 0.06 inch). 
Table 4.3. Summary of $J$ and $d J / d a$ values for Pipe DP2-F30 obtained from compact specimens tested at $288 \mathrm{C}(550 \mathrm{~F})$ at Battelle.

(L-C orientation; 23 percent side grooves)

\begin{tabular}{|c|c|c|c|c|c|}
\hline \multirow[b]{2}{*}{$\begin{array}{l}\text { Specimen } \\
\text { Ident. No. } \\
\end{array}$} & \multirow[b]{2}{*}{ Rate } & \multicolumn{2}{|c|}{$\mathrm{J}$ at Initiation } & \multicolumn{2}{|c|}{$\mathrm{dJ} / \mathrm{da}(\mathrm{a})$} \\
\hline & & $\mathrm{kJ} / \mathrm{m}^{2}$ & $i n-1 b / i n^{2(a)}$ & $\mathrm{MJ} / \mathrm{m}^{3}$ & $i n-1 b / i n^{3}$ \\
\hline $\begin{array}{l}F 30-112 \\
F 30-114\end{array}$ & $\begin{array}{l}\text { Quasi-static } \\
\text { Quasi-static }\end{array}$ & $\begin{array}{l}69 \\
74\end{array}$ & $\begin{array}{l}395 \\
425\end{array}$ & $\begin{array}{l}98 \\
92\end{array}$ & $\begin{array}{l}14200 \\
13300\end{array}$ \\
\hline 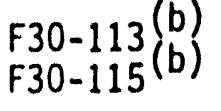 & $\begin{array}{l}\text { Quasi-static } \\
\text { Quasi-static }\end{array}$ & $\begin{array}{l}70 \\
67\end{array}$ & $\begin{array}{l}400 \\
385\end{array}$ & $\begin{array}{l}139 \\
105\end{array}$ & $\begin{array}{l}20200 \\
15200\end{array}$ \\
\hline $\begin{array}{l}F 30-108 \\
F 30-109 \\
F 30-110 \\
F 30-111\end{array}$ & $\begin{array}{l}\text { Dynamic } \\
\text { Dynamic } \\
\text { Dynamic } \\
\text { Dynamic }\end{array}$ & $\begin{array}{l}61 \\
75 \\
50 \\
49\end{array}$ & $\begin{array}{l}350 \\
430 \\
285 \\
280\end{array}$ & $\begin{array}{r}157 \\
178 \\
94 \\
79\end{array}$ & $\begin{array}{l}22800 \\
25800 \\
13600 \\
11500\end{array}$ \\
\hline
\end{tabular}

(a) Determined for crack extension between 0.15 and $1.5 \mathrm{~mm}$ (0.006 and 0.06 inch).

(b) Specimen was partially unloaded several times prior to maximum load to simulate MEA unloading-compliance test procedure. 
Table 4.4. Summary of $J_{i}$ and $d J / d a$ values for Pipe DP2-F29.

$$
\text { Tested at } 288 \mathrm{C}(550 \mathrm{~F})
$$

\begin{tabular}{|c|c|c|c|c|c|c|}
\hline \multirow{2}{*}{$\begin{array}{l}\text { Spec. } \\
\text { Ident. } \\
\text { No. }\end{array}$} & \multirow[b]{2}{*}{$\begin{array}{l}\text { \%Side- } \\
\text { Grooves } \\
\end{array}$} & \multirow[b]{2}{*}{ Rate $^{(a)}$} & \multicolumn{2}{|c|}{$J$ at Initiation } & \multicolumn{2}{|c|}{$\mathrm{dJ} / \mathrm{da}$} \\
\hline & & & $\mathrm{kJ} / \mathrm{m}^{2}$ & $i n-1 b / i n^{2}$ & $\mathrm{MJ} / \mathrm{m}^{3}$ & $i n-1 b / i n^{3}$ \\
\hline F29-17 & 0 & QS & 111 & 635 & 113 & 16410 \\
\hline $\begin{array}{l}F 29-18 \\
\text { F29-11 } \\
\text { F29-13 }\end{array}$ & $\begin{array}{l}20 \\
20 \\
20\end{array}$ & $\begin{array}{l}Q S \\
Q S \\
Q S\end{array}$ & $\begin{array}{r}149 \\
147 \\
92\end{array}$ & $\begin{array}{l}850 \\
840 \\
525\end{array}$ & $\begin{array}{r}89 \\
100 \\
125\end{array}$ & $\begin{array}{l}12910 \\
14550 \\
18200\end{array}$ \\
\hline $\begin{array}{l}F 29-9 \\
F 29-14 \\
\text { F29-15 }\end{array}$ & $\begin{array}{l}20 \\
20 \\
20\end{array}$ & $\begin{array}{l}\text { Dyn } \\
\text { Dyn } \\
\text { Dyn }\end{array}$ & $\begin{array}{l}68 \\
88 \\
89\end{array}$ & $\begin{array}{l}390 \\
505 \\
510\end{array}$ & $\begin{array}{l}62 \\
55 \\
56\end{array}$ & $\begin{array}{l}8930 \\
8020 \\
8140\end{array}$ \\
\hline
\end{tabular}


Table 4.5. Summary of $J$ and $d J / d a$ values for submerged-arc weld (DP2-F29W) in Pipe DP2-F29.

$$
\text { Tested at } 288 \mathrm{C}(550 \mathrm{~F})
$$

\begin{tabular}{|c|c|c|c|c|c|c|}
\hline \multirow{2}{*}{$\begin{array}{c}\text { Spec. } \\
\text { Ident. } \\
\text { No. }\end{array}$} & \multirow[b]{2}{*}{$\begin{array}{l}\text { \%Side- } \\
\text { Grooves }\end{array}$} & \multirow[b]{2}{*}{ Rate $^{(b)}$} & \multicolumn{2}{|c|}{$J$ at Initiation } & \multicolumn{2}{|c|}{$d J / d a$} \\
\hline & & & $\mathrm{kJ} / \mathrm{m}^{2}$ & $i n-1 b / i n^{2}$ & $\mathrm{MJ} / \mathrm{m}^{3}$ & $i n-1 b / i n^{3}$ \\
\hline$F 29 W-12$ & 20 & QS & 82 & 470 & 68 & 9860 \\
\hline $\begin{array}{l}F 29 W-9 \\
F 29 W-10 \\
F 29 W-11\end{array}$ & $\begin{array}{l}20 \\
20 \\
20\end{array}$ & $\begin{array}{l}\text { Dyn } \\
\text { Dyn } \\
\text { Dyn }\end{array}$ & $\begin{array}{l}118 \\
131 \\
127\end{array}$ & $\begin{array}{l}675 \\
745 \\
725\end{array}$ & $\begin{array}{r}109 \\
102 \\
94\end{array}$ & $\begin{array}{l}15760 \\
14820 \\
13620\end{array}$ \\
\hline
\end{tabular}

\footnotetext{
(a) $Q S=$ quasi-static Dyn = dynamic
} 
Table 4.6. Summary of $J_{i}$ and $d J / d a$ values for Pipe DP2-A23 obtained from compact specimens tested at $288 \mathrm{C}(550 \mathrm{~F})$.

$$
\begin{aligned}
& \text { L-C orientation; } 20 \text { percent side grooves (MEA) } \\
& \text { or } 23 \text { percent side grooves (Battelle) }
\end{aligned}
$$

\begin{tabular}{|c|c|c|c|c|c|}
\hline \multirow[b]{2}{*}{$\begin{array}{l}\text { Spec. } \\
\text { Ident. No. }\end{array}$} & \multirow[b]{2}{*}{ Rate } & \multicolumn{2}{|c|}{$J$ at Initiation } & \multicolumn{2}{|c|}{$d J / d a(a)$} \\
\hline & & $\mathrm{kJ} / \mathrm{m}^{2}$ & $i n-1 b / i n^{2(a)}$ & $\mathrm{MJ} / \mathrm{m}^{3}$ & $i n-1 b / i n^{3}$ \\
\hline $\begin{array}{l}2 P 17-9 L C^{(b)} \\
2 P 17-13 L C^{(b)}\end{array}$ & $\begin{array}{l}\text { Quasi-static } \\
\text { Quasi-static }\end{array}$ & $\begin{array}{l}597 \\
538\end{array}$ & $\begin{array}{l}3405 \\
3070\end{array}$ & $\begin{array}{l}286 \\
315\end{array}$ & $\begin{array}{l}41500 \\
45700\end{array}$ \\
\hline$A 23-113$ & Quasi-static & 646 & 3685 & 242 & 35100 \\
\hline$A 23-x^{(c)}$ & Dynamic & 675 & 3850 & 285 & 41300 \\
\hline
\end{tabular}

\footnotetext{
(a) Determined for crack extension between 0.15 and $1.5 \mathrm{~mm}$ (0.006 and 0.06 inch).

(b) Specimen was fabricated at MEA.

(c) Specimen No. A23-X represents a composite of five nominally identical compact specimens tested dynamically to differnt total displacements and different crack lengths; individual specimens were No.'s A23-108, A23-109, A23-110, A23-111, and A23-112.
} 
Table 4.7. Summary of $J_{j}$ and $d J / d a$ values for Pipe DP2-A8.

Tested at $288 \mathrm{C}(550 \mathrm{~F})$

\begin{tabular}{|c|c|c|c|c|c|c|}
\hline \multirow{2}{*}{$\begin{array}{l}\text { Spec. } \\
\text { Ident. } \\
\text { No. } \\
\end{array}$} & \multirow[b]{2}{*}{$\begin{array}{l}\text { \&Side- } \\
\text { Grooves }\end{array}$} & \multirow[b]{2}{*}{ Rate ${ }^{(a)}$} & \multicolumn{2}{|c|}{$J$ at Initiation } & \multicolumn{2}{|c|}{ dJ/da } \\
\hline & & & $\mathrm{kJ} / \mathrm{m}^{2}$ & $i n-1 b / i n^{2}$ & $\mathrm{MJ} / \mathrm{m}^{3}$ & $i n-1 b / i n^{3}$ \\
\hline$A 8-41$ & 0 & QS & 710 & 4050 & 610 & 88500 \\
\hline $\begin{array}{l}A 8-43 \\
A 8-12 A\end{array}$ & $\begin{array}{l}20 \\
20\end{array}$ & $\begin{array}{l}\text { QS } \\
\text { QS }\end{array}$ & $\begin{array}{l}623 \\
854\end{array}$ & $\begin{array}{l}3555 \\
4875\end{array}$ & $\begin{array}{l}524 \\
481\end{array}$ & $\begin{array}{l}76000 \\
69720\end{array}$ \\
\hline $\begin{array}{l}A B-9 A \\
A B-10 A \\
A B-11 A\end{array}$ & $\begin{array}{l}20 \\
20 \\
20\end{array}$ & $\begin{array}{l}\text { Dyn } \\
\text { Dyn } \\
\text { Dyn }\end{array}$ & $\begin{array}{r}1302 \\
943 \\
1399\end{array}$ & $\begin{array}{l}7430 \\
5335 \\
7985\end{array}$ & $\begin{array}{l}500 \\
566 \\
388\end{array}$ & $\begin{array}{l}72470 \\
82060 \\
56320\end{array}$ \\
\hline
\end{tabular}


Table 4.8. Summary of $J_{i}$ and $d J / d a$ values for submerged-arc weld (DP2-A8W) in a Type 304 austenitic stainless steel pipe.

Tested at 550F (288C); L-C orientation

Specimen \&side-

Ident. No. Grooves

$\frac{\text { Rate }}{\text { (a) }} \frac{\mathrm{J} \text { at Initiation }}{\frac{\mathrm{kJ} / \mathrm{m}^{2}}{\mathrm{~N}}} \frac{\mathrm{in}-\mathrm{lb} / \mathrm{in}^{2}}{315} \frac{\mathrm{dJ} / \mathrm{da}}{\frac{\mathrm{MJ} / \mathrm{m}^{3}}{135} \frac{\mathrm{in}-\mathrm{lb} / \mathrm{in}^{3}}{19550}}$

ABW-107

ABW-108

Dyn

140

116

800

660

$A B W-111$

20

Dyn

(b)

(b)

180

26140

205

29700

(b)

(b)

(a) $Q S=$ quasi-static Dyn = dynamic

(b) No electric potential data were obtained for Specimen No. A8W-111; hence the J-R curve could not be calculated 
Table 4.9. Summary of $J$ and $d J / d a$ values for compact specimens from Pipe DP2-A40 tested at $300 \mathrm{C}(572 \mathrm{~F})$.

\begin{tabular}{|c|c|c|c|c|c|c|c|}
\hline \multirow[b]{2}{*}{$\begin{array}{l}\text { Specimen } \\
\text { Ident. No. }\end{array}$} & \multirow[b]{2}{*}{ Size } & \multirow[b]{2}{*}{$\begin{array}{l}\text { \&Side- } \\
\text { Grooves }\end{array}$} & \multirow[b]{2}{*}{ Rate $^{(a)}$} & \multicolumn{2}{|c|}{$\mathrm{J}$ at Initiation } & \multicolumn{2}{|c|}{$d J / d a$} \\
\hline & & & & $\mathrm{kJ} / \mathrm{m}^{2}$ & $i n-1 b / i n^{2}$ & $\mathrm{MJ} / \mathrm{m}^{3}$ & $\ln -1 \mathrm{~b} / \mathrm{in}^{3}$ \\
\hline$A 40-3$ & $0.8 \mathrm{~T}$ & 20 & QS & 88 & 501 & 147 & 21330 \\
\hline $\begin{array}{l}A 40-1 \\
A 40-2 \\
A 40-4\end{array}$ & $\begin{array}{c}0.8 \mathrm{~T} \\
0.8 \mathrm{~T} \\
1 \mathrm{~T}\end{array}$ & $\begin{array}{l}20 \\
20 \\
20\end{array}$ & $\begin{array}{l}\text { Dyn } \\
\text { Dyn } \\
\text { Dyn }\end{array}$ & $\begin{array}{r}109 \\
146 \\
93\end{array}$ & $\begin{array}{l}621 \\
833 \\
533\end{array}$ & $\begin{array}{l}253 \\
181 \\
263\end{array}$ & $\begin{array}{l}36700 \\
26320 \\
38150\end{array}$ \\
\hline$T$ & 70 & $i t i c$ & & & & & \\
\hline
\end{tabular}



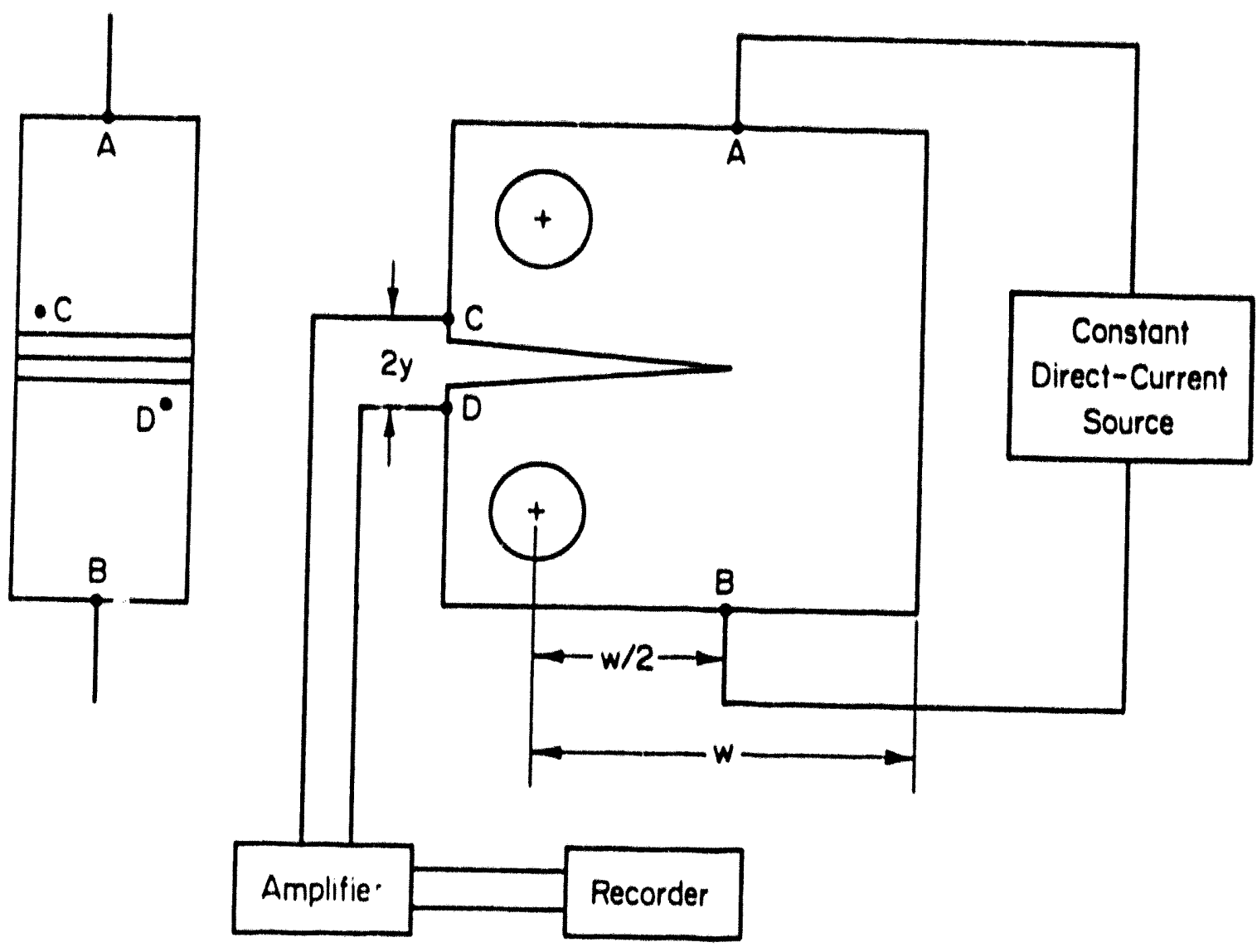

Figure 4.1 Schematic illustration of direct-current electric potential method employed at Battelle to monitor crack growth in C(T) tests. 


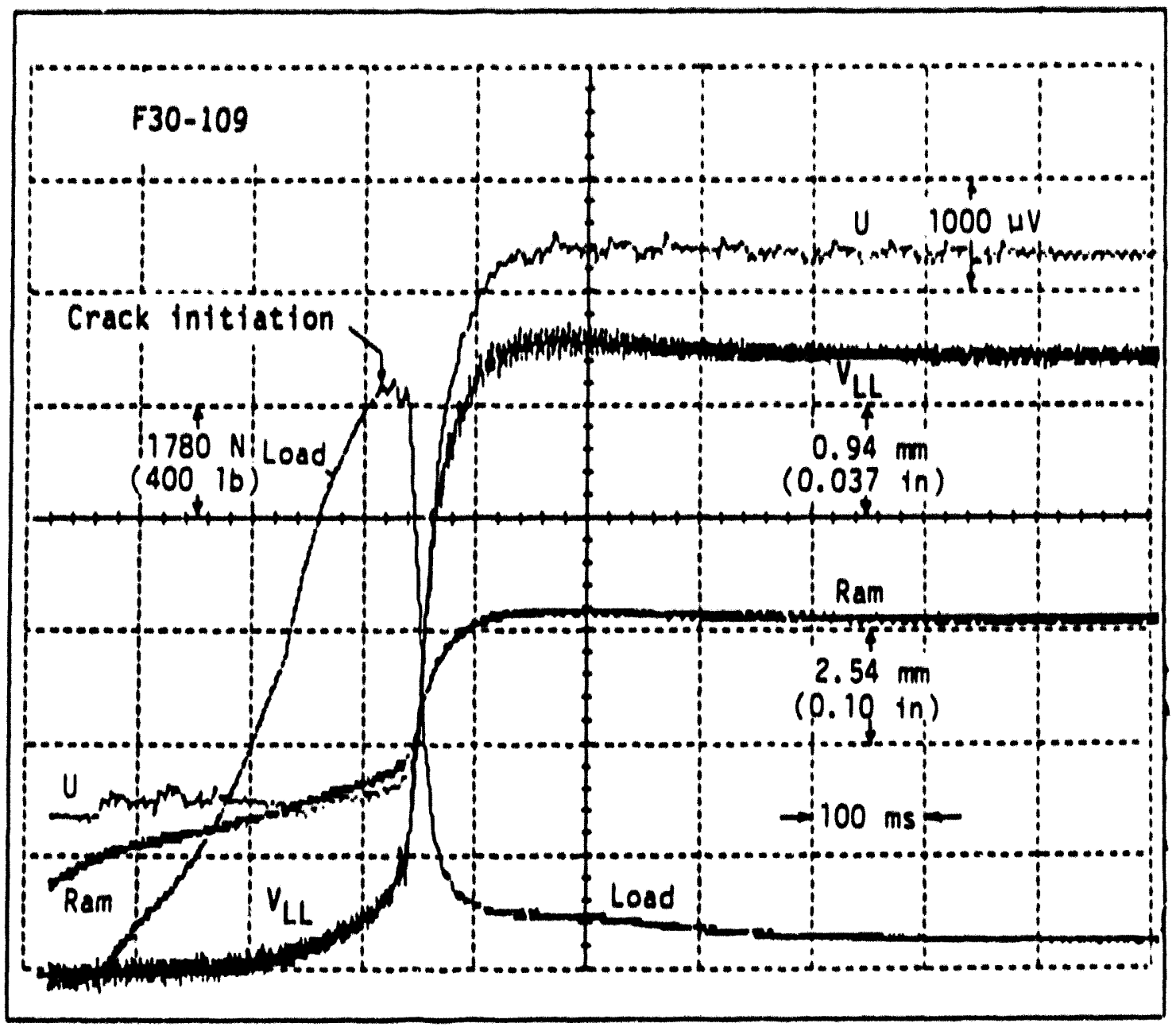

Figure 4.2 Transient recorder trace for dynamic test of Al06 Grade $B$ carbon steel specimen F30-109 at $288 \mathrm{C}(550 \mathrm{~F})$.

$1-T 1.0-11 / 89-F 4.2$ 


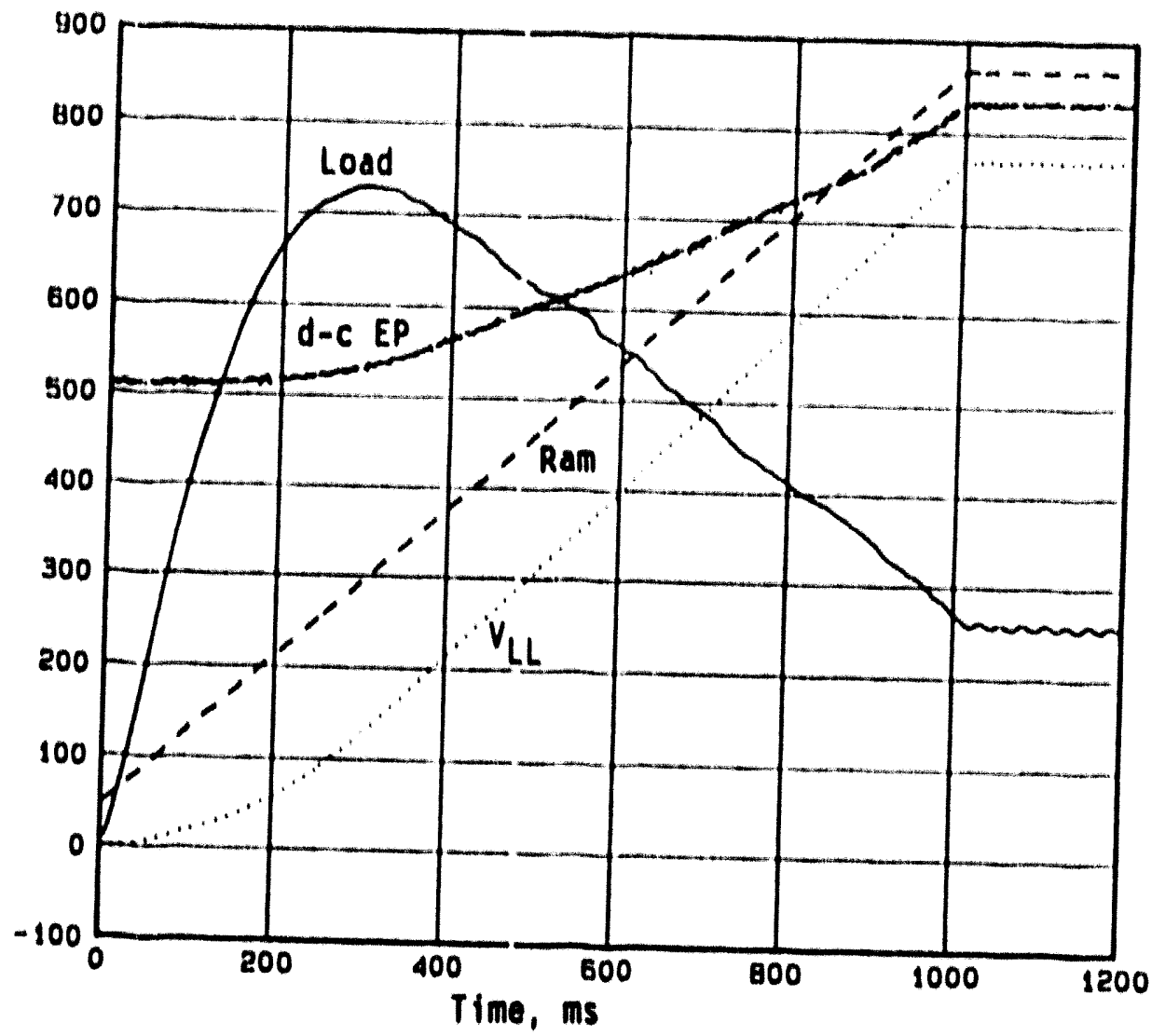

Figure 4.3 Example of unreduced data for dynamic test of austenitic stainless steel weld $C(T)$ specimen A8W-107 at $288 \mathrm{C}(550 \mathrm{~F})$.

$1-11.0-11 / 89-54.3$ 


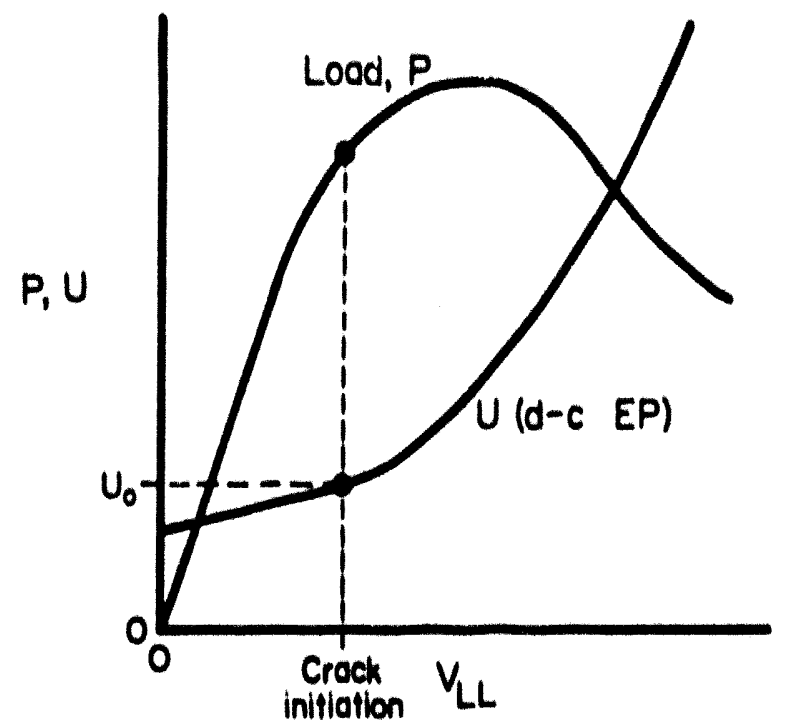

(a) Load and d-c EP versus load line displacement

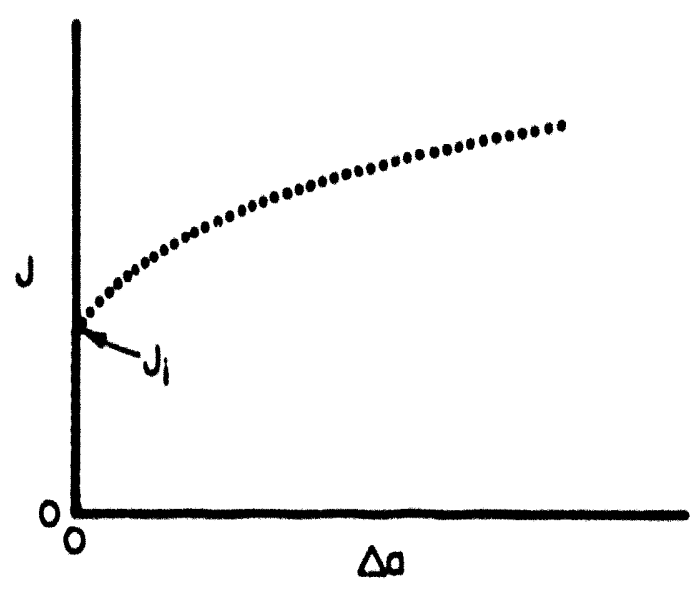
(b) J versus $\Delta a$ calculated from data in (a)

Figure 4.4 Schematic illustration of the method used at Battelle in the Degraded Piping and IPIRG programs to estimate the crack initiation point and to construct the J-R curve. 


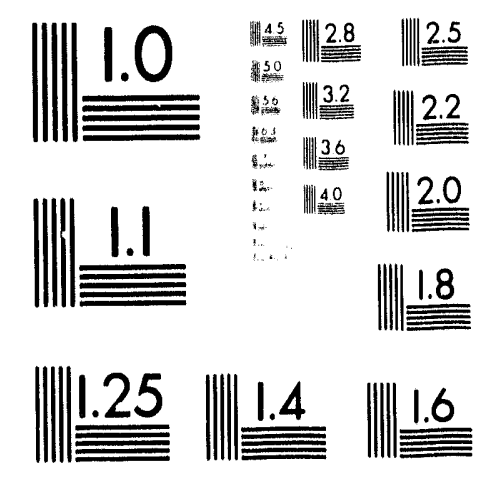



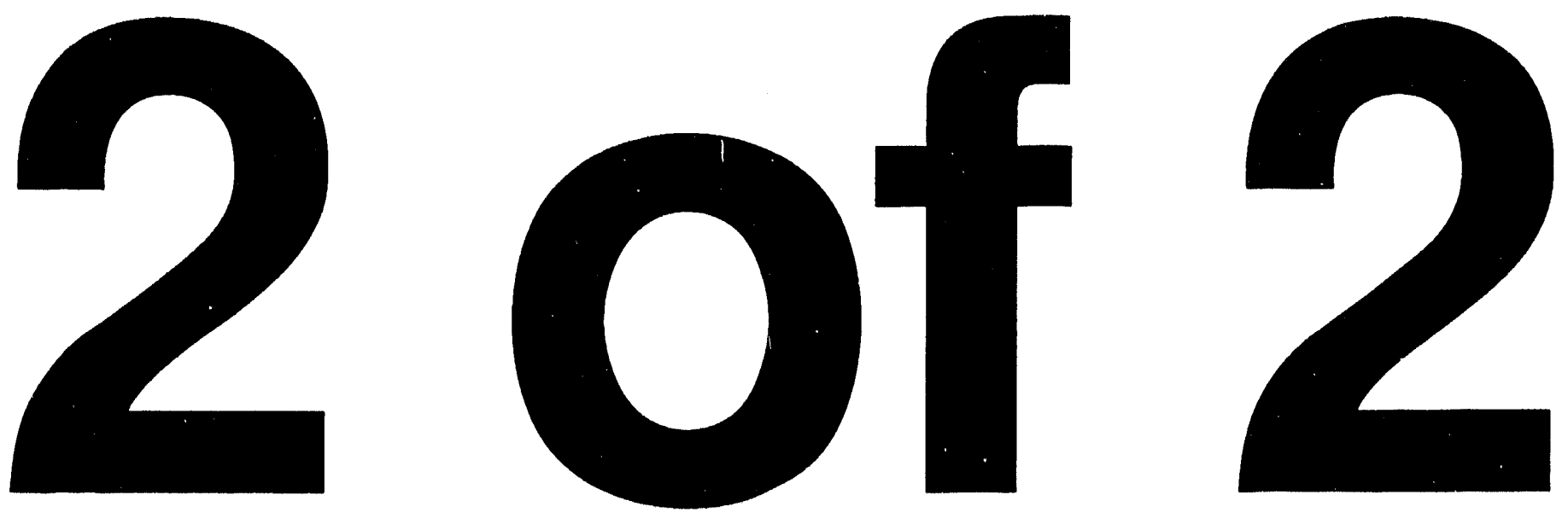


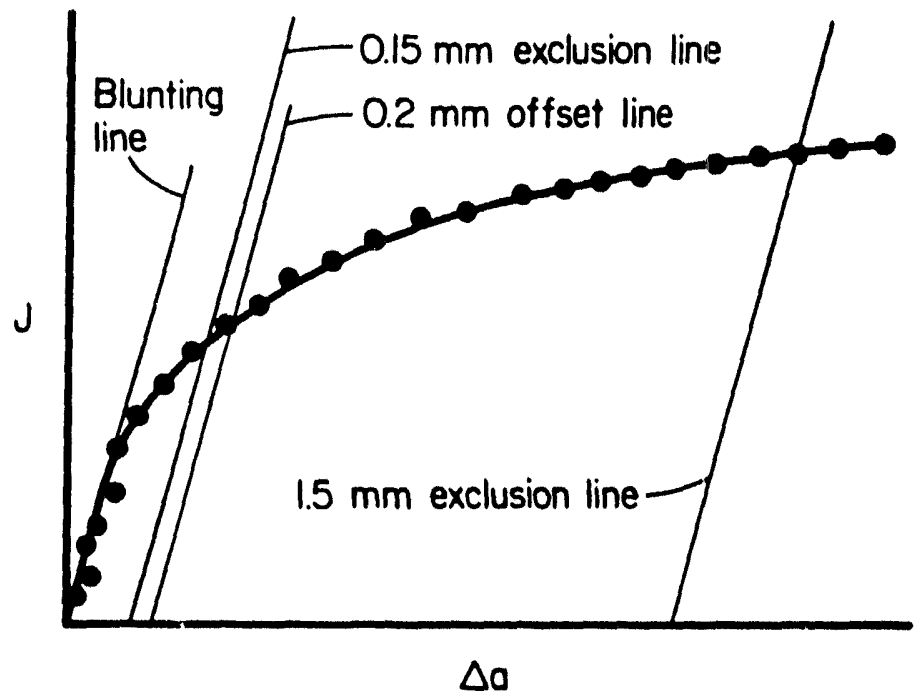

Figure 4.5 Schematic illustration of a J-resistance curve that employs a blunting line in estimating the point of crack initiation.

$1-T 1.0-11 / 89-F 4.5$ 


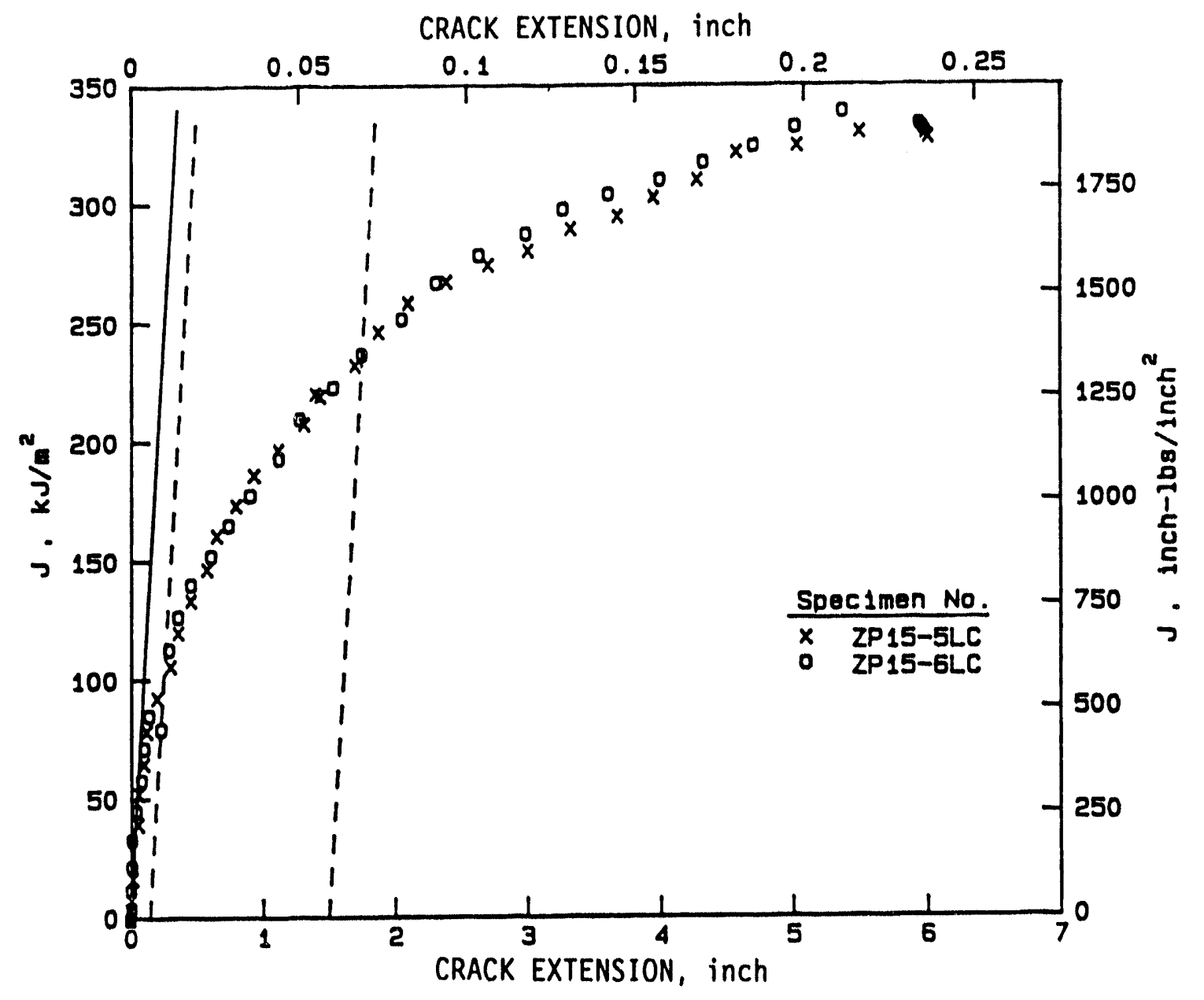

Figure 4.6 J versus crack extension for Pipe DP2-F30 (A106 Grade B carbon steel) compact specimens tested quasi-staticaily at $288 \mathrm{C}(550 \mathrm{~F})$ at MEA.

I - T1 $.0-11 / 89-F 4.6$ 


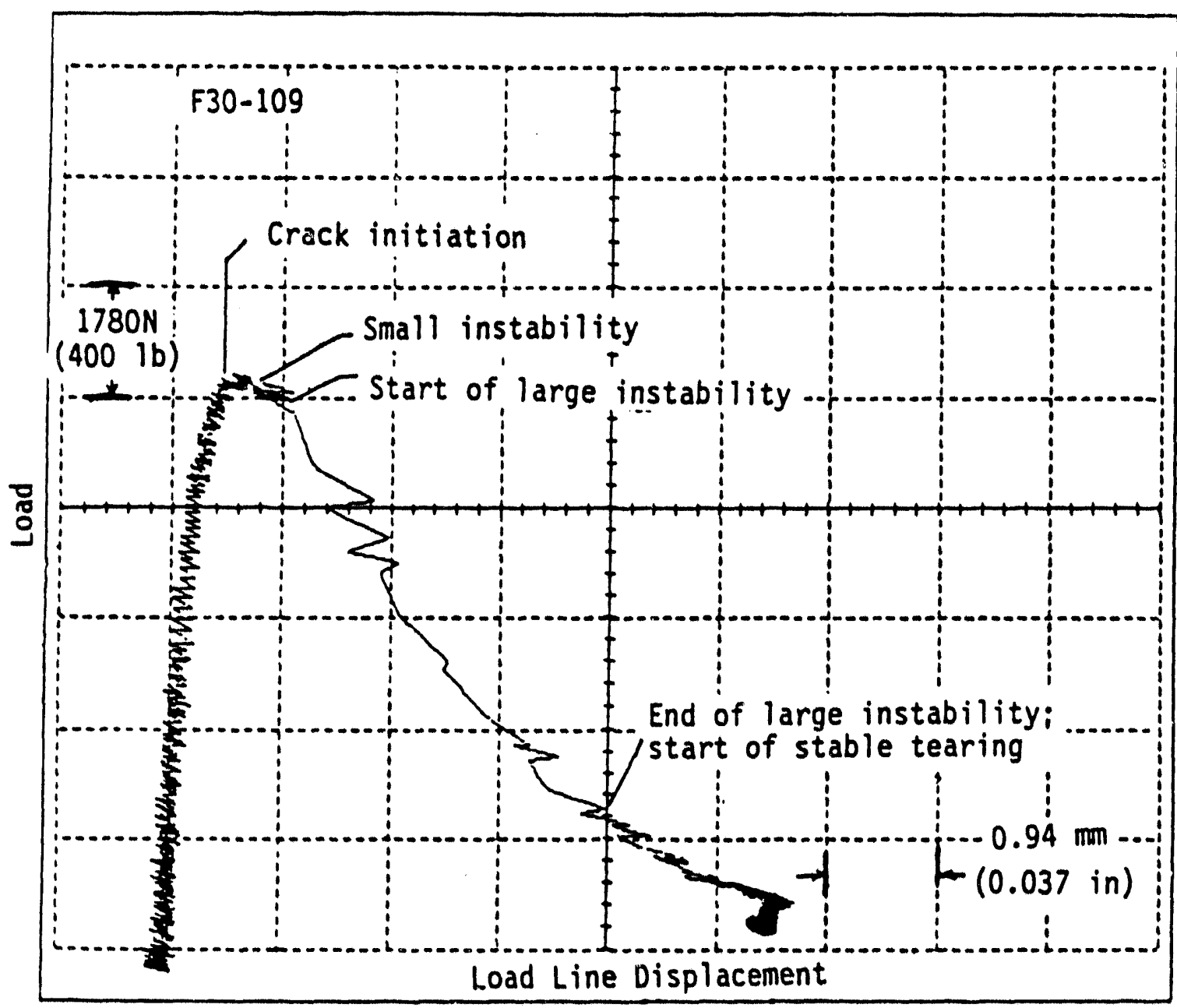

Figure 4.7 Load-displacement curve for dynamic test of Al06 Grade B carbon steel specimen F30-109 at 288 C $(550 \mathrm{~F})$. 


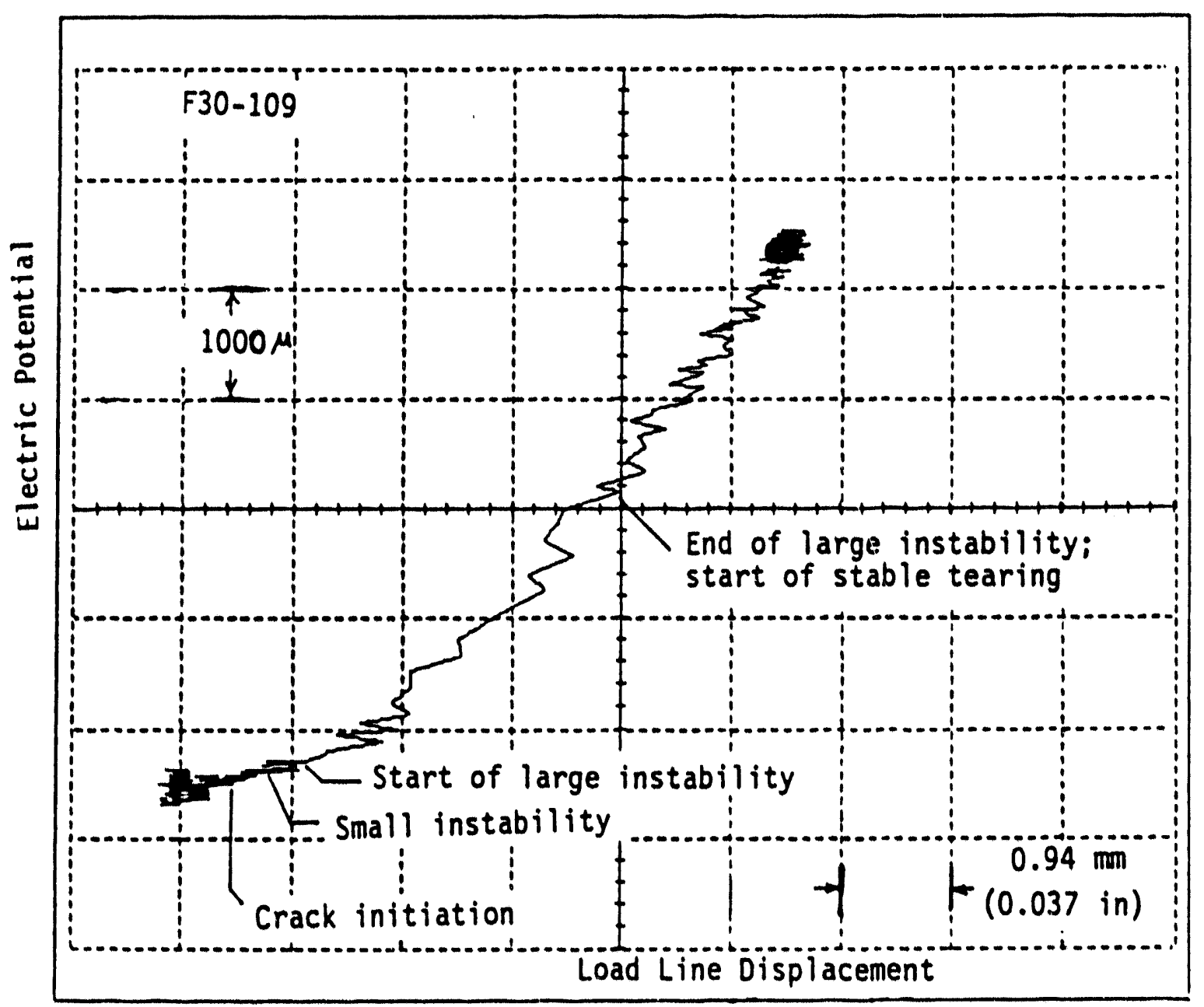

Figure 4.8 Electric potential versus displacement curve for dynamic test of A106 Grade B carbon steel specimen F $30-109$ at 288 C (550 F).

I $-\mathrm{T} 1.0-11 / 89-\mathrm{F} 4.8$ 


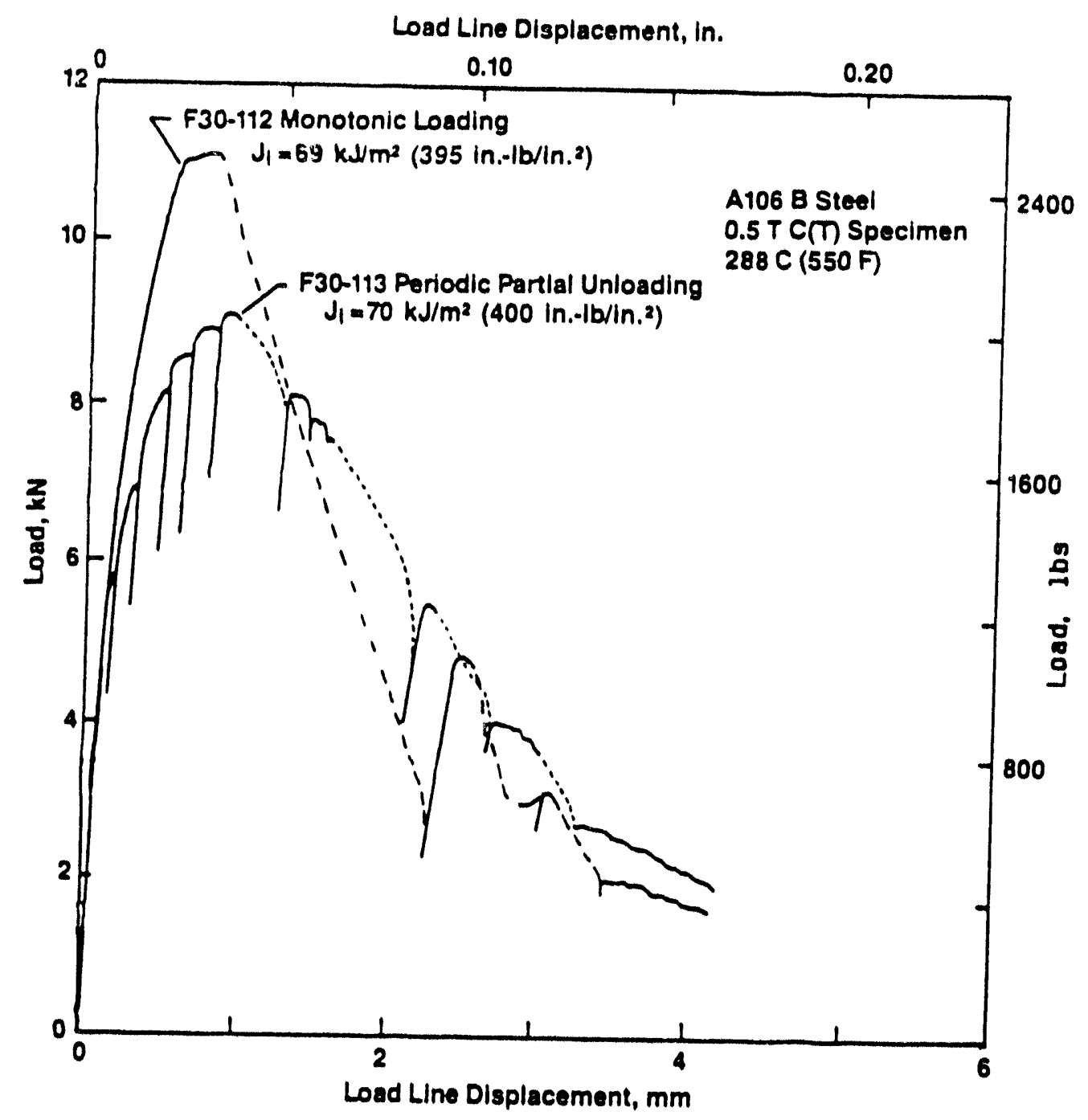

Figure 4.9 Load-displacement curves for quasi-static tests of compact specimens from Pipe DP2-F30 (A106 Grade B carbon steel), illustrating crack instabilities with and without partial unloadings.

$1-T 1.0-11 / 89-F 4.9$ 


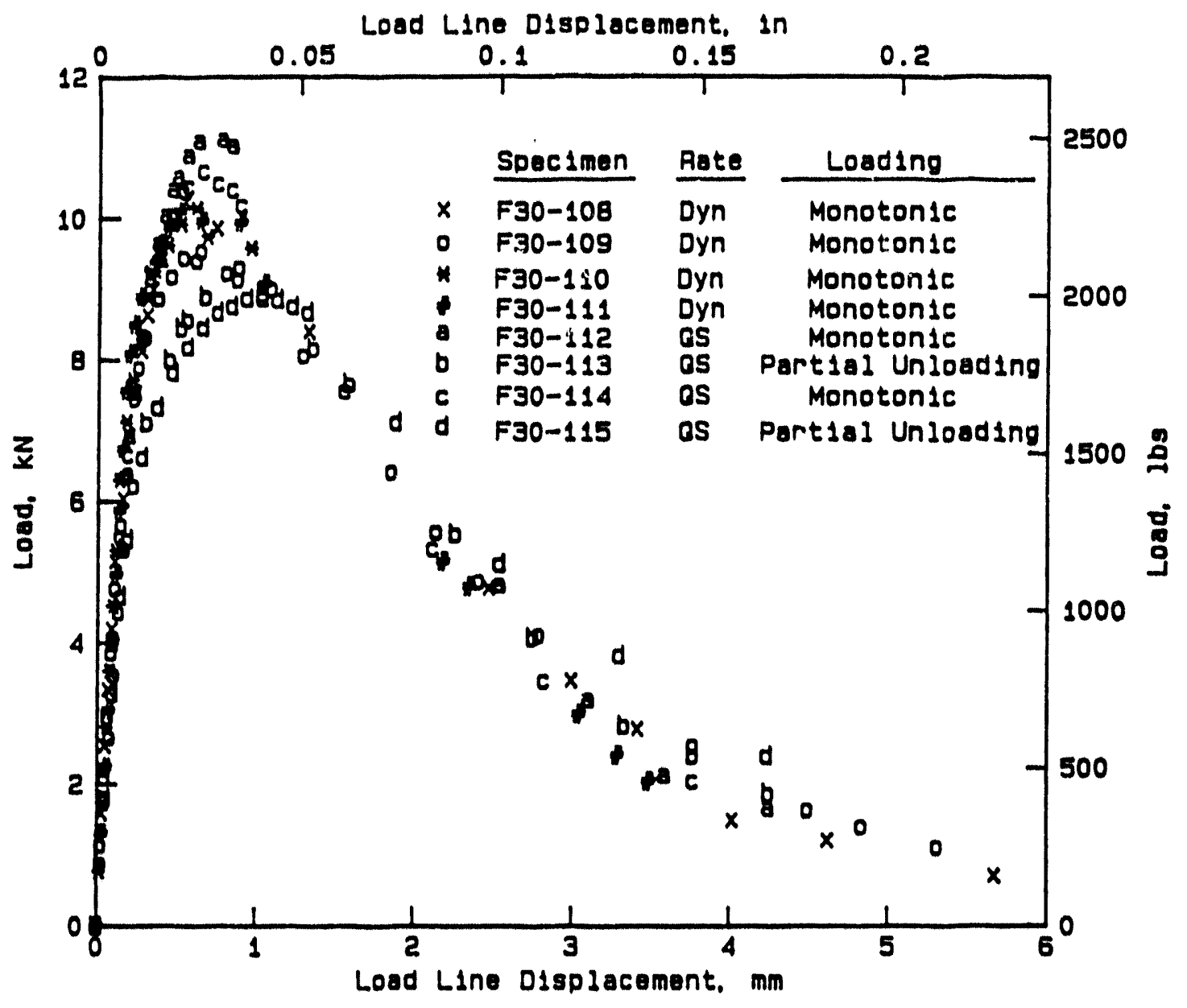

Figure 4.10 Load-displacement data for compact specimens from Pipe DP2-F30 (A106 Grade B carbon steel), tested at $288 \mathrm{C}(550 \mathrm{~F})$.

$$
1-T 1.0-11 / 89-F 4.10
$$




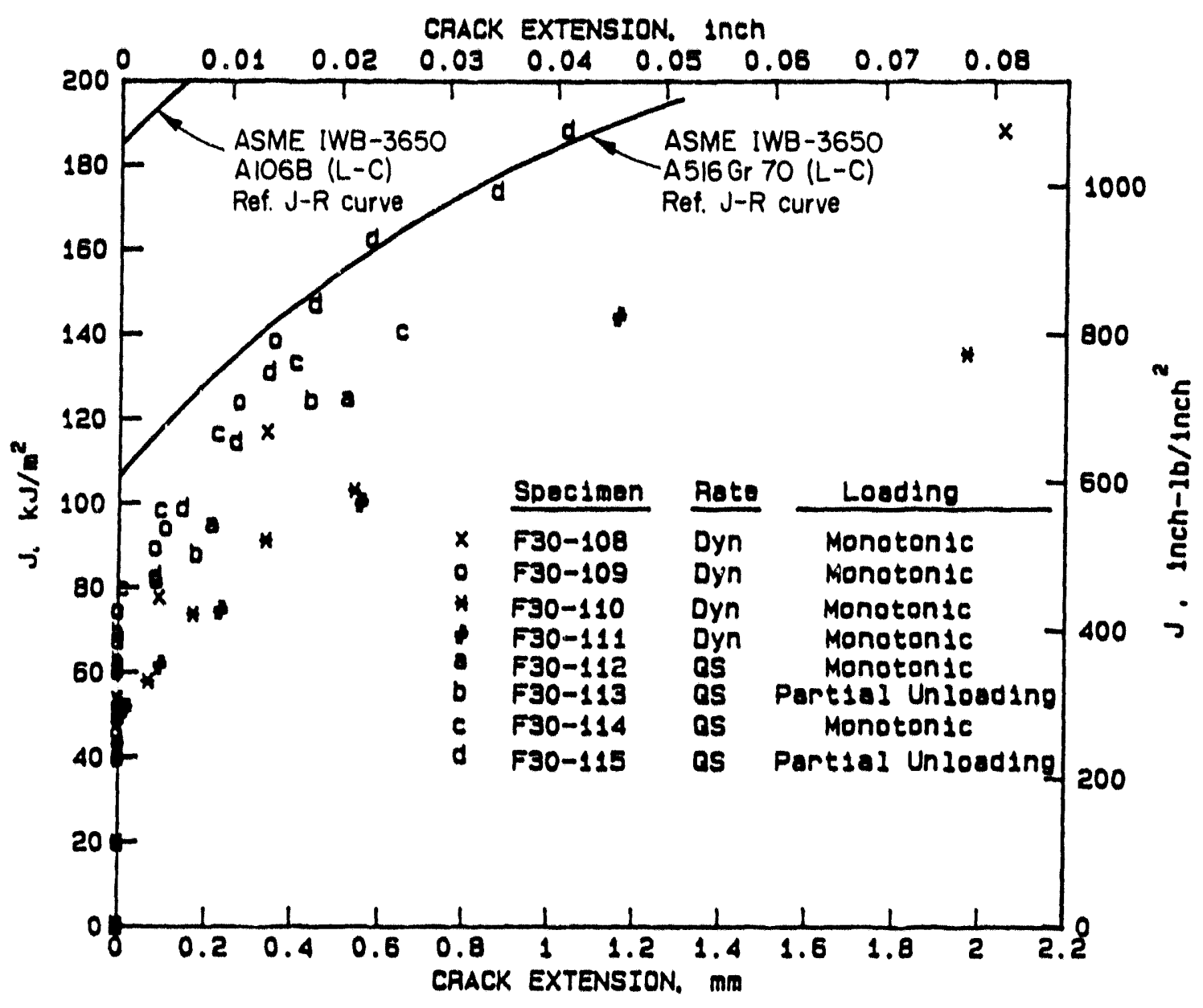

Figure $4.11 \mathrm{~J}$-resistance curves for compact specimens, up to the point of the first large crack instability, from Pipe DP2-F30 (A106 Grade B carbon steel) tested at $288 \mathrm{C}(550 \mathrm{~F})$ in L-C orientation.

$1-T 1.0-11 / 89-F 4.11$ 


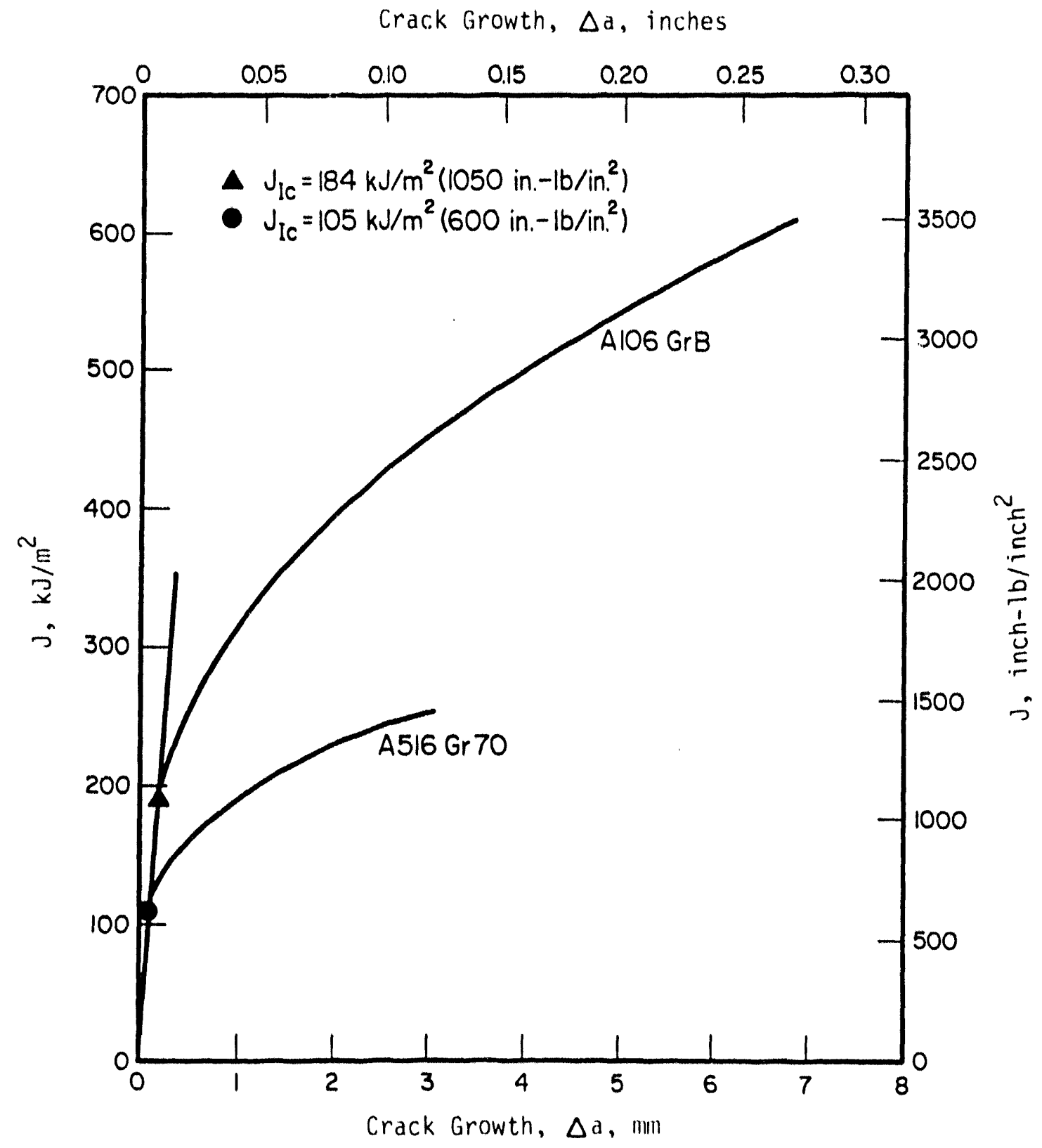

Figure 4.12 J-R curves at $288 \mathrm{C}(550 \mathrm{~F})$ used in ASME IWB-3650 ferritic-pipe flaw evaluation criteria (Ref. 4.11).

I-T.10-11/89-F4.12 


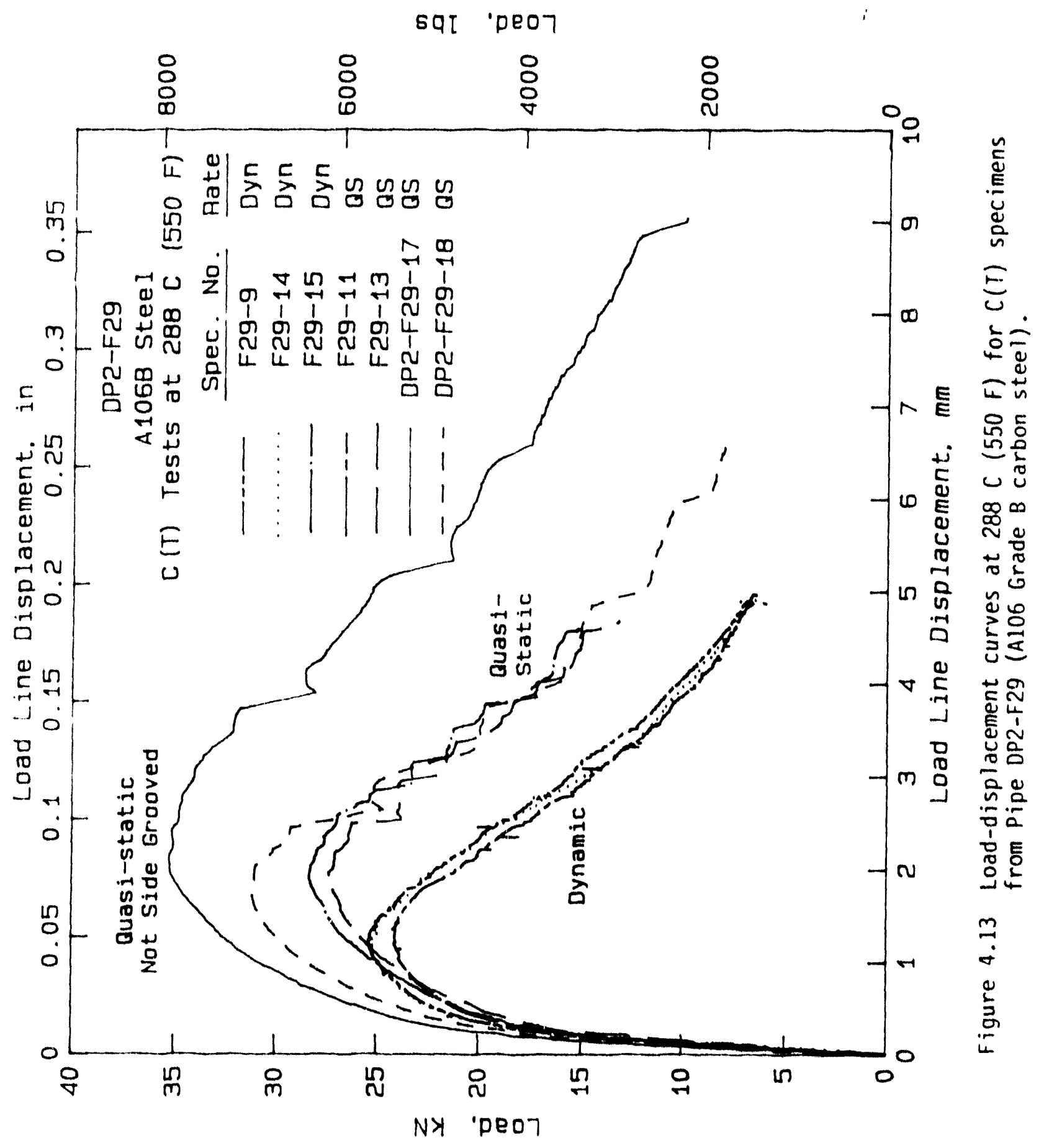




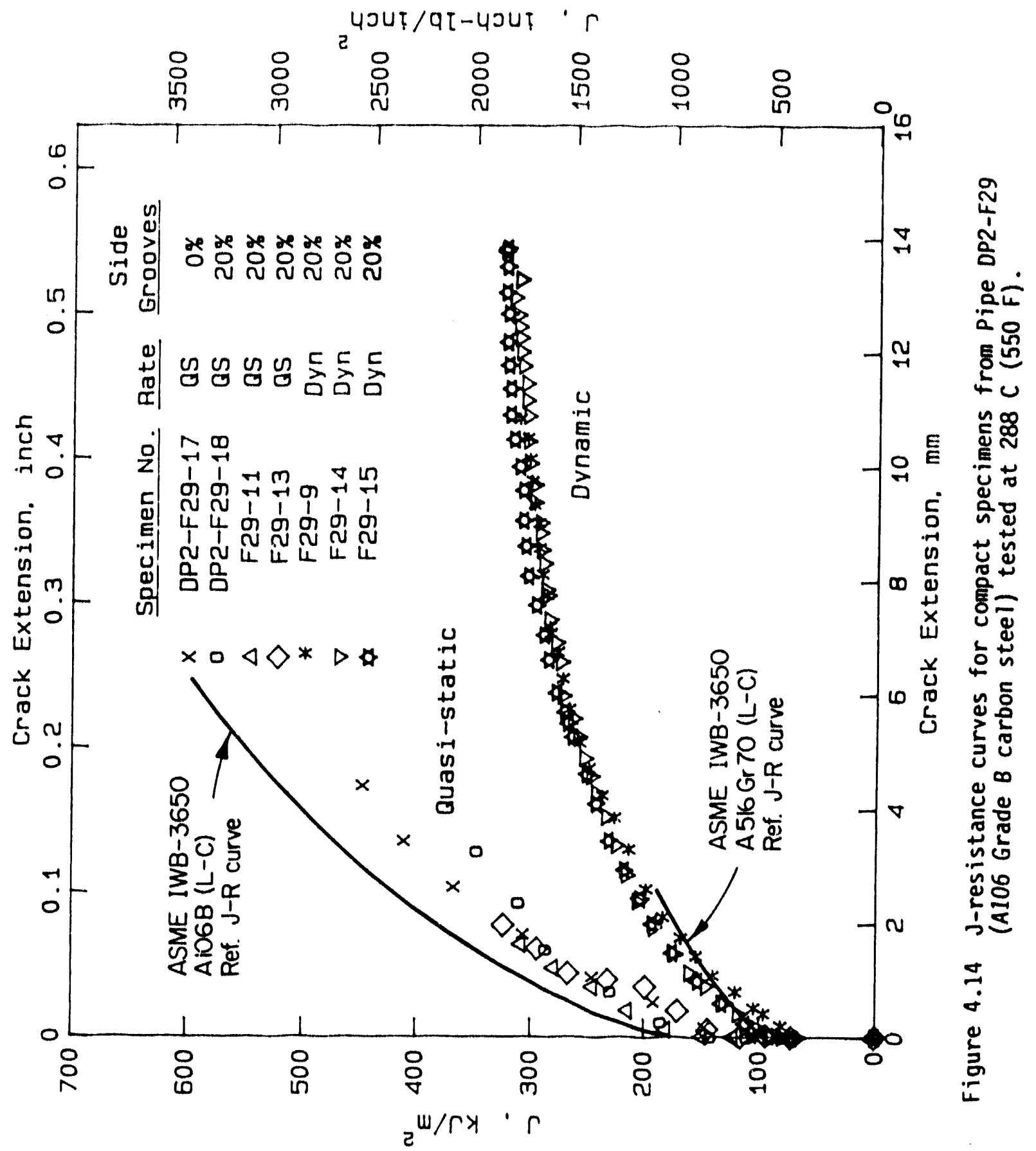




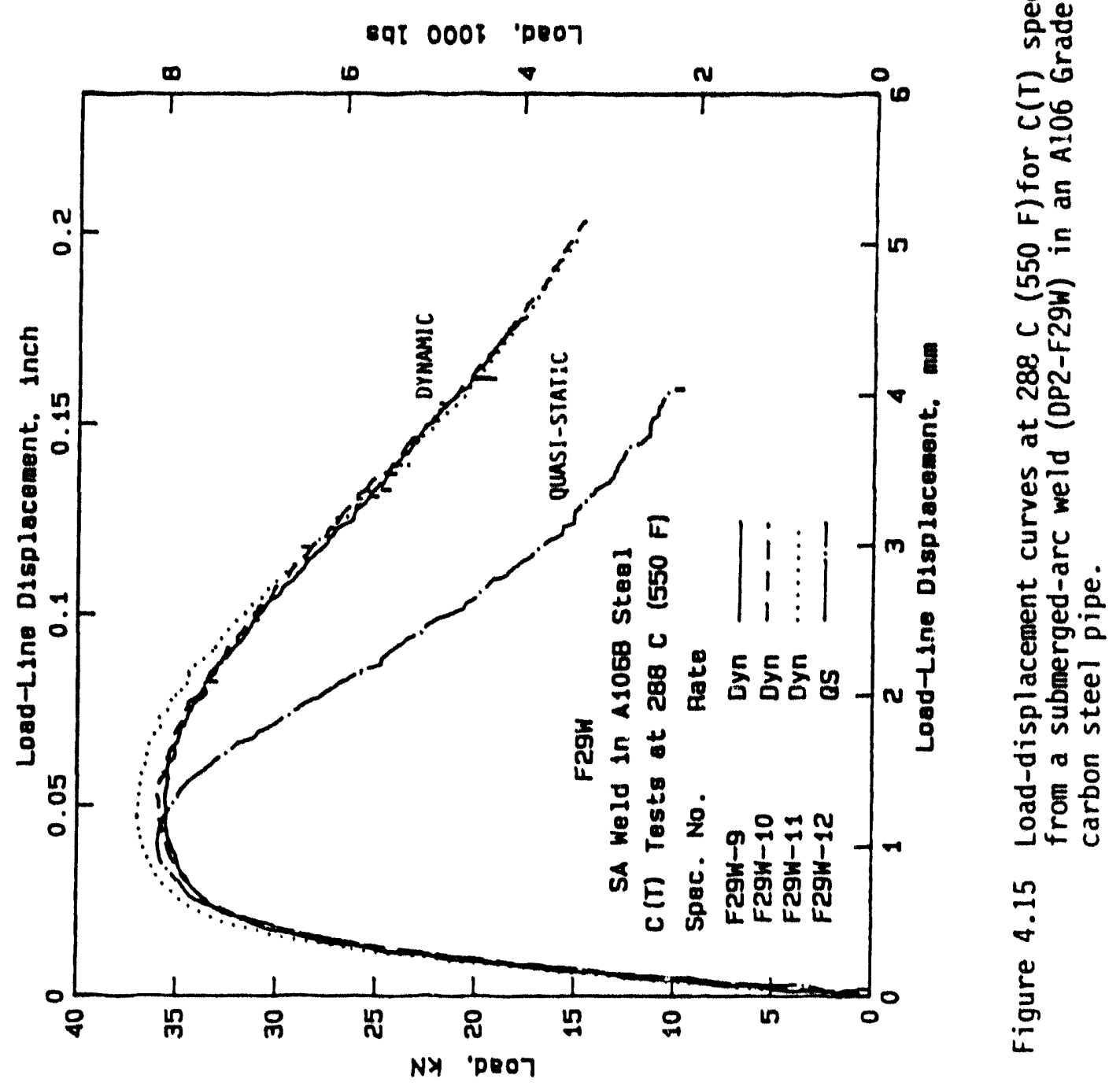




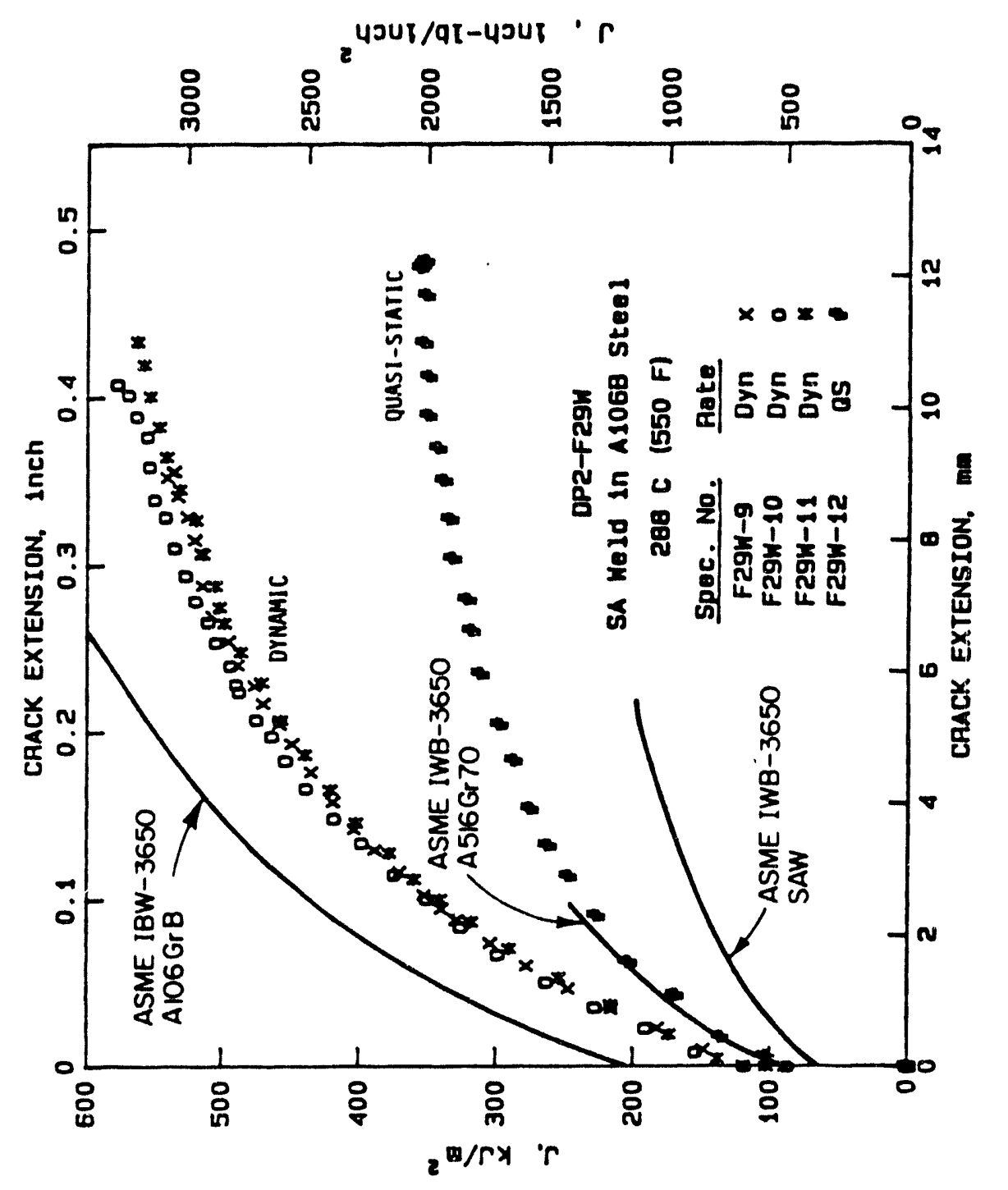

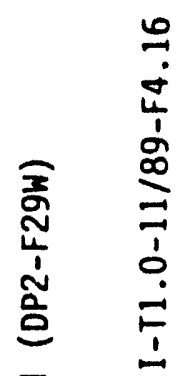

$\frac{0}{3}$

占

అ

인

4

䒭品

E

号品

노음

늠

응 巳

ㄴํㄴ든

ㄴํㅇ

U

承

웜

造

$\approx 0$

ฮั

느드

茴 


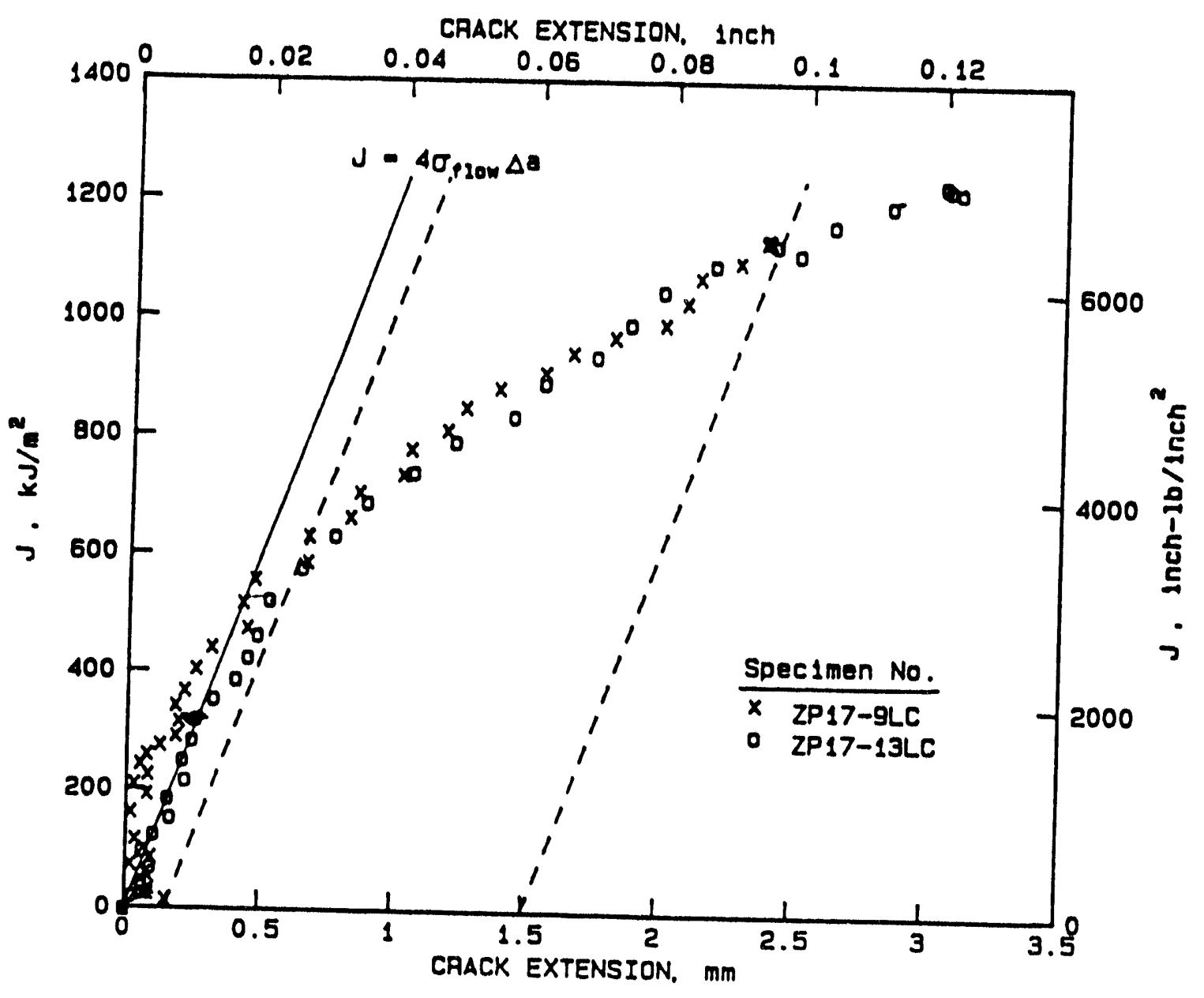

Figure 4.17 J versus crack extension for Pipe DP2-A23 (Type 304 stainless steel) specimens tested quasi-statically at

I $-\mathrm{T} 1.0-11 / 89-\mathrm{F} 4.17$ 


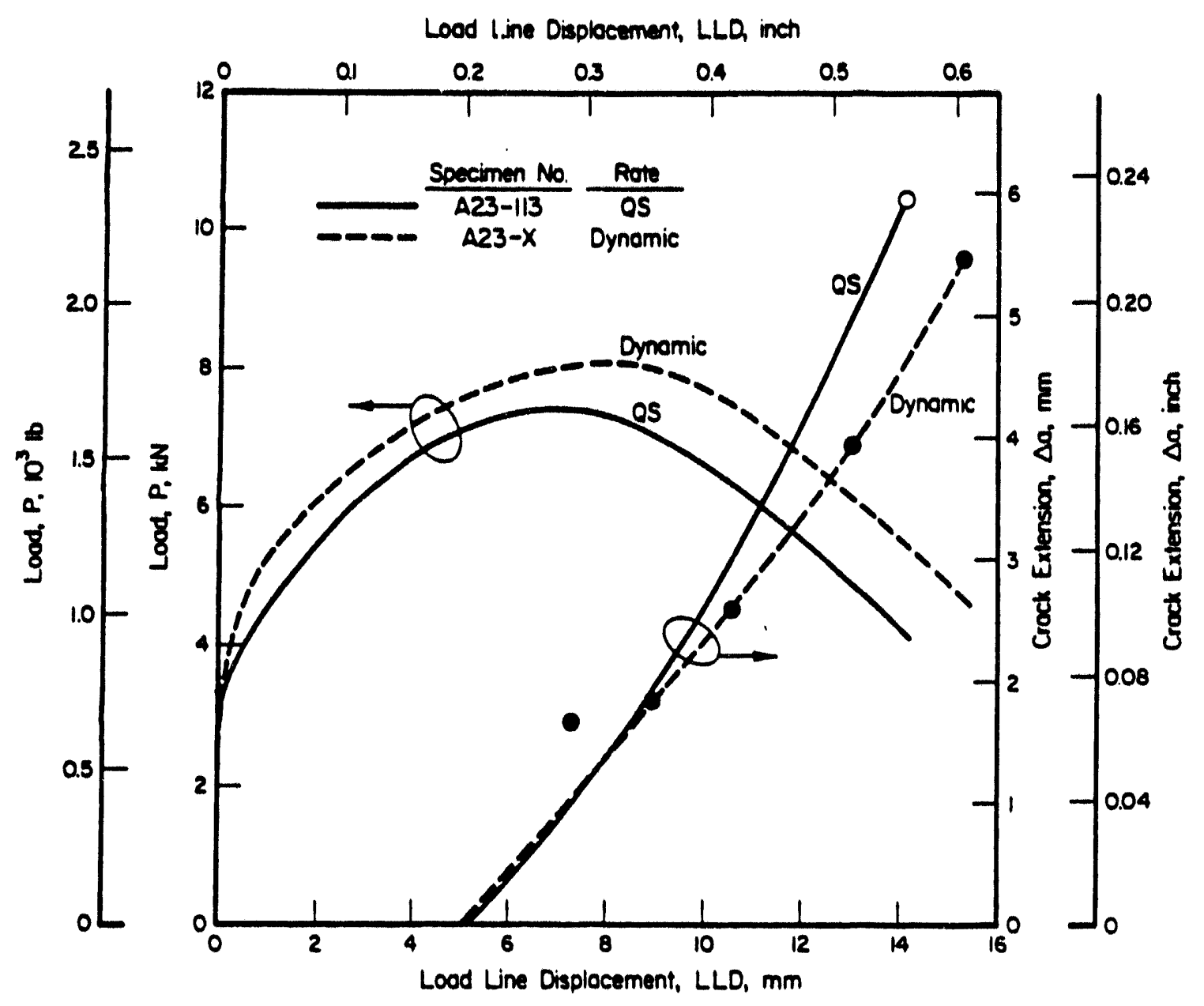

Figure 4.18 Load-displacement-crack extension curves for compact specimens from Pipe DP2-A23 (Type 304 stainless steel), tested at $288 \mathrm{C}(550 \mathrm{~F})$.

I-T1.0-11/89-F4.18 


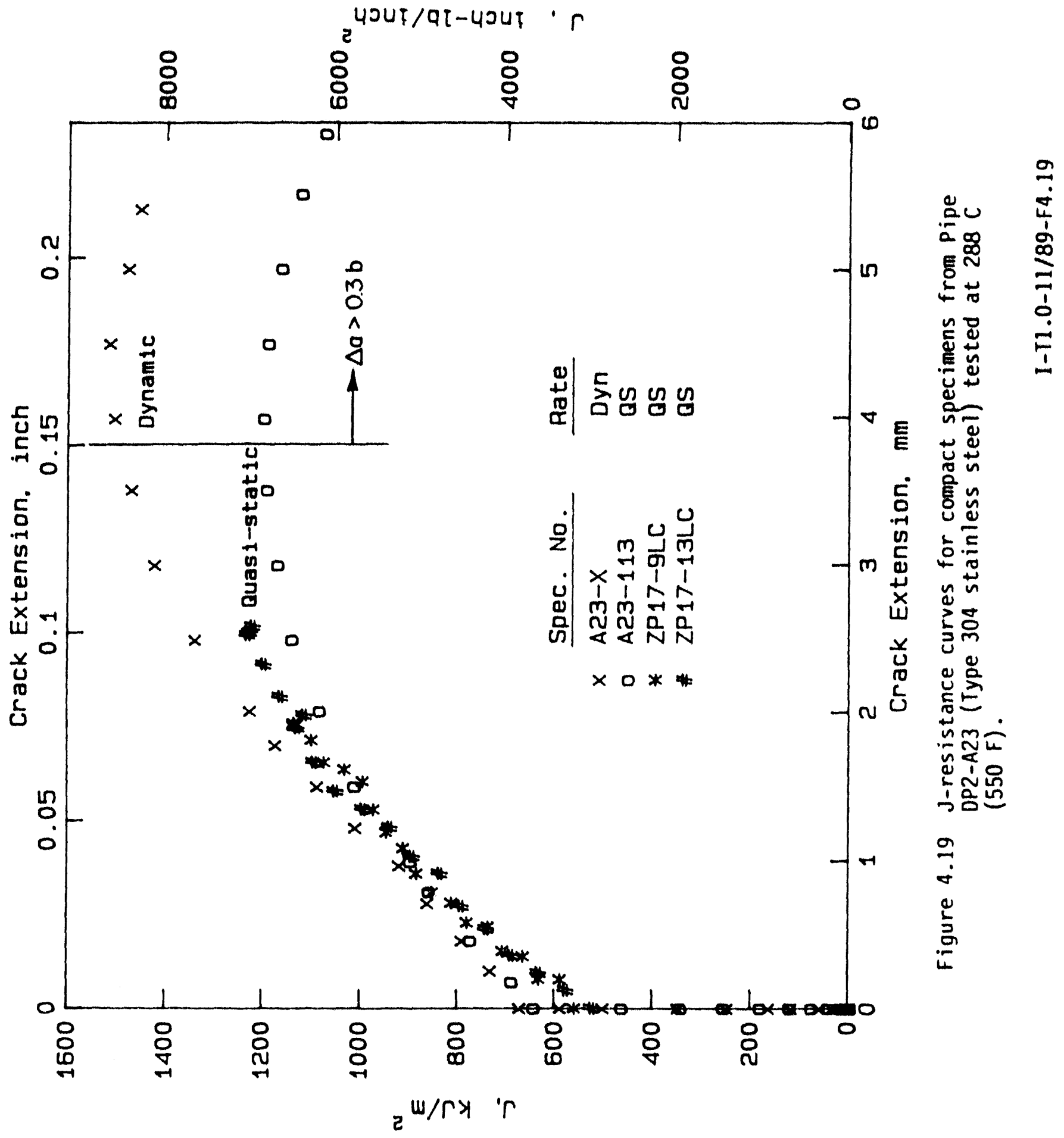




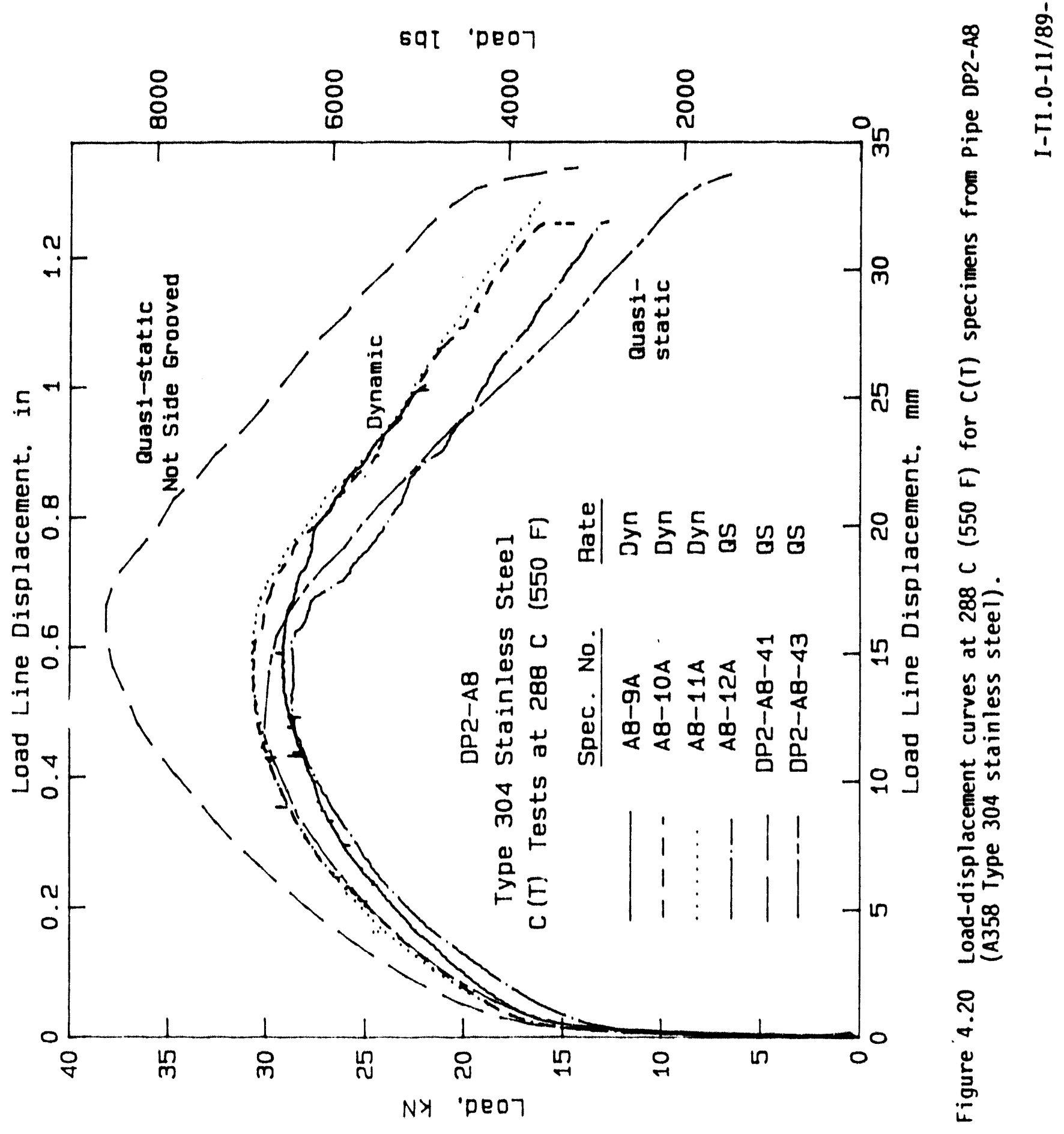




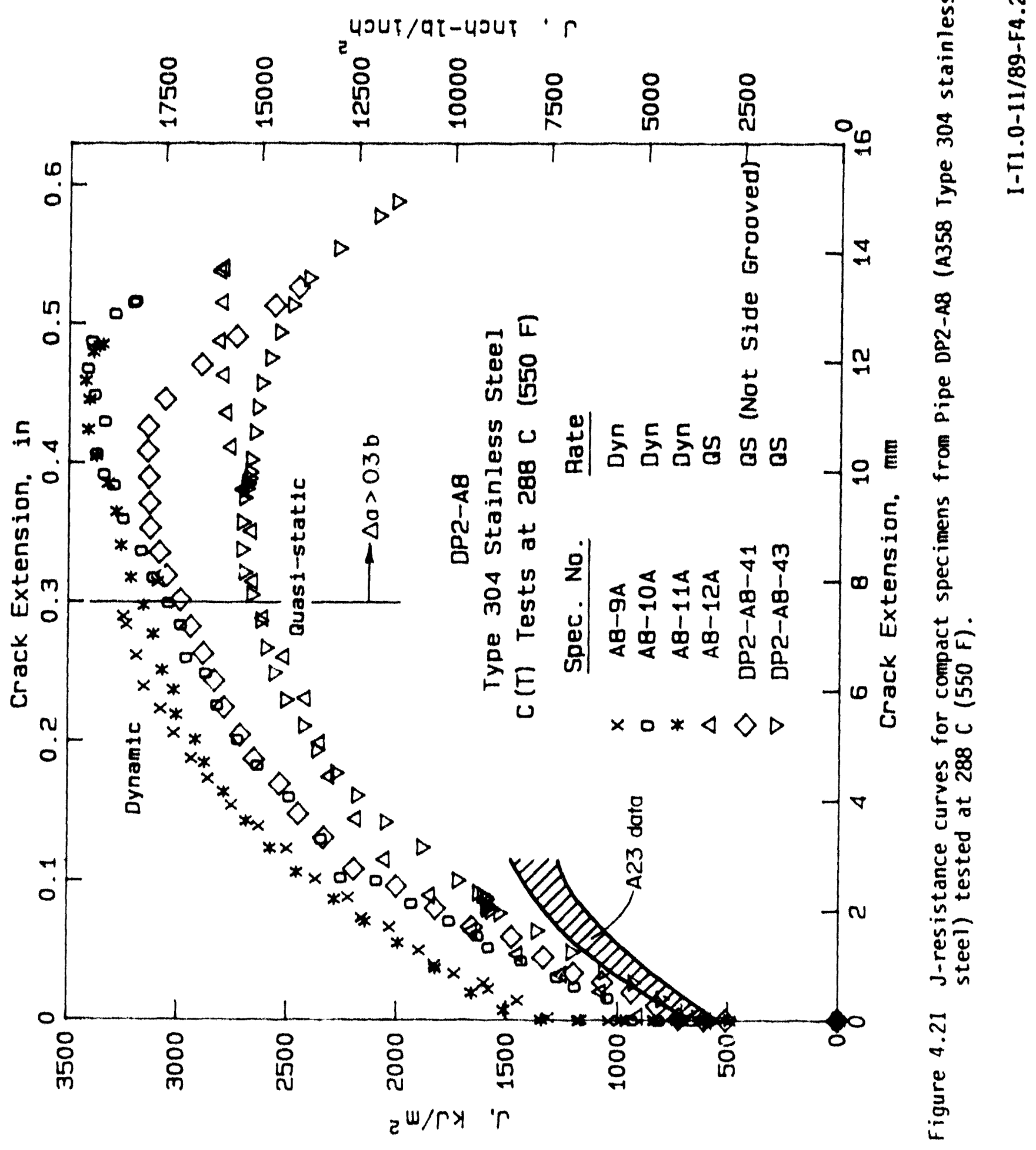




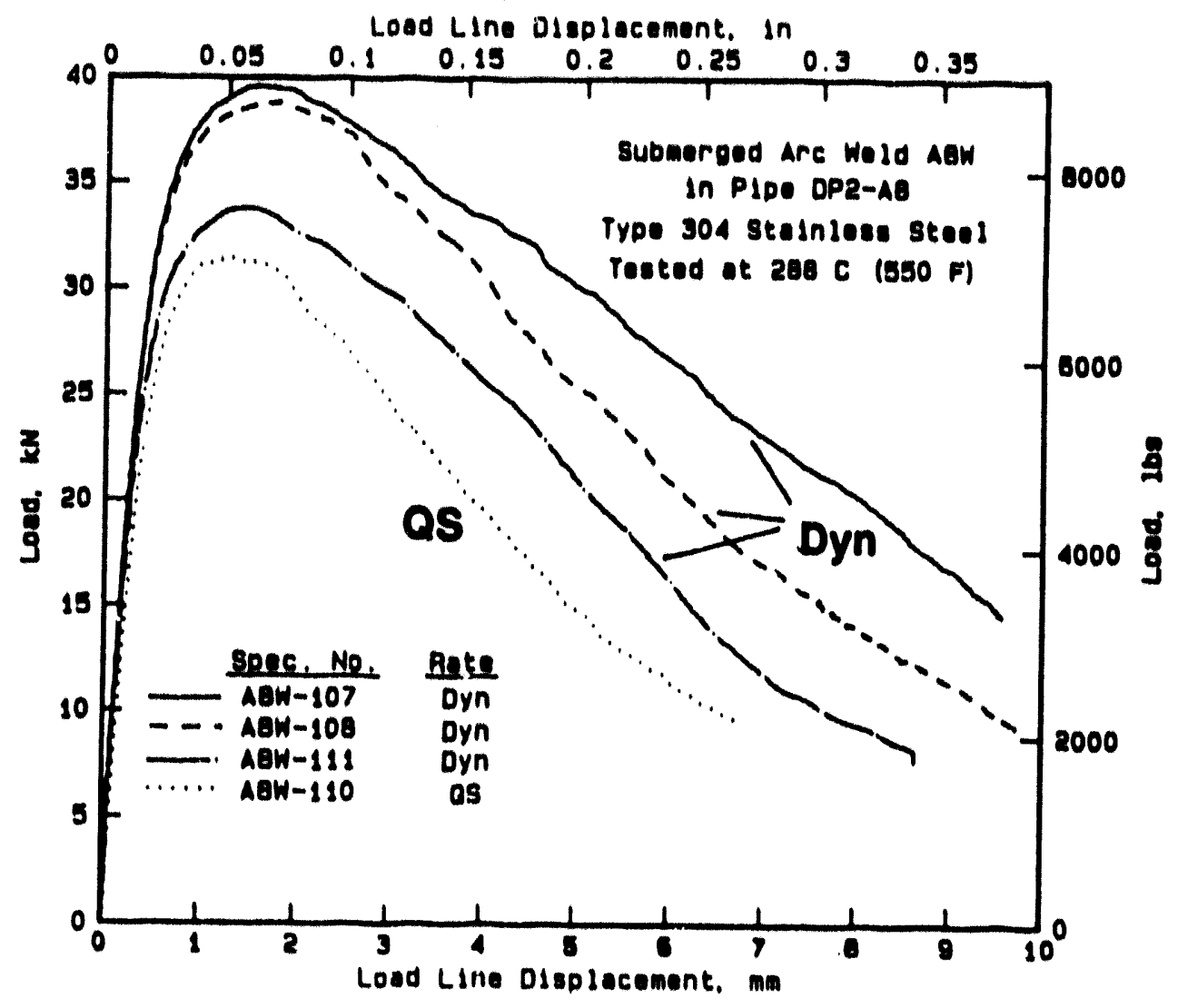

Figure 4.22 Load-displacement curves at $288 \mathrm{C}(550 \mathrm{~F})$ for $\mathrm{C}(\mathrm{T})$ specimens from a submerged-arc weld (DP2-A8W) in a Type 304 stainless steel pipe.

$I-T 1.0-11 / 89-F 4.22$ 


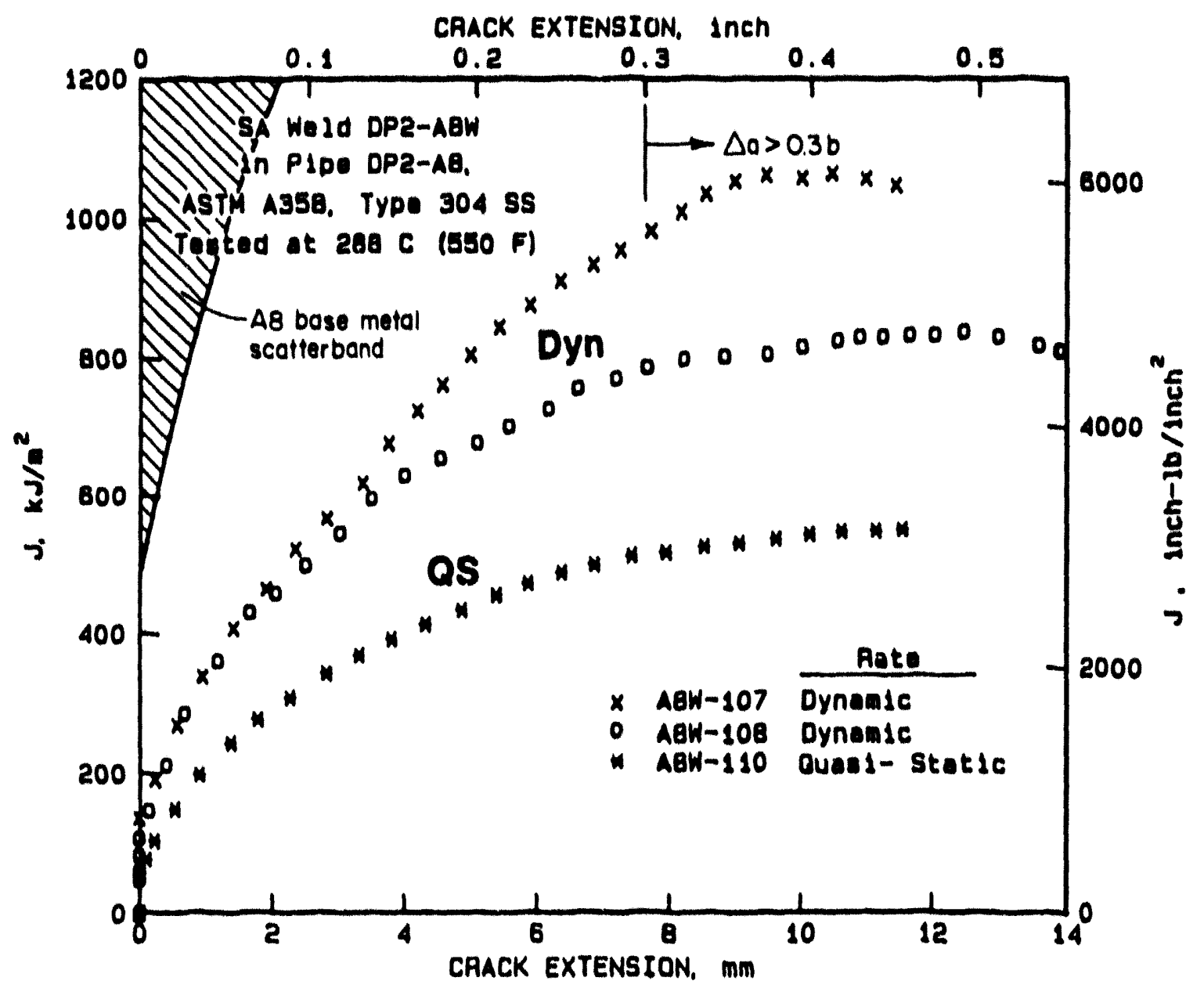

Figure 4.23 J-resistance curves at $288 \mathrm{C}(550 \mathrm{~F})$ for coinpact specinens from a submerged-arc weld (DP2-ABW) in a Type 304 stainless steel pipe. 


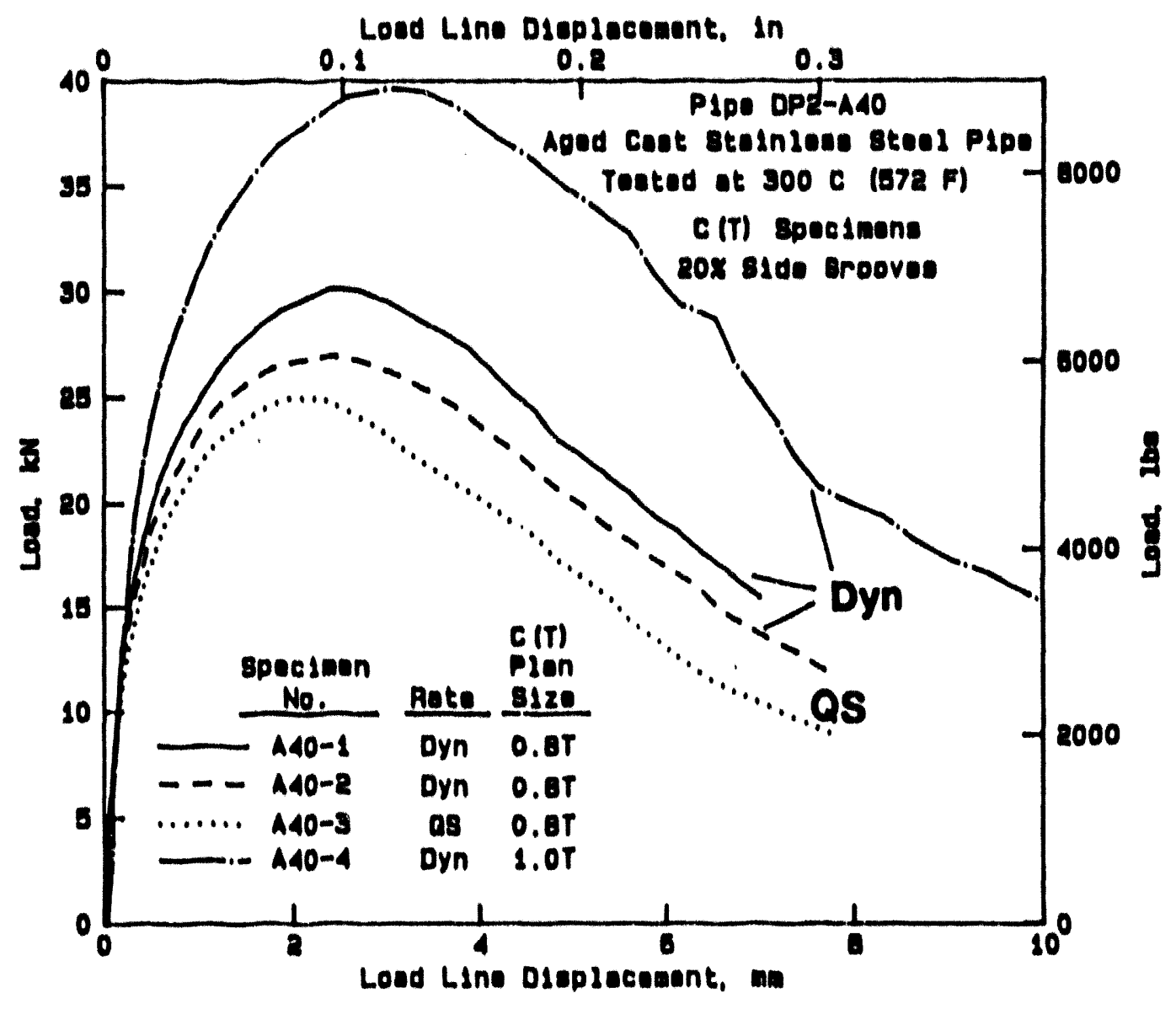

Figure 4.24 Load-displacement curves at $300 \mathrm{C}(572 \mathrm{~F})$ for $C(T)$ specimens from Pipe DP2-A40 (Aged A351 Type CFBM cast stainless steel). 


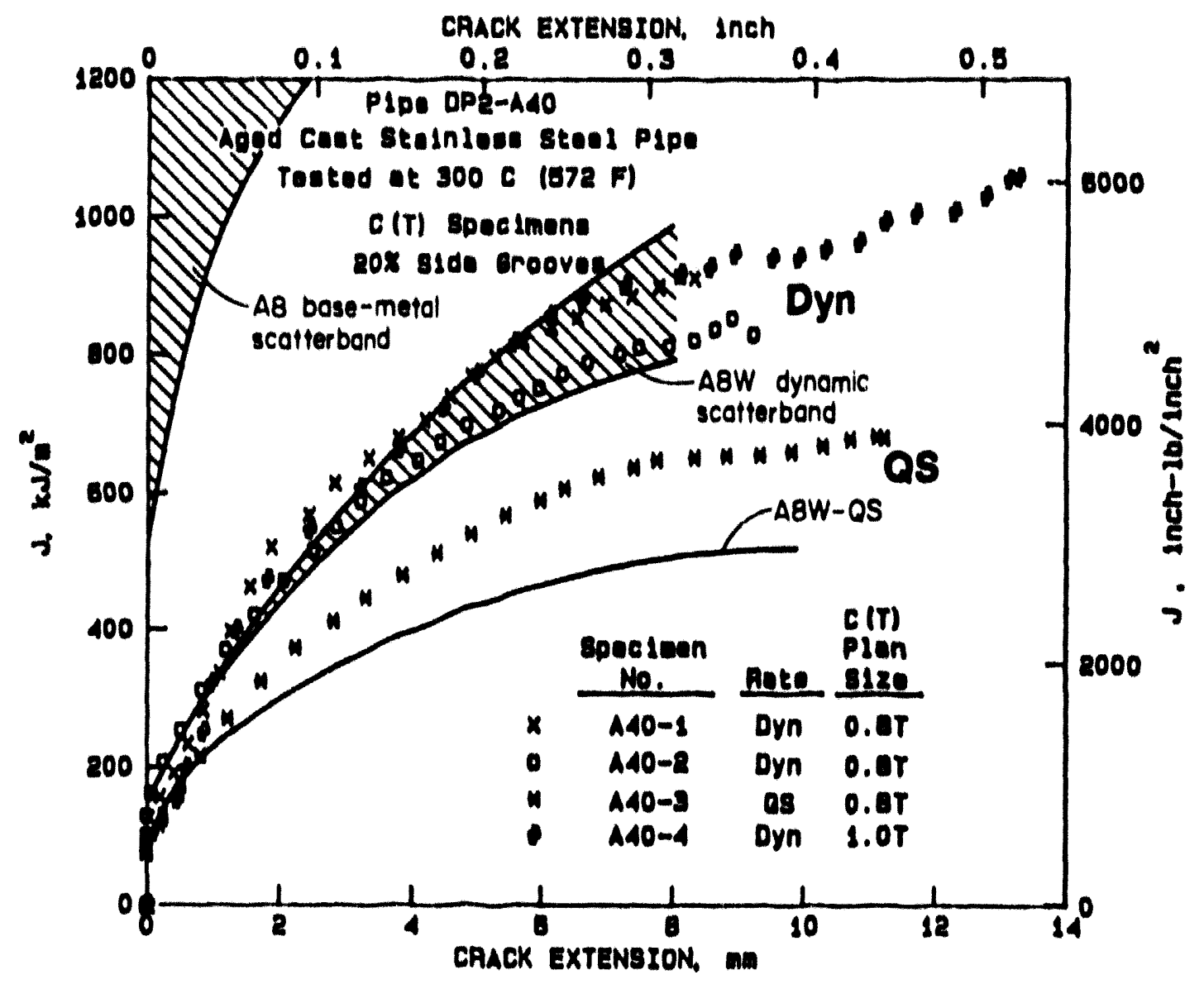

Figure 4.25 J-resistance curves at $300 \mathrm{C}(572 \mathrm{~F})$ for compact specimens from Pipe DP2-A40 (Aged A351 Type CFBM cast stainless steel). 


\subsection{DISCUSSION OF RESULTS}

The effect of increasing the rate of displacement in tensfle and $C(T)$ tests conducted at $288 \mathrm{C}(550 \mathrm{~F})$ is summarized in Table 5.1. Table 5.1 shows the approximate percentage change in tensile properties as the strain rate was increased by a factor of approximately $10^{4}$ to $10^{5}$, and the approximate percentage change in several toughness parameters $\left(J_{i}, J\right.$ at $2 \mathrm{~mm}$ of crack extension, and $\mathrm{dJ} / \mathrm{da}$ ) as the value of $\mathrm{dJ} / \mathrm{dt}$ was increased by a factor of 2500 to 6000 .

The results shown in Table 5.1 reveal that the carbon steel materials responded to increasing strain rate in a significantly different manner than did the stainless steel materials. The carbon steels, because of the fact that each was susceptible to dynamic strain aging, showed marked effects of strain rate on tensile strength. Of special importance to nuclear piping applications, the tensile strength of all three carbon steels and the fracture elongation of the two base metals were lowered substantially by the increased strain rate. The stainless steels, on the other hand, showed little change in either strength or elongation, except for the cast stainless steel, which showed increased elongation with increasing strain rate. Each of the stainless steels did exhibit a higher yield strength with increasing strain rate, whereas the yield strength of the carbon steels was virtually unchanged.

The observed differences between the two types of materials in tensile tests were carried over into the J-R curve tests as well. Each of the stainless steels increased in toughness as $\mathrm{dJ} / \mathrm{dt}$ was increased, as evidenced by $J$ values after $2 \mathrm{~mm}$ of crack extension and by $d J / d a$ values." In some cases, the gain was modest and in other cases the gain was substantial. In contrast to the relatively consistent behavior among the stainless steels, the behavior among the carbon steels was inconsistent in the $C(T)$ tests. One of the carbon steels (DP2-F30), exhibited a relatively modest reduction in crack-initiation toughness and a modest increase in $d J / d a$ at the higher displacement rate, and experienced crack jumps at both rates. Another ferritic steel (DP2-F29) showed a sizable reduction in toughness at the higher rate; however, the crack jumps observed in low rate tests were not observed in the high rate tests. Finally, the submerged-arc weld material (DP2-F29W) showed an impressive increase in toughness at the higher displacement rate, and was not susceptible to crack jumps at either rate.

The reasons for the different strain rate response of the three carbon steel materials are not known with certainty. It can be hypothesized that the differences in response are the result of differences in the way in which interstitial atoms (nitrogen and carbon) interact with dislocations at $288 \mathrm{C}(550 \mathrm{~F})$ to produce the many unusual effects associated with dynamic strain aging. These differences could give rise to different temperature- and strain-rate dependence of dynamic strain

* One exception was Pipe DP2-A3 which showed a slight decrease in $d J / d a$. 
aging among the three steels. Thus, their sirength-versus-temperature curves might show peak strengths occurring at different temperatures, they might display serrations on the stress-strain curve over different temperature ranges, and so on.

Even though the causes of the different behaviors among the three carbon steels cannot be adequately explained at this time, it is important to note that the results were clear in one regard--one of the carbon steels tested (DP2-F29) exhibited significant losses of both strength and toughness at the higher displacement rate. That result means that we must assume a similar response in any other carbon steel pipe unless contrary evidence is available.

In addition to measuring displacement-rate effects, this investigation confirmed a result obtained in the Degraded Piping Program, namely, the fracture resistance of submerged-arc welds in austenitic stainless steels is much poorer than that of base metal. The weld studied in this program (DP2-ABW) for example, displayed a $J_{j}$ value that was only about 10 percent of the value for its base-metal counterpart, and of about the same magnitude as that for the carbon-steel weld (DP2-F29W). 


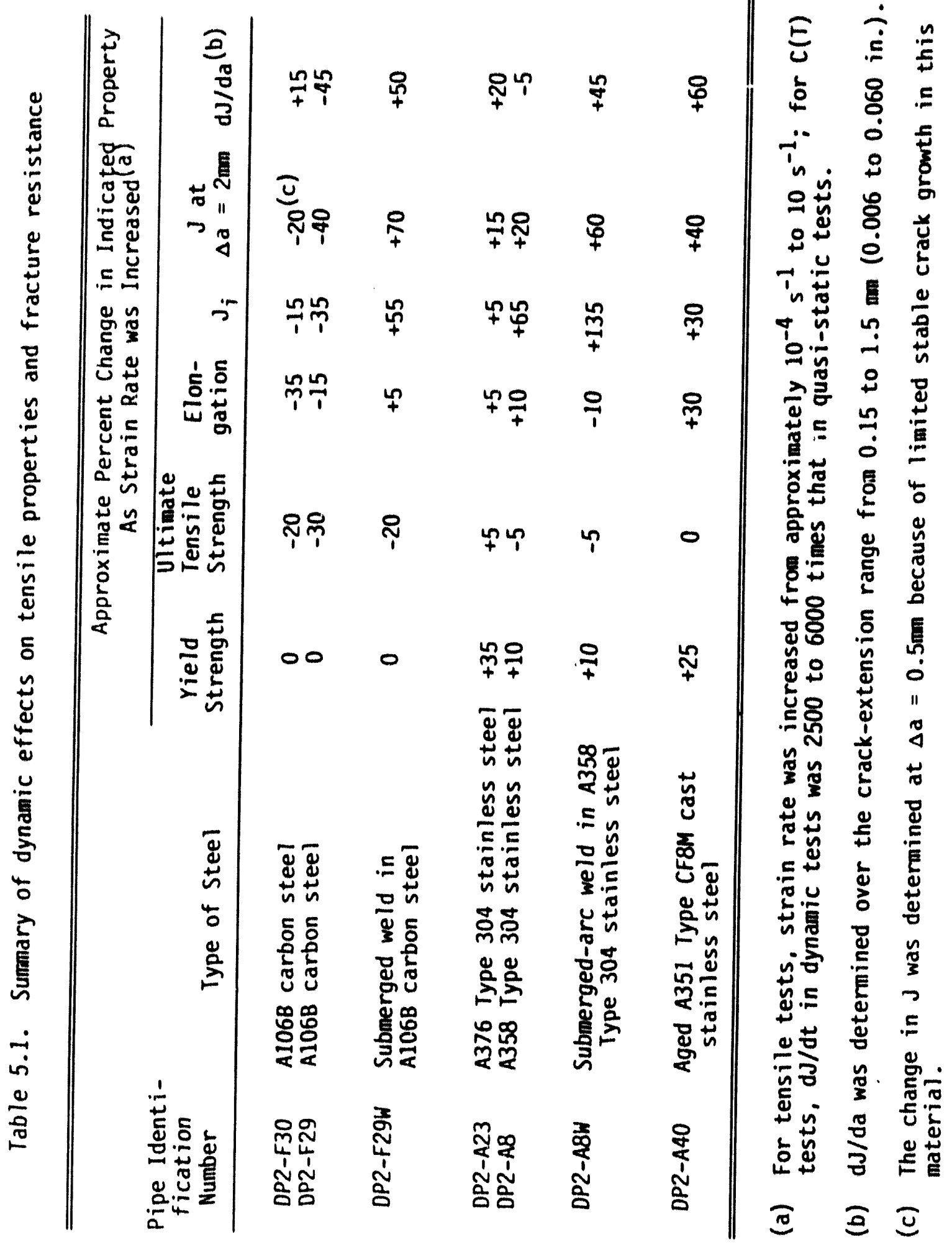




\subsection{SIGNIFICANCE OF RESULTS TO PIPE FRACTURE ANALYSES}

The main objective of the present work was to investigate the appropriateness of using quasi-statically determined stress-strain response and crack growth resistance characteristics of materials in analyses that involve higher rates of loading. The investigation was limited to studying the behavior of TP304 austenitic stainless steel, A106 Grade B ferritic steel, an artificially aged cast stainless steel, and stainless and ferritic submerged arc welds at $288 \mathrm{C}(550 \mathrm{~F})$. While the effects described are well defined for these materials, it is not clear how similar materials will behave, and generalization of these results to a wide class of steels is premature. Stress-strain characteristics of these materials were investigated from quasi-static up to a maximum applied strain rate of 10 per second. To investigate possible rate effects on crack growth initiation and tearing resistance, laboratory specimens were loaded such that the rate of increase of $\mathrm{J}$ up to initiation was comparable to that in the dynamic monotonically loaded pipe specimens in Subtask 1.2. Comparisons were made with quasi-static data on the basis of $J-R$ curve estimates.

In Section 6.1, the significance of the results from this report are considered in the context of flaw evaluation analyses. In Section 6.2, comparisons are made between the trends from the laboratory specimen results and results of Subtask 1.1 and 1.2 pipe fracture experiments. Where appropriate, recommendations are made for experimentation and rate-dependent plasticity analyses of data so that more precise predictive methods may be established.

\subsection{Significance of Laboratory Specimen Test Results on Pipe Fracture}

The main pruperties that could change and affect the pipe fracture analyses are the stress-strain curves and the crack growth resistance. Considerations for each of these properties are discussed below. The results relative to ASME Section III values for strength and J-R curves in the ASME Section XI pipe flaw evaluation procedures are also discussed.

\subsubsection{Tensile Test Results}

To put the results of this investigation in perspective, the nominal elastic strain rates in the flawed pipe need to be considered relative to the information used in pipe fracture analyses.

Some examples of nominal strain rates in a pipe remote from a crack are:

- for a typical quasi-static pipe fracture test, such as those in the Degraded Piping Program, the nominal strain rates are approximately $10^{-6}$ per second, 

- for a sejsmic event, the nominal strain rates are estimated to be
from $10^{-3}$ to $10^{-2}$ per second, and

- for hydrodynalic loads, such as water hammer from a valve closure, the nominal elastic strain rates are estimated to be
greater than 1.0 per second.

The tensile test results presented in this report were obtained at strain rates of approximately $10^{-4}, 1$, and 10 per second. As was noted in Section 3.0, increasing the strain rate from $10^{-4}$ to 10 per second had no significant adverse effects on the $288 \mathrm{C}(550 \mathrm{~F})$ tensile properties of the stainless steel pipe materials investigated, but did consistently raise the yield strength by at least 10 percent. Hence, quasi-static tensile data appear to be adequate for representing stressstrain behavior remote from the crack location in both seismic events and water hammer events for these stainless steel pipe materials.

The situation is somewhat different for the ferritic steel tested. Significant strain rate effects were observed in $288 \mathrm{C}(550 \mathrm{~F})$ tensile tests in this steel. In particular, ultimate tensile strength values were lowered 20 to 30 percent at the highest rate relative to values obtained in quasi-static tests. Based on the results obtained for the carbon steels, it appears that it would be acceptable to use quasistatic tensile data to represent the behavior remote from the crack location for this carbon steel pipe in seismic events. A water hammer event, however, would appear to require tensile data at higher rates, similar to the higher rates used in this study, even in regions remote from the crack. Of course, if the stresses in the pipe remote from the crack are elastic and the elastic modulus does not change significantly with strain rate, then the strain rate is of little importance in those
regions.

Probably of greater importance than the nominal strain rate remote from the crack are the strain rates in the net section and near the crack tip. crack tip for the program Brickstad estimated the strain rate close to the order of 3 per second from finitenic stainless steel pipe test to be on the strain rates employed in tensile element analysis. The two higher second) were chosen because they were in this study (1 and $10 \mathrm{per}$ than the strain rate existing they were believed to be equal to or greater including most of the region in the net section of cracked pipes. More seismic the average strain rate in the hammer events, are needed to determine ferritic pipes. For the crack tip area for the net-section calculating the flow stress used in ermine the stress-strain curves for the J-estimation fractures used in either the limit-load analys is or the net of the section will be necessary to provide guidance for the selection coefficients used in the to be used to calculate the Ramberg-0sgood 
Relative to Section III of the ASME Boiler and Pressure Vessel Code, both the ferritic and stainless steels tested had yield and ultimate strengths greater than the specified minimum values at room temperature. At $288 \mathrm{C}(550 \mathrm{~F})$, the ferritic pipe had both yield and ultimate strengths above the ASME Section III values, even at the higher strain rates where ultimate strength was diminished relative to the quasistatic ultimate strength. However, if a carbon steel were to have an ultimate strength close to the ASME Code minimum value at room temperature, it is possible that the $288 \mathrm{C}(550 \mathrm{~F})$ ultimate strength at the high strain rate would be lower than the Code value. For the stainless steel pipe, the ultimate strength was slightly below the Code value at $288 \mathrm{C}(550 \mathrm{~F})$ even at the quasi-static test rates.

\subsubsection{J-R Curve Toughness Results}

For the dynamic J-R curve test results in this report, the 0.2 seconds to crack initiation was equivalent to the time to initiation for a dynamic monotonically loaded pipe specimen. This equivalent time was determined by ANSYS finite element analyses using a cracked pipe element The $C(T)$ tests conducted in this program employed monotonic, rather than cyclic, loading. The cyclic effects that could occur in the pipe fracture experiments were not investigated in the labortory specimen tests (other than the limited investigation of unloading compliance on steel F30). In pipe experiments conducted in IPIRG Subtask 1.2, the cyclic load interactions with ductile tearing were found to be significant in reducing the apparent $J-R$ curves when fully reversed loading was used (Ref. 6.1). It should be noted that the calculated J-R curves are from an ASTM analysis procedure which ignores possible rate effects. The ASTM analysis procedure was used as an estimate until further detailed analyses are conducted to establish the magnitude of the error.

\subsubsection{Significance of Results and Comparison to ASME J-R Curves for In-Service Flaw Evaluations}

The J-R curves were compared to the ASME J-R curves used in the technical basis for ASME Section XI Article IWB-3650 (Ref. 6.2). It was found that the $P$ ipe Number $F 30$ carbon steel base metal J-R curves were lower than the ASME $J-R$ curve which was used as the lower bound curve in establishing the end-of-life flaw sizes for ferritic pipe base metal flaws. There was relatively little difference between the dynamic and quasi-static J-R curves for Pipe F30. In comparing the monotonically loaded pipe fracture data for Pipe F-30 obtained in Subtasks 1.1 and 1.2 to the ASME ferritic pipe flaw evaluation procedures, it was found that the ASME IWB-3650 flaw evaluation procedure significantly underpredicted the experimental maximum loads as long as the ASME Section III $\mathrm{S}_{\mathrm{m}}$ values were used in determining the flow stress. This underprediction was due mainly to the actual yield and ultimate strengths of Pipe F30 being significantly higher than the Code minimum values. If the actual strength values of this pipe were used to 
determine the $S_{m}$ then the ASME IWB-3650 analys is procedure only slightly underpredicted the maximum loads. Hence, there is some inherent safety margin in the IWB-3650 analys is procedure that compensated for the lower toughness of the F30 pipe under monotonic loading.

For Pipe Number F29, the J-R curve was reduced significantly at the higher testing rate, but the high-rate $J-R$ curve was still above the ASME lower bound base metal $J-R$ curve. No dynamic pipe test data exist from the IPIRG Subtask 1.1 and 1.2 experiments for this pipe, but this pipe is being used in at least one IPIRG Subtask 1.3 pipe experiment.

The toughness of Pipe Number F29W, a submerged-arc weld (SAW) at the quasi-static rates was well above the toughness of a similar weld tested in the Degraded Piping Program. The reason for the difference in seemingly identically prepared welds was not investigated. Unlike the behavior exhibited by the base metal, the toughness of the SAW actually increased with higher rate testing even though the ultimate tensile strength of both the base metal and the weld metal were lower at the higher strain rates. The J-R curve of F29W at both rates was above the ASME J-R curve for ferritic submerged arc welds. This situation creates an interesting trade off in a dynamic pipe fracture analys is for a crack in a ferritic weld, where the base metal strength and the weld metal toughness are used. In this case, the loss of strength may be compensated for by the higher toughness of the weld at the higher rate. Wliether all ferritic welds increase in toughness with the increasing loading rate is not known.

For the wrought stainless steels (Pipe Numbers $A 23$ and $A B$ ), the toughness increased slightly with the rates of testing used. Hence, the laboratory specimen data suggest that the use of quasi-static toughness and strength data for wrought stainless steels appears reasonable for seismically loaded pipe flaw evaluations.

For the artificially aged French cast stainless steel (Pipe Number A40) and the stainless steel submerged arc weld (Pipe Number ABW), the toughness increased significantly with increased loading rate. If this observation is generally true, then quasi-static material property data is conservative for use in dynamic pipe flaw evaluations for these materials.

\subsubsection{Significance for Leak-Before-Break Analysis}

From the work described in this report, it appears that the main concern relative to leak-before-break would be for ferritic pipe. In LBB analysis, actual material properties are frequently used rather than lower bounds. These property data typically are from quasi-static tests. From the results on ferritic steels in this report, it appears tu be advisable to use dynamic toughness data. The dynamic strength data should probably be used as well, but further assessments of simple methods to account for the rate dependency (e.g., using the average 
strain rates in the net-section of a cracked pipe and near the cracked tip) should be performed to see if the high rate tensile data are necessary.

\subsection{Comparison of Laboratory Specimen Results to IPIRG Subtask 1.1 and 1.2 Pipe Fracture Experiment Results}

The laboratory specimen results from this report suggest that for austenitic steels, the higher loading rate from a seismic event should not have any adverse effects on the pipe fracture behavior, whereas for a ferritic base metal, the seismic loading rate could be detrimental to the fracture behavior. In this section, the trends from the results of dynamic pipe fracture experiments conducted in IPIRG Subtask 1.1 and 1.2 are compared with the trends from the laboratory specimen results.

\subsubsection{Results of Tests on Ferritic Pipe DP2-F30}

The quasi-static versus dynamic pipe test results from IPIRG Subtask 1.2 for Pipe DP2-F30 under displacement-controlled loading qualitatively agreed with the laboratory specimen data. That is, the dynamically loaded pipe test (Experiment 1.2-8) had a lower maximum stress and lower fracture resistance than the identical quasi-static monotonically loaded pipe test (Experiment 1.2-7). The same trend of lower failure stresses and fracture resistance with increasing rates was also observed when comparing quasi-static and dynamic fully reversed pipe experiments (Experiments 1.2-6 and 1.2-4, respectively). Hence, there are two sets of pipe experiments in Subtask 1.2 whose results agreed with the laboratory specimen test results.

The inertially loaded pipe fracture experiments in Subtask 1.1, however did not show lower maximum stresses than the quasi-static pipe fracture results of Subtask 1.2. This is a clear discrepancy between the laboratory specimen tests and the Subtask 1.2 pipe test results. The fracture resistance curves from the inertially loaded pipe fracture experiment were not calculated since the inertially loaded pipe experiments were conducted under combined pressure and bending. The approximate solutions for a pipe eta-factor J-R curve, for a pipe under tension and bending, were not readily available, but could be calculated using the LBB.ENG method, Ref. 6.3.

Hence, for all the ferritic steel laboratory specimen and pipe test data, the trends are consistent with the exception of the Subtask 1.1 pipe experiments.

\subsubsection{Results of Tests on Austenitic Pipe DP2-A23}

The quasi-static versus dynamic pipe test results from IPIRG Subtask 1.2 for Pipe DP2-A23 under displacement-controlled loading produced J-R curves that showed no significant loading rate dependency. That is, the 
dynamically loaded pipe test (Experiment 1.2-1) had a similar fracture resistance to the identical quasi-static monotonically loaded pipe test the laboratory specimen the Degraded Piping Program). This agrees with data for the austenitic pipe experiments

In the analysis of the Subtask 1.2 IPIRG Experiments (Ref. 6.1), it was found that the net-section stresses at maximum load were larger by 15 percent for the quasi-static (4131-5) experiment than the dynamic experiment (1.2pipe experiments. These results than usually observed from identical that the pipe diameter for Experi were examined closer, and it was found correct pipe diameter there is iment 4131-5 was misreported. Using the net-section stress at maximum loas than 1 percent difference in the the Subtask 1.2 pipe experiments between the two experiments. Hence, results.

However, the net-section stress for the inertially loaded (dynamic) pipe fracture experiments in Subtask 1.1 are 15 percent greater than the netexperiments. As for Subtask 1.2 quasi-static or dynamic pipe resistance curves from the ferritic pipe experiments, the fracture were not calculated since inertially loaded pipe fracture experiment conducted under combined pressure and bending. Hence, for all the stainless steel Subtask 1.2 pipe and laboratory specimen data, the trends of the data show no strain rate sensitivity. observed in subtask 1.2 experiments.

\subsubsection{Resolution of Discrepancies in Irends from Laboratory Specimen
and Pipe Experiments}

The reasons for the lack of agreement when comparing the laboratory specimen and the Subtask 1.2 pipe experiments to the Subtask 1.1 pipe fracture experiments should be explored further. Also, the $J-R$ curves calculated for comparisong-wall cracked pipe experiments should be Finally, the Subtask son to the Subtask 1.2 pipe J-R curve data. duplicate pipe experiments perfontal data should be reexamined or discrepancies.

\subsection{References}

6.1 Wilkowski, G., Vieth, P., Kramer, G., Marschall, C., and Landow, M., "Results of Separate-Effects Pipe Fracture Experiments". Post-SMiRT-11
Conference, August 1991, Paper 4.2.

6.2. Evaluation of Flaws in Ferritic Piping", FPRI Report NP-6045, prepared
by Novetech Corporation, October 1988.

6.3 Brust, F. W. "Approximate Methods for Fracture Analyses of ThroughWall Cracked Pipes". NRC Topical Report by Battelle Columbus Division,
NUREG/CR 4853, February 1987 . 

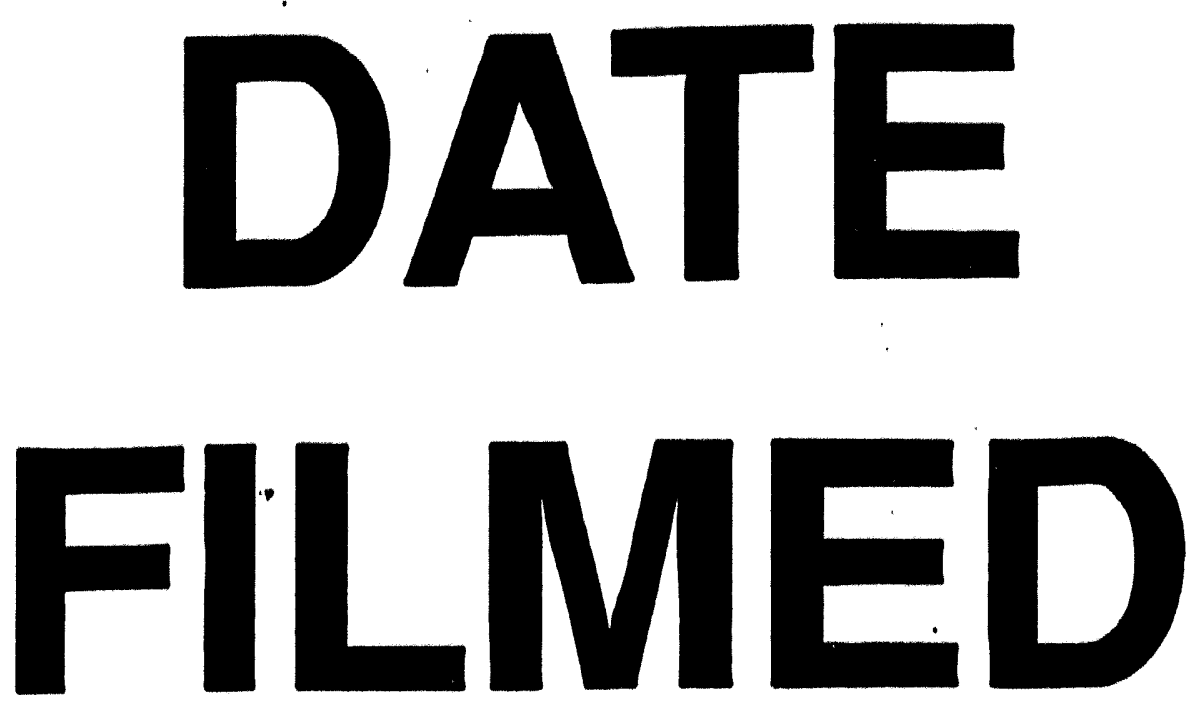

$12 / 21 / 93$
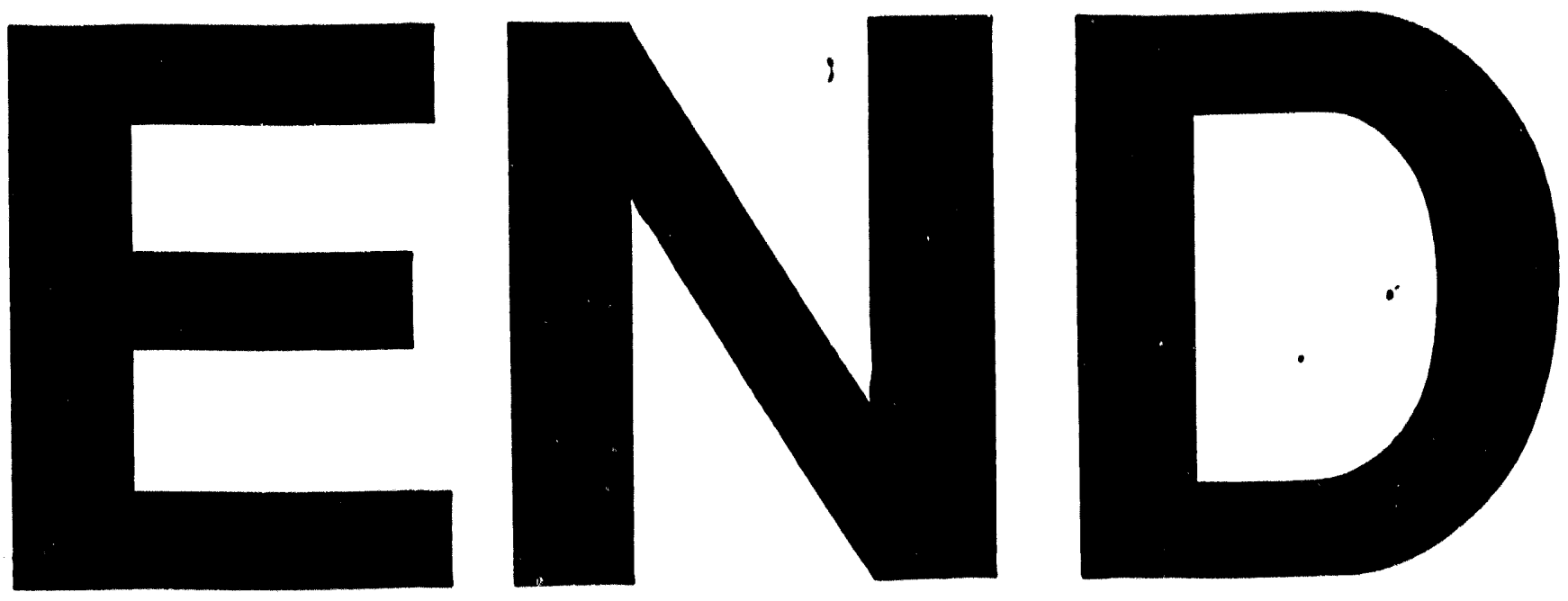
